\title{
FEDERAL INSECTICIDE, FUNGICIDE, AND RODENTICIDE ACT
}

\author{
[As Amended Through P.L. 110-246, Effective May 22, 2008] \\ TABLE OF CONTENTS
}

U.S.C. Act Sec. Page

7 U.S.C.

prec. 121 1. Short title and table of contents .................... 3

$136 \quad 2$. Definitions ..................................................

136a 3. Registration of pesticides ............................. 16

136a-1 4. Reregistration of registered pesticides .......... 36

136c 5. Experimental use permits ........................... 58

136d 6. Administrative review; suspension ............... 59

136e 7. Registration of establishments ..................... 65

$136 \mathrm{f} \quad$ 8. Books and records ....................................... 66

$136 \mathrm{~g} \quad$ 9. Inspection of establishments, etc. ................. 66

136h 10. Protection of trade secrets and other infor- 68

136i 11. Use of restricted use pesticides; applicators $\quad 70$

136j 12. Unlawful acts .......................................... $\quad 72$

136k 13. Stop sale, use, removal, and seizure ........... $\quad 75$

$1361 \quad$ 14. Penalties ....................................................

$136 \mathrm{~m} \quad$ 15. Indemnities ….......................................

136n 16. Administrative procedure; judicial review .. $\quad 80$

136o 17. Imports and exports ................................. $\quad 80$

136p 18. Exemption of Federal and State agencies .. $\quad 82$

$136 q$ 19. Storage, disposal, transportation, and re- 82

136r 20. Research and monitoring ............................ 87

136s 21. Solicitation of comments; notice of public 87 hearings.

136t 22. Delegation and cooperation …..................... 87

$136 \mathrm{u} 23$. State cooperation, aid, and training ........... $\quad 88$

$136 \mathrm{v} 24$. Authority of States .................................... $\quad 88$

136w 25. Authority of Administrator ........................ $\quad 89$

136w-1 26. State primary enforcement responsibility .. 93 
TABLE OF CONTENTS—Continued

136w-2 27. Failure by the State to assure enforcement of State pesticide use regulations.

136w-3 28. Identification of pests; cooperation with 94 Department of Agriculture's program.

136w-4 29. Annual report ………….......................... $\quad 95$

136w-5 30. Minimum requirements for training of 95 maintenance applicators and service technicians.

136w-6 31. Environmental Protection Agency minor 95 use program.

136w-7 32. Department of Agriculture minor use pro- $\quad 96$ gram.

136w-8 33. Pesticide registration service fees …........... 97

136x 34. Severability ............................................... 109

136y 35. Authorization for appropriations ................. 109

Bracketed material and footnotes did not appear in Acts. 


\section{AN ACT}

To regulate the marketing of economic poisons and devices, and for other purposes.

Be it enacted by the Senate and House of Representatives of the United States of America in Congress assembled,

SECTION 1. [7 U.S.C. prec. 121] SHORT TITLE AND TABLE OF CONTENTS.

(a) SHORT Tithe.-This Act may be cited as the "Federal Insecticide, Fungicide, and Rodenticide Act".

(b) TABLE OF CONTENTS.-1-1

Section 1. Short title and table of contents.

(a) Short title.

(b) Table of contents.

Sec. 2. Definitions.

(a) Active ingredient.

(b) Administrator.

(c) Adulterated.

(d) Animal.

(e) Certified applicator, etc.

(1) Certified applicator.

(2) Private applicator.

(3) Commercial applicator

(4) Under the direct supervision of a certified applicator.

(f) Defoliant.

(g) Desiccant.

(h) Device.

(i) District court.

(j) Environment.

(k) Fungus.

(l) Imminent hazard.

(m) Inert ingredient.

(n) Ingredient statement.

(o) Insect.

(p) Label and labeling.

(1) Label.

(2) Labeling

(q) Misbranded.

(r) Nematode.

(s) Person.

(t) Pest.

(u) Pesticide.

(v) Plant regulator.

(w) Producer and produce.

(x) Protect health and the environment.

(y) Registrant.

(z) Registration.

(aa) State.

(bb) Unreasonable adverse effects on the environment.

(cc) Weed.

(dd) Establishment.

(ee) To use any registered pesticide in a manner inconsistent with

its labeling.

(ff) Outstanding data requirement.

(gg) To distribute or sell.

Sec. 3. Registration of pesticides.

${ }^{1-1}$ So in original. The table of contents does not correspond to the contents of the Act. Public Law 104-170 did not make conforming amendments to the table of contents. 
(a) Requirement of registration.

(b) Exemptions.

(c) Procedure for registration.

(1) Statement required.

(2) Data in support of registration.

(3) Time for acting with respect to application.

(4) Notice of application.

(5) Approval of registration.

(6) Denial of registration.

(7) Registration under special circumstances.

(8) Interim administrative review.

(d) Classification of pesticides.

(1) Classification for general use, restricted use, or both.

(2) Change in classification.

(3) Change in classification from restricted use to general use.

(e) Products with same formulation and claims.

(f) Miscellaneous

(1) Effect of change of labeling or formulation.

(2) Registration not a defense.

(3) Authority to consult other Federal agencies.

Sec. 4. Reregistration of registered pesticides.

(a) General rule.

(b) Reregistration phases.

(c) Phase one.

(1) Priority for reregistration.

(2) Reregistration lists.

(3) Judicial review.

(4) Notice to registrants.

(d) Phase two.

(1) In general.

(2) Notice of intent to seek or not to seek reregistration.

(3) Missing or inadequate data.

(4) Time periods.

(5) Cancellation and removal.

(6) Suspensions and penalties.

(e) Phase three.

(1) Information about studies.

(2) Time periods.

(3) Cancellation.

(4) Guidelines.

(5) Monitoring.

(f) Phase four.

(1) Independent review and identification of outstanding data requirements.

(2) Time periods.

(3) Suspensions and penalties.

(g) Phase five.

(1) Data review.

(2) Reregistration and other actions.

(h) Compensation of data submitter.

(i) Fees.

(1) Initial fee for food or feed use pesticide active ingredients.

(2) Final fee for food or feed use pesticide active ingredients.

(3) Fees for other pesticide active ingredients.

(4) Reduction or waiver of fees for minor use and other pesticides.

(5) Maintenance fee.

(6) Other fees.

(7) Apportionment.

(j) Exemption of certain registrants.

(k) Reregistration and expedited processing fund.

(1) Establishment.

(2) Source and use.

(3) ${ }^{1-2}$ Review of inert ingredients; expedited processing of similar applications.

(4) Unused funds.

(5) Accounting.

(1) Judicial review.

Sec. 5. Experimental use permits.

(a) Issuance.

(b) Temporary tolerance level.

(c) Use under permit.

(d) Studies.

(e) Revocation.

(f) State issuance of permits.

(g) Exemption for agricultural research agencies.

Sec. 6. Administrative review; suspension.

1-2 So in original (as added by sec. 501(g)(1) of P.L. 108-199). Probably should be indented further. 
(a) Cancellation after five years.

(1) Procedure.

(2) Information

(b) Cancellation and change in classification or labels.

(c) Suspension.

(1) Order

(2) Expedite hearing.

(3) Emergency order.

(4) Judicial review.

(d) Public hearings and scientific review.

(e) Conditional registration.

(f) General provisions.

(1) Voluntary cancellation.

(2) Publication of notice.

(3) Transfer of registration of pesticides registered for minor agricultural uses.

(g) Notice for stored pesticides with canceled or suspended registrations.

(1) In general.

(2) Copies.

(h) Judicial review.

Sec. 7. Registration of establishments.

(a) Requirements.

(b) Registration.

(c) Information required.

(d) Confidential records and information

Sec. 8. Records.

(a) Requirement.

(b) Inspection.

Sec. 9. Inspection of establishments, etc.

(a) In general.

(b) Warrants.

(c) Enforcement.

(1) Certification of facts to Attorney General.

(2) Notice not required.

(3) Warning notices.

Sec. 10. Protection of trade secrets and other information.

(a) In general.

(b) Disclosure.

(c) Disputes.

(d) Limitations.

(e) Disclosure to contractors.

(f) Penalty for disclosure by Federal employees.

(g) Disclosure to foreign and multinational pesticide producers.

Sec. 11. Use of restricted use pesticides; applicators.

(a) Certification procedure.

(1) Federal certification.

(2) State certification.

(b) State plans.

(c) Instruction in integrated pest management techniques.

(d) In general.

(e) Separate standards.

Sec. 12. Unlawful acts.

(a) In general.

(b) Exemptions.

Sec. 13. Stop sale, use, removal, and seizure.

(a) Stop sale, etc., orders.

(b) Seizure.

(c) Disposition after condemnation.

(d) Court costs, etc.

Sec. 14. Penalties.

(a) Civil penalties.

(1) In general.

(2) Private applicator.

(3) Hearing.

(4) Determination of penalty.

(5) References to Attorney General.

(b) Criminal penalties.

(1) In general.

(2) Private applicator.

(3) Disclosure of information.

(4) Acts of officers, agents, etc.

Sec. 15. Indemnities. 
(a) General indemnification.
(1) In general.
(2) Exception.
(3) Report.
(4) Appropriation.

(b) Indemnification of end users, dealers, and distributors.

(1) End users.

(2) Dealers and distributors.

(3) Source.

(4) Administrative settlement.

(c) Amount of payment.

(1) In general.

(2) Special rule.

Sec. 16. Administrative procedure; judicial review.

(a) District court review.

(b) Review by Court of Appeals.

(c) Jurisdiction of district courts.

(d) Notice of judgments.

Sec. 17. Imports and exports.

(a) Pesticides and devices intended for export.

(b) Cancellation notices furnished to foreign governments.

(c) Importation of pesticides and devices.

(d) Cooperation in international efforts.

(e) Regulations.

Sec. 18. Exemption of Federal and State agencies.

Sec. 19. Storage, disposal, transportation, and recall.

(a) Storage, disposal, and transportation.

(1) Data requirements and registration of pesticides.

(2) Pesticides.

(3) Containers, rinsates, and other materials.

(b) Recalls.

(1) In general.

(2) Voluntary recall.

(3) Mandatory recall.

(4) Recall procedure.

(5) Contents of recall plan.

(6) Requirements or procedures.

(c) Storage costs.

(1) Submission of plan

(2) Reimbursement.

(d) Administration of storage, disposal, transportation, and recall programs.

(1) Voluntary agreements.

(2) Rule and regulation review.

(3) Limitations.

(4) Seizure and penalties.

(e) Container design

(1) Procedures.

(2) Compliance.

(f) Pesticide residue removal.

(1) Procedures.

(2) Compliance.

(3) Solid Waste Disposal Act.

(g) Pesticide container study.

(1) Study.

(2) Report.

(h) Relationship to Solid Waste Disposal Act.

Sec. 20. Research and monitoring.

(a) Research.

(b) National monitoring plan.

(c) Monitoring.

Sec. 21. Solicitation of comments; notice of public hearings.

(a) Secretary of Agriculture.

(b) Views.

(c) Notice.

Sec. 22. Delegation and cooperation.

(a) Delegation.

(b) Cooperation.

Sec. 23. State cooperation, aid, and training.

(a) Cooperative agreements.

(b) Contracts for training.

(c) Information and education.

Sec. 24. Authority of States.

(a) In general.

(b) Uniformity.

(c) Additional uses.

Sec. 25. Authority of Administrator. 
(a) In General.

(1) Regulations.

(2) Procedure.

(3) Congressional committees.

(4) Congressional review of regulations.

(b) Exemption of pesticides.

(c) Other authority.

(d) Scientific advisory panel.

Sec. 26. State primary enforcement responsibility.

(a) In general.

(b) Special rules.

(c) Administrator.

Sec. 27. Failure by the State to assure enforcement of State pesticide use

(a) Referral

(b) Notice.

(c) Construction.

Sec. 28. Identification of pests; cooperation with Department of Agriculture's

program.
(a) In general.

(b) Pest control availability.

(1) In general.

(2) Report.

(c) Integrated pest management.

Sec. 29. Annual report.

Sec. 30. Minimum requirements for training of maintenance applicators and service technicians.

Sec. 31. Environmental Protection Agency minor use program.

Sec. 32. Department of Agriculture minor use program.

(a) In general.

(b)(1) Minor use pesticide data.

(2) Minor Use Pesticide Data Revolving Fund.

Sec. 33. Pesticide registration service fees.

(a) Definition of costs.

(b) Fees.

(1) In general.

(2) Covered pesticide registration applications

(3) Schedule of covered applications and registration service fees.

(4) Pending pesticide registration applications.

(5) Resubmission of pesticide registration applications.

(6) Fee adjustment.

(7) Waivers and reductions.

(8) Refunds.

(c) Pesticide Registration Fund.

(1) Establishment.

(2) Transfers to Fund.

(3) Expenditures from Fund.

(4) Collections and appropriations Acts.

(5) Unused funds.

(d) Assessment of fees.

(1) Definition of covered functions.

(2) Minimum amount of appropriations.

(3) Use of fees.

(4) Compliance.

(5) Subsequent authority.

(e) Reforms to reduce decision time review periods.

(f) Decision time review periods.

(1) In general.

(2) Report.

(3) Applications subject to decision time review periods.

(4) Start of decision time review period.

(5) Extension of decision time review period.

(g) Judicial review.

(1) In general.

(2) Scope.

(3) Timing.

(4) Remedies.

(h) Accounting.

(i) Auditing.

(1) Financial statements of agencies.

(2) Components.

(3) Inspector General.

(j) Personnel levels.

(k) Reports.

(1) In general.

(2) Contents.

(l) Savings clause.

(m) Termination of effectiveness.

(1) In general.

(2) Phase out.

Sec. 34. Severability.

Sec. 35. Authorization for appropriations.

SEC. 2. [7 U.S.C. 136] DEFINITIONS. For purposes of this Act- 
(a) ACTIVE InGREDIENT.-The term "active ingredient" means-

(1) in the case of a pesticide other than a plant regulator, defoliant, desiccant, or nitrogen stabilizer, an ingredient which will prevent, destroy, repel, or mitigate any pest;

(2) in the case of a plant regulator, an ingredient which, through physiological action, will accelerate or retard the rate of growth or rate of maturation or otherwise alter the behavior of ornamental or crop plants or the product thereof;

(3) in the case of a defoliant, an ingredient which will cause the leaves or foliage to drop from a plant;

(4) in the case of a desiccant, an ingredient which will artificially accelerate the drying of plant tissue; and

(5) in the case of a nitrogen stabilizer, an ingredient which will prevent or hinder the process of nitrification, denitrification, ammonia volatilization, or urease production through action affecting soil bacteria.

(b) ADMINISTRATOR.-The term "Administrator" means the Administrator of the Environmental Protection Agency.

(c) ADULTERATED.-The term "adulterated" applies to any pesticide if-

(1) its strength or purity falls below the professed standard of quality as expressed on its labeling under which it is sold;

(2) any substance has been substituted wholly or in part for the pesticide; or

(3) any valuable constituent of the pesticide has been wholly or in part abstracted.

(d) ANIMAL.-The term "animal" means all vertebrate and invertebrate species, including but not limited to man and other mammals, birds, fish, and shellfish.

(e) CERTIFIED APPLICATOR, ETC.-

(1) CERTIFIED APPLICATOR.-The term "certified applicator" means any individual who is certified under section 11 as authorized to use or supervise the use of any pesticide which is classified for restricted use. Any applicator who holds or applies registered pesticides, or uses dilutions of registered pesticides consistent with subsection (ee), only to provide a service of controlling pests without delivering any unapplied pesticide to any person so served is not deemed to be a seller or distributor of pesticides under this Act.

(2) PRIVATE APPLICATOR.-The term "private applicator" means a certified applicator who uses or supervises the use of any pesticide which is classified for restricted use for purposes of producing any agricultural commodity on property owned or rented by the applicator or the applicator's employer or (if applied without compensation other than trading of personal services between producers of agricultural commodities) on the property of another person.

(3) COMMERCIAL APPLICATOR.-The term "commercial applicator" means an applicator (whether or not the applicator is a private applicator with respect to some uses) who uses or supervises the use of any pesticide which is classified for restricted use for any purpose or on any property other than as provided by paragraph (2).

(4) UNDER THE DIRECT SUPERVISION OF A CERTIFIED APPLICATOR.-Unless otherwise prescribed by its labeling, a pesticide shall be considered to be applied under the direct supervision 
of a certified applicator if it is applied by a competent person acting under the instructions and control of a certified applicator who is available if and when needed, even though such certified applicator is not physically present at the time and place the pesticide is applied.

(f) DEFoliant.-The term "defoliant" means any substance or mixture of substances intended for causing the leaves or foliage to drop from a plant, with or without causing abscission.

(g) DeSICCANT.-The term "desiccant" means any substance or mixture of substances intended for artificially accelerating the drying of plant tissue.

(h) DEVICE.-The term "device" means any instrument or contrivance (other than a firearm) which is intended for trapping, destroying, repelling, or mitigating any pest or any other form of plant or animal life (other than man and other than bacteria, virus, or other microorganism on or in living man or other living animals); but not including equipment used for the application of pesticides when sold separately therefrom.

(i) DISTRICT COURT.-The term "district court" means a United States district court, the District Court of Guam, the District Court of the Virgin Islands, and the highest court of American Samoa.

(j) ENVIRONMENT.- The term "environment" includes water, air, land, and all plants and man and other animals living therein, and the interrelationships which exist among these.

(k) FunGUS.-The term "fungus" means any non-chlorophyllbearing thallophyte (that is, any non-chlorophyll-bearing plant of a lower order than mosses and liverworts), as for example, rust, smut, mildew, mold, yeast, and bacteria, except those on or in living man or other animals and those on or in processed food, beverages, or pharmaceuticals.

(l) IMMINENT HAZARD.-The term "imminent hazard" means a situation which exists when the continued use of a pesticide during the time required for cancellation proceeding would be likely to result in unreasonable adverse effects on the environment or will involve unreasonable hazard to the survival of a species declared endangered by the Secretary of the Interior under Public Law 91-135.

(m) INERT INGREDIENT.-The term "inert ingredient" means an ingredient which is not active.

(n) INGREDIENT STATEMENT.-The term "ingredient statement" means a statement which contains-

(1) the name and percentage of each active ingredient, and the total percentage of all inert ingredients, in the pesticide; and

(2) if the pesticide contains arsenic in any form, a statement of the percentages of total and water soluble arsenic, calculated as elementary arsenic.

(o) INSECT.-The term "insect" means any of the numerous small invertebrate animals generally having the body more or less obviously segmented, for the most part belonging to the class insecta, comprising six-legged, usually winged forms, as for example, beetles, bugs, bees, flies, and to other allied classes of arthropods whose members are wingless and usually have more than six legs, as for example, spiders, mites, ticks, centipedes, and wood lice.

(p) LABEL AND LABELING.- 
(1) LABEL.-The term "label" means the written, printed, or graphic matter on, or attached to, the pesticide or device or any of its containers or wrappers.

(2) LABELING.-The term "labeling" means all labels and all other written, printed, or graphic matter-

(A) accompanying the pesticide or device at any time; or

(B) to which reference is made on the label or in literature accompanying the pesticide or device, except to current official publications of the Environmental Protection Agency, the United States Departments of Agriculture and Interior, the Department of Health and Human Services, State experiment stations, State agricultural colleges, and other similar Federal or State institutions or agencies authorized by law to conduct research in the field of pesticides.

(q) MisbRanded.-

(1) A pesticide is misbranded if-

(A) its labeling bears any statement, design, or graphic representation relative thereto or to its ingredients which is false or misleading in any particular;

(B) it is contained in a package or other container or wrapping which does not conform to the standards established by the Administrator pursuant to section 25(c)(3);

(C) it is an imitation of, or is offered for sale under the name of, another pesticide;

(D) its label does not bear the registration number assigned under section 7 to each establishment in which it was produced;

(E) any word, statement, or other information required by or under authority of this Act to appear on the label or labeling is not prominently placed thereon with such conspicuousness (as compared with other words, statements, designs, or graphic matter in the labeling) and in such terms as to render it likely to be read and understood by the ordinary individual under customary conditions of purchase and use;

(F) the labeling accompanying it does not contain directions for use which are necessary for effecting the purpose for which the product is intended and if complied with, together with any requirements imposed under section 3(d) of this Act, are adequate to protect health and the environment;

(G) the label does not contain a warning or caution statement which may be necessary and if complied with, together with any requirements imposed under section 3(d) of this Act, is adequate to protect health and the environment; or

(H) in the case of a pesticide not registered in accordance with section 3 of this Act and intended for export, the label does not contain, in words prominently placed thereon with such conspicuousness (as compared with other words, statements, designs, or graphic matter in the labeling) as to render it likely to be noted by the ordinary individual under customary conditions of purchase and use, the 
following: "Not Registered for Use in the United States of America".

(2) A pesticide is misbranded if-

(A) the label does not bear an ingredient statement on that part of the immediate container (and on the outside container or wrapper of the retail package, if there be one, through which the ingredient statement on the immediate container cannot be clearly read) which is presented or displayed under customary conditions of purchase, except that a pesticide is not misbranded under this subparagraph if-

(i) the size or form of the immediate container, or the outside container or wrapper of the retail package, makes it impracticable to place the ingredient statement on the part which is presented or displayed under customary conditions of purchase; and

(ii) the ingredient statement appears prominently on another part of the immediate container, or outside container or wrapper, permitted by the Administrator; (B) the labeling does not contain a statement of the use classification under which the product is registered;

(C) there is not affixed to its container, and to the outside container or wrapper of the retail package, if there be one, through which the required information on the immediate container cannot be clearly read, a label bearing-

(i) the name and address of the producer, registrant, or person for whom produced;

(ii) the name, brand, or trademark under which the pesticide is sold;

(iii) the net weight or measure of the content, except that the Administrator may permit reasonable variations; and

(iv) when required by regulation of the Administrator to effectuate the purposes of this Act, the registration number assigned to the pesticide under this Act, and the use classification; and

(D) the pesticide contains any substance or substances in quantities highly toxic to man, unless the label shall bear, in addition to any other matter required by this Act-

(i) the skull and crossbones;

(ii) the word "poison" prominently in red on a background of distinctly contrasting color; and

(iii) a statement of a practical treatment (first aid or otherwise) in case of poisoning by the pesticide.

(r) NEMATODE.-The term "nematode" means invertebrate animals of the phylum nemathelminthes and class nematoda, that is, unsegmented round worms with elongated, fusiform, or saclike bodies covered with cuticle, and inhabiting soil, water, plants, or plant parts; may also be called nemas or eelworms.

(s) PERSON.-The term "person" means any individual, partnership, association, corporation, or any organized group of persons whether incorporated or not.

(t) PEST.-The term "pest" means (1) any insect, rodent, nematode, fungus, weed, or (2) any other form of terrestrial or aquatic plant or animal life or virus, bacteria, or other micro-organism (except viruses, bacteria, or other micro-organisms on or in living man 
or other living animals) which the Administrator declares to be a pest under section 25(c)(1).

(u) PESTICIDE.-The term "pesticide" means (1) any substance or mixture of substances intended for preventing, destroying, repelling, or mitigating any pest, (2) any substance or mixture of substances intended for use as a plant regulator, defoliant, or desiccant, and (3) any nitrogen stabilizer, except that the term "pesticide" shall not include any article that is a "new animal drug" within the meaning of section 201(w) of the Federal Food, Drug, and Cosmetic Act (21 U.S.C. 321(w)), that has been determined by the Secretary of Health and Human Services not to be a new animal drug by a regulation establishing conditions of use for the article, or that is an animal feed within the meaning of section 201(x) of such Act (21 U.S.C. 321(x)) bearing or containing a new animal drug. The term "pesticide" does not include liquid chemical sterilant products (including any sterilant or subordinate disinfectant claims on such products) for use on a critical or semi-critical device, as defined in section 201 of the Federal Food, Drug, and Cosmetic Act (21 U.S.C. 321). For purposes of the preceding sentence, the term "critical device" includes any device which is introduced directly into the human body, either into or in contact with the bloodstream or normally sterile areas of the body and the term "semi-critical device" includes any device which contacts intact mucous membranes but which does not ordinarily penetrate the blood barrier or otherwise enter normally sterile areas of the body.

(v) Plant REgUlATOR.-The term "plant regulator" means any substance or mixture of substances intended, through physiological action, for accelerating or retarding the rate of growth or rate of maturation, or for otherwise altering the behavior of plants or the produce thereof, but shall not include substances to the extent that they are intended as plant nutrients, trace elements, nutritional chemicals, plant inoculants, and soil amendments. Also, the term "plant regulator" shall not be required to include any of such of those nutrient mixtures or soil amendments as are commonly known as vitamin-hormone horticultural products, intended for improvement, maintenance, survival, health, and propagation of plants, and as are not for pest destruction and are nontoxic, nonpoisonous in the undiluted packaged concentration.

(w) PRODUCER AND PRODUCE.-The term "producer" means the person who manufacturers, prepares, compounds, propagates, or processes any pesticide or device or active ingredient used in producing a pesticide. The term "produce" means to manufacture, prepare, compound, propagate, or process any pesticide or device or active ingredient used in producing a pesticide. The dilution by individuals of formulated pesticides for their own use and according to the directions on registered labels shall not of itself result in such individuals being included in the definition of "producer" for the purposes of this Act.

(x) Protect Health AND the Environment.-The terms "protect health and the environment" and "protection of health and the environment" mean protection against any unreasonable adverse effects on the environment.

(y) REGISTRANT.-The term "registrant" means a person who has registered any pesticide pursuant to the provisions of this Act. tion.

(z) REGISTRATION.-The term "registration" includes reregistra- 
(aa) STATE.-The term "State" means a State, the District of Columbia, the Commonwealth of Puerto Rico, the Virgin Islands, Guam, the Trust Territory of the Pacific Islands, and American Samoa.

(bb) UnREASONABLE ADVERSE EFFECTS ON THE ENVIRONMENT.-The term "unreasonable adverse effects on the environment" means (1) any unreasonable risk to man or the environment, taking into account the economic, social, and environmental costs and benefits of the use of any pesticide, or (2) a human dietary risk from residues that result from a use of a pesticide in or on any food inconsistent with the standard under section 408 of the Federal Food, Drug, and Cosmetic Act (21 U.S.C. 346a). ${ }^{2-1}$ The Administrator shall consider the risks and benefits of public health pesticides separate from the risks and benefits of other pesticides. In weighing any regulatory action concerning a public health pesticide under this Act, the Administrator shall weigh any risks of the pesticide against the health risks such as the diseases transmitted by the vector to be controlled by the pesticide.

(cc) WEED.-The term "weed" means any plant which grows where not wanted.

(dd) ESTABLISHMENT.-The term "establishment" means any place where a pesticide or device or active ingredient used in producing a pesticide is produced, or held, for distribution or sale.

(ee) To Use ANY Registered Pesticide IN A MANNER INCONSISTENT WITH ITS LABELING.-The term "to use any registered pesticide in a manner inconsistent with its labeling" means to use any registered pesticide in a manner not permitted by the labeling, except that the term shall not include (1) applying a pesticide at any dosage, concentration, or frequency less than that specified on the labeling unless the labeling specifically prohibits deviation from the specified dosage, concentration, or frequency, (2) applying a pesticide against any target pest not specified on the labeling if the application is to the crop, animal, or site specified on the labeling, unless the Administrator has required that the labeling specifically state that the pesticide may be used only for the pests specified on the labeling after the Administrator has determined that the use of the pesticide against other pests would cause an unreasonable adverse effect on the environment, (3) employing any method of application not prohibited by the labeling unless the labeling specifically states that the product may be applied only by the methods specified on the labeling, (4) mixing a pesticide or pesticides with a fertilizer when such mixture is not prohibited by the labeling, (5) any use of a pesticide in conformance with section 5,18 , or 24 of this Act, or (6) any use of a pesticide in a manner that the Administrator determines to be consistent with the purposes of this Act. After March 31, 1979, the term shall not include the use of a pesticide for agricultural or forestry purposes at a dilution less than label dosage unless before or after that date the Administrator issues a regulation or advisory opinion consistent with the study provided for in section 27(b) of the Federal Pesticide Act of 1978, which regulation or advisory opinion specifically requires the use of definite amounts of dilution.

(ff) OUtstanding DATA REQUiREMEnT.-

${ }^{2-1}$ Sec. 304 of P.L. 104-170 amended sec. 2(bb) (7 U.S.C. 136(bb)) by inserting “(1)" and ", or (2)" and all that follows through "346a).", without specifying the Act that was being amended. The amendments were executed to this Act to effectuate the probable intent of Congress. 
(1) IN GENERAL.-The term "outstanding data requirement" means a requirement for any study, information, or data that is necessary to make a determination under section 3(c)(5) and which study, information, or data-

(A) has not been submitted to the Administrator; or

(B) if submitted to the Administrator, the Administrator has determined must be resubmitted because it is not valid, complete, or adequate to make a determination under section $3(\mathrm{c})(5)$ and the regulations and guidelines issued under such section.

(2) FACTORS.- - In making a determination under paragraph (1)(B) respecting a study, the Administrator shall examine, at a minimum, relevant protocols, documentation of the conduct and analysis of the study, and the results of the study to determine whether the study and the results of the study fulfill the data requirement for which the study was submitted to the Administrator.

(gg) To DistRIBUTE OR SELL.-The term "to distribute or sell" means to distribute, sell, offer for sale, hold for distribution, hold for sale, hold for shipment, ship, deliver for shipment, release for shipment, or receive and (having so received) deliver or offer to deliver. The term does not include the holding or application of registered pesticides or use dilutions thereof by any applicator who provides a service of controlling pests without delivering any unapplied pesticide to any person so served.

(hh) NiTROGEN STABILIZER.-The term "nitrogen stabilizer" means any substance or mixture of substances intended for preventing or hindering the process of nitrification, denitrification, ammonia volatilization, or urease production through action upon soil bacteria. Such term shall not include-

(1) dicyandiamide;

(2) ammonium thiosulfate; or

(3) any substance or mixture of substances.-

(A) that was not registered pursuant to section 3 prior to January 1, 1992; and

(B) that was in commercial agronomic use prior to January 1, 1992, with respect to which after January 1, 1992, the distributor or seller of the substance or mixture has made no specific claim of prevention or hindering of the process of nitrification, denitrification, ammonia volatilization urease production regardless of the actual use or purpose for, or future use or purpose for, the substance or mixture.

Statements made in materials required to be submitted to any State legislative or regulatory authority, or required by such authority to be included in the labeling or other literature accompanying any such substance or mixture shall not be deemed a specific claim within the meaning of this subsection.

(jj) 2-2 MAINTENANCE APPLICATOR.-The term "maintenance applicator" means any individual who, in the principal course of such individual's employment, uses, or supervises the use of, a pesticide not classified for restricted use (other than a ready to use consumer products pesticide); for the purpose of providing structural pest control or lawn pest control including janitors, general maintenance

${ }^{2-2}$ So in original (as added by sec. 120 of P.L. 104-170). This subsection should probably be "(ii)" and subsequent subsections should be redesignated accordingly. 
personnel, sanitation personnel, and grounds maintenance personnel. The term "maintenance applicator" does not include private applicators as defined in section 2(e)(2); individuals who use antimicrobial pesticides, sanitizers or disinfectants; individuals employed by Federal, State, and local governments or any political subdivisions thereof, or individuals who use pesticides not classified for restricted use in or around their homes, boats, sod farms, nurseries, greenhouses, or other noncommercial property.

(kk) SERVICE TEChNICIAN.-The term "service technician" means any individual who uses or supervises the use of pesticides (other than a ready to use consumer products pesticide) for the purpose of providing structural pest control or lawn pest control on the property of another for a fee. The term "service technician" does not include individuals who use antimicrobial pesticides, sanitizers or disinfectants; or who otherwise apply ready to use consumer products pesticides.

(1l) MINOR UsE.-The term "minor use" means the use of a pesticide on an animal, on a commercial agricultural crop or site, or for the protection of public health where-

(1) the total United States acreage for the crop is less than 300,000 acres, as determined by the Secretary of Agriculture; or

(2) the Administrator, in consultation with the Secretary of Agriculture, determines that, based on information provided by an applicant for registration or a registrant, the use does not provide sufficient economic incentive to support the initial registration or continuing registration of a pesticide for such use and-

(A) there are insufficient efficacious alternative registered pesticides available for the use;

(B) the alternatives to the pesticide use pose greater risks to the environment or human health;

(C) the minor use pesticide plays or will play a significant part in managing pest resistance; or

(D) the minor use pesticide plays or will play a significant part in an integrated pest management program.

The status as a minor use under this subsection shall continue as long as the Administrator has not determined that, based on existing data, such use may cause an unreasonable adverse effect on the environment and the use otherwise qualifies for such status.

(mm) ANTIMICROBIAL PESTICIDE.-

(1) IN GENERAL.-The term "antimicrobial pesticide" means a pesticide that-

(A) is intended to-

(i) disinfect, sanitize, reduce, or mitigate growth or development of microbiological organisms; or

(ii) protect inanimate objects, industrial processes or systems, surfaces, water, or other chemical substances from contamination, fouling, or deterioration caused by bacteria, viruses, fungi, protozoa, algae, or slime; and

(B) in the intended use is exempt from, or otherwise not subject to, a tolerance under section 408 of the Federal Food, Drug, and Cosmetic Act (21 U.S.C. 346a and 348) or a food additive regulation under section 409 of such Act. 
(2) EXCLUDED PRODUCTS.-The term "antimicrobial pesticide" does not include -

(A) a wood preservative or antifouling paint product for which a claim of pesticidal activity other than or in addition to an activity described in paragraph (1) is made;

(B) an agricultural fungicide product; or

(C) an aquatic herbicide product.

(3) INCLUDED PRODUCTS.-The term "antimicrobial pesticide" does include any other chemical sterilant product (other than liquid chemical sterilant products exempt under subsection (u)), any other disinfectant product, any other industrial microbiocide product, and any other preservative product that is not excluded by paragraph (2).

(nn) Public Health Pesticide.-The term "public health pesticide" means any minor use pesticide product registered for use and used predominantly in public health programs for vector control or for other recognized health protection uses, including the prevention or mitigation of viruses, bacteria, or other microorganisms (other than viruses, bacteria, or other microorganisms on or in living man or other living animal) that pose a threat to public health.

(oo) VECTOR.-The term "vector" means any organism capable of transmitting the causative agent of human disease or capable of producing human discomfort or injury, including mosquitoes, flies, fleas, cockroaches, or other insects and ticks, mites, or rats.

\section{SEC. 3. [7 U.S.C. 136a] REGISTRATION OF PESTICIDES.}

(a) REQUIREMENT OF REGISTRATION.-Except as provided by this Act, no person in any State may distribute or sell to any person any pesticide that is not registered under this Act. To the extent necessary to prevent unreasonable adverse effects on the environment, the Administrator may by regulation limit the distribution, sale, or use in any State of any pesticide that is not registered under this Act and that is not the subject of an experimental use permit under section 5 or an emergency exemption under section 18.

(b) ExEMPTIONS.-A pesticide which is not registered with the Administrator may be transferred if-

(1) the transfer is from one registered establishment to another registered establishment operated by the same producer solely for packaging at the second establishment or for use as a constituent part of another pesticide produced at the second establishment; or

(2) the transfer is pursuant to and in accordance with the requirements of an experimental use permit.

(c) Procedure For Registration.-

(1) STATEMENT REQUIRED.-Each applicant for registration of a pesticide shall file with the Administrator a statement which includes-

(A) the name and address of the applicant and of any

other person whose name will appear on the labeling;

(B) the name of the pesticide;

(C) a complete copy of the labeling of the pesticide, a statement of all claims to be made for it, and any directions for its use;

(D) the complete formula of the pesticide; 
(E) a request that the pesticide be classified for general use or for restricted use, or for both; and

(F) except as otherwise provided in paragraph (2)(D), if requested by the Administrator, a full description of the tests made and the results thereof upon which the claims are based, or alternatively a citation to data that appear in the public literature or that previously had been submitted to the Administrator and that the Administrator may consider in accordance with the following provisions:

(i) With respect to pesticides containing active ingredients that are initially registered under this Act after the date of enactment of the Federal Pesticide Act of 1978 [September 30, 1978], data submitted to support the application for the original registration of the pesticide, or an application for an amendment adding any new use to the registration and that pertains solely to such new use, shall not, without the written permission of the original data submitter, be considered by the Administrator to support an application by another person during a period of ten years following the date the Administrator first registers the pesticide, except that such permission shall not be required in the case of defensive data.

(ii) The period of exclusive data use provided under clause (i) shall be extended 1 additional year for each 3 minor uses registered after the date of enactment of this clause [Aug. 3, 1996] and within 7 years of the commencement of the exclusive use period, up to a total of 3 additional years for all minor uses registered by the Administrator if the Administrator, in consultation with the Secretary of Agriculture, determines that, based on information provided by an applicant for registration or a registrant, that-

(I) there are insufficient efficacious alternative registered pesticides available for the use;

(II) the alternatives to the minor use pesticide pose greater risks to the environment or human health;

(III) the minor use pesticide plays or will play a significant part in managing pest resistance; or

(IV) the minor use pesticide plays or will play a significant part in an integrated pest management program.

The registration of a pesticide for a minor use on a crop grouping established by the Administrator shall be considered for purposes of this clause 1 minor use for each representative crop for which data are provided in the crop grouping. Any additional exclusive use period under this clause shall be modified as appropriate or terminated if the registrant voluntarily cancels the product or deletes from the registration the minor uses which formed the basis for the extension of the additional exclusive use period or if the Administrator determines that the registrant is not actually marketing the product for such minor uses. 
(iii) Except as otherwise provided in clause (i), with respect to data submitted after December 31, 1969 , by an applicant or registrant to support an application for registration, experimental use permit, or amendment adding a new use to an existing registration, to support or maintain in effect an existing registration, or for reregistration, the Administrator may, without the permission of the original data submitter, consider any such item of data in support of an application by any other person (hereinafter in this subparagraph referred to as the "applicant") within the fifteen-year period following the date the data were originally submitted only if the applicant has made an offer to compensate the original data submitter and submitted such offer to the Administrator accompanied by evidence of delivery to the original data submitter of the offer. The terms and amount of compensation may be fixed by agreement between the original data submitter and the applicant, or, failing such agreement, binding arbitration under this subparagraph. If, at the end of ninety days after the date of delivery to the original data submitter of the offer to compensate, the original data submitter and the applicant have neither agreed on the amount and terms of compensation nor on a procedure for reaching an agreement on the amount and terms of compensation, either person may initiate binding arbitration proceedings by requesting the Federal Mediation and Conciliation Service to appoint an arbitrator from the roster of arbitrators maintained by such Service. The procedure and rules of the Service shall be applicable to the selection of such arbitrator and to such arbitration proceedings, and the findings and determination of the arbitrator shall be final and conclusive, and no official or court of the United States shall have power or jurisdiction to review any such findings and determination, except for fraud, misrepresentation, or other misconduct by one of the parties to the arbitration or the arbitrator where there is a verified complaint with supporting affidavits attesting to specific instances of such fraud, misrepresentation, or other misconduct. The parties to the arbitration shall share equally in the payment of the fee and expenses of the arbitrator. If the Administrator determines that an original data submitter has failed to participate in a procedure for reaching an agreement or in an arbitration proceeding as required by this subparagraph, or failed to comply with the terms of an agreement or arbitration decision concerning compensation under this subparagraph, the original data submitter shall forfeit the right to compensation for the use of the data in support of the application. Notwithstanding any other provision of this Act, if the Administrator determines that an applicant has failed to participate in a procedure for reaching an agreement or in an arbitration proceeding as required by this subparagraph, or failed to comply with the terms of an 
agreement or arbitration decision concerning compensation under this subparagraph, the Administrator shall deny the application or cancel the registration of the pesticide in support of which the data were used without further hearing. Before the Administrator takes action under either of the preceding two sentences, the Administrator shall furnish to the affected person, by certified mail, notice of intent to take action and allow fifteen days from the date of delivery of the notice for the affected person to respond. If a registration is denied or canceled under this subparagraph, the Administrator may make such order as the Administrator deems appropriate concerning the continued sale and use of existing stocks of such pesticide. Registration action by the Administrator shall not be delayed pending the fixing of compensation.

(iv) After expiration of any period of exclusive use and any period for which compensation is required for the use of an item of data under clauses (i), (ii), and (iii), the Administrator may consider such item of data in support of an application by any other applicant without the permission of the original data submitter and without an offer having been received to compensate the original data submitter for the use of such item of data.

(v) The period of exclusive use provided under clause (ii) shall not take effect until 1 year after enactment of this clause [Aug. 3, 1996], except where an applicant or registrant is applying for the registration of a pesticide containing an active ingredient not previously registered.

(vi) With respect to data submitted after the date of enactment of this clause [Aug. 3, 1996] by an applicant or registrant to support an amendment adding a new use to an existing registration that does not retain any period of exclusive use, if such data relates solely to a minor use of a pesticide, such data shall not, without the written permission of the original data submitter, be considered by the Administrator to support an application for a minor use by another person during the period of 10 years following the date of submission of such data. The applicant or registrant at the time the new minor use is requested shall notify the Administrator that to the best of their knowledge the exclusive use period for the pesticide has expired and that the data pertaining solely to the minor use of a pesticide is eligible for the provisions of this paragraph. If the minor use registration which is supported by data submitted pursuant to this subsection is voluntarily canceled or if such data are subsequently used to support a nonminor use, the data shall no longer be subject to the exclusive use provisions of this clause but shall instead be considered by the Administrator in accordance with the provisions of clause (i), as appropriate. 
(G) If the applicant is requesting that the registration or amendment to the registration of a pesticide be expedited, an explanation of the basis for the request must be submitted, in accordance with paragraph (10) of this subsection.

(2) DATA IN SUPPORT OF REGISTRATION.-

(A) IN GENERAL.-The Administrator shall publish guidelines specifying the kinds of information which will be required to support the registration of a pesticide and shall revise such guidelines from time to time. If thereafter the Administrator requires any additional kind of information under subparagraph (B) of this paragraph, the Administrator shall permit sufficient time for applicants to obtain such additional information. The Administrator, in establishing standards for data requirements for the registration of pesticides with respect to minor uses, shall make such standards commensurate with the anticipated extent of use, pattern of use, the public health and agricultural need for such minor use, and the level and degree of potential beneficial or adverse effects on man and the environment. The Administrator shall not require a person to submit, in relation to a registration or reregistration of a pesticide for minor agricultural use under this Act, any field residue data from a geographic area where the pesticide will not be registered for such use. In the development of these standards, the Administrator shall consider the economic factors of potential national volume of use, extent of distribution, and the impact of the cost of meeting the requirements on the incentives for any potential registrant to undertake the development of the required data. Except as provided by section 10, within 30 days after the Administrator registers a pesticide under this Act the Administrator shall make available to the public the data called for in the registration statement together with such other scientific information as the Administrator deems relevant to the Administrator's decision.

(B) AdDitional DATA.- (i) If the Administrator determines that additional data are required to maintain in effect an existing registration of a pesticide, the Administrator shall notify all existing registrants of the pesticide to which the determination relates and provide a list of such registrants to any interested person.

(ii) Each registrant of such pesticide shall provide evidence within ninety days after receipt of notification that it is taking appropriate steps to secure the additional data that are required. Two or more registrants may agree to develop jointly, or to share in the cost of developing, such data if they agree and advise the Administrator of their intent within ninety days after notification. Any registrant who agrees to share in the cost of producing the data shall be entitled to examine and rely upon such data in support of maintenance of such registration. The Administrator shall issue a notice of intent to suspend the registration of a pesticide in accordance with the procedures prescribed by clause (iv) if a registrant fails to comply with this clause. 
(iii) If, at the end of sixty days after advising the Administrator of their agreement to develop jointly, or share in the cost of developing data, the registrants have not further agreed on the terms of the data development arrangement or on a procedure for reaching such agreement, any of such registrants may initiate binding arbitration proceedings by requesting the Federal Mediation and Conciliation Service to appoint an arbitrator from the roster of arbitrators maintained by such Service. The procedure and rules of the Service shall be applicable to the selection of such arbitrator and to such arbitration proceedings, and the findings and determination of the arbitrator shall be final and conclusive, and no official or court of the United States shall have power or jurisdiction to review any such findings and determination, except for fraud, misrepresentation, or other misconduct by one of the parties to the arbitration or the arbitrator where there is a verified complaint with supporting affidavits attesting to specific instances of such fraud, misrepresentation, or other misconduct. All parties to the arbitration shall share equally in the payment of the fee and expenses of the arbitrator. The Administrator shall issue a notice of intent to suspend the registration of a pesticide in accordance with the procedures prescribed by clause (iv) if a registrant fails to comply with this clause.

(iv) Notwithstanding any other provision of this Act, if the Administrator determines that a registrant, within the time required by the Administrator, has failed to take appropriate steps to secure the data required under this subparagraph, to participate in a procedure for reaching agreement concerning a joint data development arrangement under this subparagraph or in an arbitration proceeding as required by this subparagraph, or to comply with the terms of an agreement or arbitration decision concerning a joint data development arrangement under this subparagraph, the Administrator may issue a notice of intent to suspend such registrant's registration of the pesticide for which additional data is required. The Administrator may include in the notice of intent to suspend such provisions as the Administrator deems appropriate concerning the continued sale and use of existing stocks of such pesticide. Any suspension proposed under this subparagraph shall become final and effective at the end of thirty days from receipt by the registrant of the notice of intent to suspend, unless during that time a request for hearing is made by a person adversely affected by the notice or the registrant has satisfied the Administrator that the registrant has complied fully with the requirements that served as a basis for the notice of intent to suspend. If a hearing is requested, a hearing shall be conducted under section 6(d) of this Act. The only matters for resolution at that hearing shall be whether the registrant has failed to take the action that served as the basis for the notice of intent to suspend the registration of the pesticide for which additional data is required, and whether the Administrator's determination with respect to the disposition of existing stocks is con- 
sistent with this Act. If a hearing is held, a decision after completion of such hearing shall be final. Notwithstanding any other provision of this Act, a hearing shall be held and a determination made within seventy-five days after receipt of a request for such hearing. Any registration suspended under this subparagraph shall be reinstated by the Administrator if the Administrator determines that the registrant has complied fully with the requirements that served as a basis for the suspension of the registration.

(v) Any data submitted under this subparagraph shall be subject to the provisions of paragraph (1)(D). Whenever such data are submitted jointly by two or more registrants, an agent shall be agreed on at the time of the joint submission to handle any subsequent data compensation matters for the joint submitters of such data.

(vi) Upon the request of a registrant the Administrator shall, in the case of a minor use, extend the deadline for the production of residue chemistry data under this subparagraph for data required solely to support that minor use until the final deadline for submission of data under section 4 for the other uses of the pesticide established as of the date of enactment of the Food Quality Protection Act of 1996 [Aug. 3, 1996], if-

(I) the data to support other uses of the pesticide on a food are being provided;

(II) the registrant, in submitting a request for such an extension, provides a schedule, including interim dates to measure progress, to assure that the data production will be completed before the expiration of the extension period;

(III) the Administrator has determined that such extension will not significantly delay the Administrator's schedule for issuing a reregistration eligibility determination required under section 4 ; and

(IV) the Administrator has determined that based on existing data, such extension would not significantly increase the risk of any unreasonable adverse effect on the environment. ${ }^{3-1}$ If the Administrator grants an extension under this clause, the Administrator shall monitor the development of the data and shall ensure that the registrant is meeting the schedule for the production of the data. If the Administrator determines that the registrant is not meeting or has not met the schedule for the production of such data, the Administrator may proceed in accordance with clause (iv) regarding the continued registration of the affected products with the minor use and shall inform the public of such action. Notwithstanding the provisions of this clause, the Administrator may take action to modify or revoke the extension under this clause if the Administrator determines that the extension for the minor use may cause an unreasonable adverse effect on the environment. In such circumstance, the Ad-

${ }^{3-1}$ Indentation of the following sentences of this clause is so in original (as added by sec. 201(c)(1) of P.L. 104-170). Probably should be indented the same as flush matter of this clause. 
ministrator shall provide, in writing to the registrant, a notice revoking the extension of time for submission of data. Such data shall instead be due in accordance with the date established by the Administrator for the submission of the data.

(vii) If the registrant does not commit to support a specific minor use of the pesticide, but is supporting and providing data in a timely and adequate fashion to support uses of the pesticide on a food, or if all uses of the pesticide are nonfood uses and the registrant does not commit to support a specific minor use of the pesticide but is supporting and providing data in a timely and adequate fashion to support other nonfood uses of the pesticide, the Administrator, at the written request of the registrant, shall not take any action pursuant to this clause in regard to such unsupported minor use until the final deadline established as of the date of enactment of the Food Quality Protection Act of 1996 [Aug. 3, 1996], for the submission of data under section 4 for the supported uses identified pursuant to this clause unless the Administrator determines that the absence of the data is significant enough to cause human health or environmental concerns. On the basis of such determination, the Administrator may refuse the request for extension by the registrant. Upon receipt of the request from the registrant, the Administrator shall publish in the Federal Register a notice of the receipt of the request and the effective date upon which the uses not being supported will be voluntarily deleted from the registration pursuant to section 6(f)(1). If the Administrator grants an extension under this clause, the Administrator shall monitor the development of the data for the uses being supported and shall ensure that the registrant is meeting the schedule for the production of such data. If the Administrator determines that the registrant is not meeting or has not met the schedule for the production of such data, the Administrator may proceed in accordance with clause (iv) of this subparagraph regarding the continued registration of the affected products with the minor and other uses and shall inform the public of such action in accordance with section 6(f)(2). Notwithstanding the provisions of this clause, the Administrator may deny, modify, or revoke the temporary extension under this subparagraph if the Administrator determines that the continuation of the minor use may cause an unreasonable adverse effect on the environment. In the event of modification or revocation, the Administrator shall provide, in writing, to the registrant a notice revoking the temporary extension and establish a new effective date by which the minor use shall be deleted from the registration.

(viii)(I) If data required to support registration of a pesticide under subparagraph $(\mathrm{A})$ is requested by a Federal or State regulatory authority, the Administrator shall, to the extent practicable, coordinate data requirements, test protocols, timetables, and standards of review and reduce burdens and redundancy caused to the registrant by multiple requirements on the registrant. 
(II) The Administrator may enter into a cooperative agreement with a State to carry out subclause (I).

(III) Not later than 1 year after the date of enactment of this clause [Aug. 3, 1996], the Administrator shall develop a process to identify and assist in alleviating future disparities between Federal and State data requirements.

(C) SIMPLIFIED PROCEDURES.-Within nine months after the date of enactment of this subparagraph [September 30, 1978], the Administrator shall, by regulation, prescribe simplified procedures for the registration of pesticides, which shall include the provisions of subparagraph (D) of this paragraph.

(D) EXEMPTION.-No applicant for registration of a pesticide who proposes to purchase a registered pesticide from another producer in order to formulate such purchased pesticide into the pesticide that is the subject of the application shall be required to-

(i) submit or cite data pertaining to such purchased product; or

(ii) offer to pay reasonable compensation otherwise required by paragraph (1)(D) of this subsection for the use of any such data.

(E) MINOR USE WAIVER.-In handling the registration of a pesticide for a minor use, the Administrator may waive otherwise applicable data requirements if the Administrator determines that the absence of such data will not prevent the Administrator from determining-

(i) the incremental risk presented by the minor use of the pesticide; and

(ii) that such risk, if any, would not be an unreasonable adverse effect on the environment.

(3) TIME FOR ACTING WITH RESPECT TO APPLICATION.-

(A) IN GENERAL.-The Administrator shall review the data after receipt of the application and shall, as expeditiously as possible, either register the pesticide in accordance with paragraph (5), or notify the applicant of the Administrator's determination that it does not comply with the provisions of the Act in accordance with paragraph (6). (B) IDENTICAL OR SUBSTANTIALLY SIMILAR.-(i) The Administrator shall, as expeditiously as possible, review and act on any application received by the Administrator that-

(I) proposes the initial or amended registration of an end-use pesticide that, if registered as proposed, would be identical or substantially similar in composition and labeling to a currently-registered pesticide identified in the application, or that would differ in composition and labeling from such currently-registered pesticide only in ways that would not significantly increase the risk of unreasonable adverse effects on the environment; or

(II) proposes an amendment to the registration of a registered pesticide that does not require scientific review of data.

(ii) In expediting the review of an application for an ac- 
(I) review the application in accordance with section $33(\mathrm{f})(4)(\mathrm{B})$ and, if the application is found to be incomplete, reject the application;

(II) not later than the applicable decision review time established pursuant to section $33(\mathrm{f})(4)(\mathrm{B})$, or, if no review time is established, not later than 90 days after receiving a complete application, notify the registrant if the application has been granted or denied; and

(III) if the application is denied, notify the registrant in writing of the specific reasons for the denial of the application.

(C) Minor USE REgistration.-

(i) The Administrator shall, as expeditiously as possible, review and act on any complete application(I) that proposes the initial registration of a new pesticide active ingredient if the active ingredient is proposed to be registered solely for minor uses, or proposes a registration amendment solely for minor uses to an existing registration; or

(II) for a registration or a registration amendment that proposes significant minor uses.

(ii) For the purposes of clause (i) -

(I) the term "as expeditiously as possible" means that the Administrator shall, to the greatest extent practicable, complete a review and evaluation of all data, submitted with a complete application, within 12 months after the submission of the complete application, and the failure of the Administrator to complete such a review and evaluation under clause (i) shall not be subject to judicial review; and

(II) the term "significant minor uses" means 3 or more minor uses proposed for every nonminor use, a minor use that would, in the judgment of the Administrator, serve as a replacement for any use which has been canceled in the 5 years preceding the receipt of the application, or a minor use that in the opinion of the Administrator would avoid the reissuance of an emergency exemption under section 18 for that minor use.

(D) ADEQUATE TIME FOR SUBMISSION OF MINOR USE DATA.- If a registrant makes a request for a minor use waiver, regarding data required by the Administrator, pursuant to paragraph $(2)(\mathrm{E})$, and if the Administrator denies in whole or in part such data waiver request, the registrant shall have a full-time period for providing such data. For purposes of this subparagraph, the term "full-time period" means the time period originally established by the Administrator for submission of such data, beginning with the date of receipt by the registrant of the Administrator's notice of denial.

(4) NoticE OF APPLICATION.-The Administrator shall publish in the Federal Register, promptly after receipt of the statement and other data required pursuant to paragraphs (1) and 
if it contains any new active ingredient or if it would entail a changed use pattern. The notice shall provide for a period of 30 days in which any Federal agency or any other interested person may comment.

(5) APPROVAL OF REGISTRATION.-The Administrator shall register a pesticide if the Administrator determines that, when considered with any restrictions imposed under subsection (d)-

(A) its composition is such as to warrant the proposed claims for it;

(B) its labeling and other material required to be submitted comply with the requirements of this Act;

(C) it will perform its intended function without unreasonable adverse effects on the environment; and

(D) when used in accordance with widespread and commonly recognized practice it will not generally cause unreasonable adverse effects on the environment.

The Administrator shall not make any lack of essentiality a criterion for denying registration of any pesticide. Where two pesticides meet the requirements of this paragraph, one should not be registered in preference to the other. In considering an application for the registration of a pesticide, the Administrator may waive data requirements pertaining to efficacy, in which event the Administrator may register the pesticide without determining that the pesticide's composition is such as to warrant proposed claims of efficacy. If a pesticide is found to be efficacious by any State under section 24(c) of this Act, a presumption is established that the Administrator shall waive data requirements pertaining to efficacy for use of the pesticide in such State.

(6) Denial of Registration.-If the Administrator determines that the requirements of paragraph (5) for registration are not satisfied, the Administrator shall notify the applicant for registration of the Administrator's determination and of the Administrator's reasons (including the factual basis) therefor, and that, unless the applicant corrects the conditions and notifies the Administrator thereof during the 30-day period beginning with the day after the date on which the applicant receives the notice, the Administrator may refuse to register the pesticide. Whenever the Administrator refuses to register a pesticide, the Administrator shall notify the applicant of the Administrator's decision and of the Administrator's reasons (including the factual basis) therefor. The Administrator shall promptly publish in the Federal Register notice of such denial of registration and the reasons therefor. Upon such notification, the applicant for registration or other interested person with the concurrence of the applicant shall have the same remedies as provided for in section 6 .

(7) REGISTRATION UNDER SPECIAL CIRCUMSTANCES.-Notwithstanding the provisions of paragraph (5)-

(A) The Administrator may conditionally register or amend the registration of a pesticide if the Administrator determines that (i) the pesticide and proposed use are identical or substantially similar to any currently registered pesticide and use thereof, or differ only in ways that would not significantly increase the risk of unreasonable adverse effects on the environment, and (ii) approving the registra- 
tion or amendment in the manner proposed by the applicant would not significantly increase the risk of any unreasonable adverse effect on the environment. An applicant seeking conditional registration or amended registration under this subparagraph shall submit such data as would be required to obtain registration of a similar pesticide under paragraph (5). If the applicant is unable to submit an item of data because it has not yet been generated, the Administrator may register or amend the registration of the pesticide under such conditions as will require the submission of such data not later than the time such data are required to be submitted with respect to similar pesticides already registered under this Act.

(B) The Administrator may conditionally amend the registration of a pesticide to permit additional uses of such pesticide notwithstanding that data concerning the pesticide may be insufficient to support an unconditional amendment, if the Administrator determines that (i) the applicant has submitted satisfactory data pertaining to the proposed additional use, and (ii) amending the registration in the manner proposed by the applicant would not significantly increase the risk of any unreasonable adverse effect on the environment. Notwithstanding the foregoing provisions of this subparagraph, no registration of a pesticide may be amended to permit an additional use of such pesticide if the Administrator has issued a notice stating that such pesticide, or any ingredient thereof, meets or exceeds risk criteria associated in whole or in part with human dietary exposure enumerated in regulations issued under this Act, and during the pendency of any risk-benefit evaluation initiated by such notice, if (I) the additional use of such pesticide involves a major food or feed crop, or (II) the additional use of such pesticide involves a minor food or feed crop and the Administrator determines, with the concurrence of the Secretary of Agriculture, there is available an effective alternative pesticide that does not meet or exceed such risk criteria. An applicant seeking amended registration under this subparagraph shall submit such data as would be required to obtain registration of a similar pesticide under paragraph (5). If the applicant is unable to submit an item of data (other than data pertaining to the proposed additional use) because it has not yet been generated, the Administrator may amend the registration under such conditions as will require the submission of such data not later than the time such data are required to be submitted with respect to similar pesticides already registered under this Act.

(C) The Administrator may conditionally register a pesticide containing an active ingredient not contained in any currently registered pesticide for a period reasonably sufficient for the generation and submission of required data (which are lacking because a period reasonably sufficient for generation of the data has not elapsed since the Administrator first imposed the data requirement) on the condition that by the end of such period the Administrator receives such data and the data do not meet or exceed risk 
criteria enumerated in regulations issued under this Act, and on such other conditions as the Administrator may prescribe. A conditional registration under this subparagraph shall be granted only if the Administrator determines that use of the pesticide during such period will not cause any unreasonable adverse effect on the environment, and that use of the pesticide is in the public interest.

(8) INTERIM ADMINISTRATIVE REVIEW.-Notwithstanding any other provision of this Act, the Administrator may not initiate a public interim administrative review process to develop a risk-benefit evaluation of the ingredients of a pesticide or any of its uses prior to initiating a formal action to cancel, suspend, or deny registration of such pesticide, required under this Act, unless such interim administrative process is based on a validated test or other significant evidence raising prudent concerns of unreasonable adverse risk to man or to the environment. Notice of the definition of the terms "validated test" and "other significant evidence" as used herein shall be published by the Administrator in the Federal Register.

(9) LABELING.-

(A) ADDITIONAL STATEMENTS.-Subject to subparagraphs (B) and (C), it shall not be a violation of this Act for a registrant to modify the labeling of an antimicrobial pesticide product to include relevant information on product efficacy, product composition, container composition or design, or other characteristics that do not relate to any pesticidal claim or pesticidal activity.

(B) REQUIREMENTS.-Proposed labeling information under subparagraph (A) shall not be false or misleading, shall not conflict with or detract from any statement required by law or the Administrator as a condition of registration, and shall be substantiated on the request of the Administrator.

(C) NOTIFICATION AND DISAPPROVAL.-

(i) Notification.-A registration may be modified under subparagraph (A) if -

(I) the registrant notifies the Administrator in writing not later than 60 days prior to distribution or sale of a product bearing the modified labeling; and

(II) the Administrator does not disapprove of the modification under clause (ii).

(ii) DISAPPROVAL.-Not later than 30 days after receipt of a notification under clause (i), the Administrator may disapprove the modification by sending the registrant notification in writing stating that the proposed language is not acceptable and stating the reasons why the Administrator finds the proposed modification unacceptable.

(iii) RESTRICTION ON SALE.-A registrant may not sell or distribute a product bearing a disapproved modification.

(iv) OвJеCтіON.-A registrant may file an objection in writing to a disapproval under clause (ii) not later than 30 days after receipt of notification of the disapproval. 
(v) FinAl ACTION.-A decision by the Administrator following receipt and consideration of an objection filed under clause (iv) shall be considered a final agency action.

(D) UsE DILUTION.-The label or labeling required under this Act for an antimicrobial pesticide that is or may be diluted for use may have a different statement of caution or protective measures for use of the recommended diluted solution of the pesticide than for use of a concentrate of the pesticide if the Administrator determines that -

(i) adequate data have been submitted to support the statement proposed for the diluted solution uses; and

(ii) the label or labeling provides adequate protection for exposure to the diluted solution of the pesticide.

(10) EXPEDITED REGISTRATION OF PESTICIDES.-

(A) Not later than 1 year after the date of enactment of this paragraph [Aug. 3, 1996], the Administrator shall, utilizing public comment, develop procedures and guidelines, and expedite the review of an application for registration of a pesticide or an amendment to a registration that satisfies such guidelines.

(B) Any application for registration or an amendment, including biological and conventional pesticides, will be considered for expedited review under this paragraph. An application for registration or an amendment shall qualify for expedited review if use of the pesticide proposed by the application may reasonably be expected to accomplish 1 or more of the following:

(i) Reduce the risks of pesticides to human health.

(ii) Reduce the risks of pesticides to nontarget organisms.

(iii) Reduce the potential for contamination of groundwater, surface water, or other valued environmental resources.

(iv) Broaden the adoption of integrated pest management strategies, or make such strategies more available or more effective.

(C) The Administrator, not later than 30 days after receipt of an application for expedited review, shall notify the applicant whether the application is complete. If it is found to be incomplete, the Administrator may either reject the request for expedited review or ask the applicant for additional information to satisfy the guidelines developed under subparagraph (A).

(d) Classification of Pesticides.-

(1) Classification FOR GENERAL USE, RESTRICTED USE, OR BOTH.-

(A) As a part of the registration of a pesticide the Administrator shall classify it as being for general use or for restricted use. If the Administrator determines that some of the uses for which the pesticide is registered should be for general use and that other uses for which it is registered should be for restricted use, the Administrator shall classify it for both general use and restricted use. Pesticide 
uses may be classified by regulation on the initial classification and registered pesticides may be classified prior to reregistration. If some of the uses of the pesticide are classified for general use and other uses are classified for restricted use, the directions relating to its general uses shall be clearly separated and distinguished from those directions relating to its restricted uses. The Administrator may require that its packaging and labeling for restricted uses shall be clearly distinguishable from its packaging and labeling for general uses.

(B) If the Administrator determines that the pesticide, when applied in accordance with its directions for use, warnings and cautions and for the uses for which it is registered, or for one or more of such uses, or in accordance with a widespread and commonly recognized practice, will not generally cause unreasonable adverse effects on the environment, the Administrator will classify the pesticide, or the particular use or uses of the pesticide to which the determination applies, for general use.

(C) If the Administrator determines that the pesticide, when applied in accordance with its directions for use, warnings and cautions and for the uses for which it is registered, or for one or more of such uses, or in accordance with a widespread and commonly recognized practice, may generally cause, without additional regulatory restrictions, unreasonable adverse effects on the environment, including injury to the applicator, the Administrator shall classify the pesticide, or the particular use or uses to which the determination applies, for restricted use:

(i) If the Administrator classifies a pesticide, or one or more uses of such pesticide, for restricted use because of a determination that the acute dermal or inhalation toxicity of the pesticide presents a hazard to the applicator or other persons, the pesticide shall be applied for any use to which the restricted classification applies only by or under the direct supervision of a certified applicator.

(ii) If the Administrator classifies a pesticide, or one or more uses of such pesticide, for restricted use because of a determination that its use without additional regulatory restriction may cause unreasonable adverse effects on the environment, the pesticide shall be applied for any use to which the determination applies only by or under the direct supervision of a certified applicator, or subject to such other restrictions as the Administrator may provide by regulation. Any such regulation shall be reviewable in the appropriate court of appeals upon petition of a person adversely affected filed within 60 days of the publication of the regulation in final form.

(2) CHANGE IN CLASsificATiON.-If the Administrator determines that a change in the classification of any use of a pesticide from general use to restricted use is necessary to prevent unreasonable adverse effects on the environment, the Administrator shall notify the registrant of such pesticide of such determination at least forty-five days before making the change and 
shall publish the proposed change in the Federal Register. The registrant, or other interested person with the concurrence of the registrant, may seek relief from such determination under section $6(\mathrm{~b})$.

(3) Change in Classification FROM RESTRICTED USE TO GENERAL USE.-The registrant of any pesticide with one or more uses classified for restricted use may petition the Administrator to change any such classification from restricted to general use. Such petition shall set out the basis for the registrant's position that restricted use classification is unnecessary because classification of the pesticide for general use would not cause unreasonable adverse effects on the environment. The Administrator, within sixty days after receiving such petition, shall notify the registrant whether the petition has been granted or denied. Any denial shall contain an explanation therefor and any such denial shall be subject to judicial review under section 16 of this Act.

(e) Products With Same Formulation and Claims.-Products which have the same formulation, are manufactured by the same person, the labeling of which contains the same claims, and the labels of which bear a designation identifying the product as the same pesticide may be registered as a single pesticide; and additional names and labels shall be added to the registration by supplemental statements.

(f) Miscellaneous.-

(1) EFFECT OF CHANGE OF LABELING OR FORMULATION.-If the labeling or formulation for a pesticide is changed, the registration shall be amended to reflect such change if the Administrator determines that the change will not violate any provision of this Act.

(2) REGiSTRATION NOT A DEFENSE.-In no event shall registration of an article be construed as a defense for the commission of any offense under this Act. As long as no cancellation proceedings are in effect registration of a pesticide shall be prima facie evidence that the pesticide, its labeling and packaging comply with the registration provisions of the Act.

(3) AUTHORITY TO CONSULT OTHER FEDERAL AGENCIES.-In connection with consideration of any registration or application for registration under this section, the Administrator may consult with any other Federal agency.

(4) MiXtures of Nitrogen STABILIZERS AND FERTILIZER PRODUCTS.-Any mixture or other combination of-

(A) 1 or more nitrogen stabilizers registered under this Act; and

(B) 1 or more fertilizer products, shall not be subject to the provisions of this section or sections $4,5,7,15$, and $17(\mathrm{a})(2)$ if the mixture or other combination is accompanied by the labeling required under this Act for the nitrogen stabilizer contained in the mixture or other combination, the mixture or combination is mixed or combined in accordance with such labeling, and the mixture or combination does not contain any active ingredient other than the nitrogen stabilizer.

(g) REgistration REvieW.-

(1)(A) General RULE.-

(i) IN GENERAL.-The registrations of pesticides are to be periodically reviewed. 
(ii) REGULATIONS.-In accordance with this subparagraph, the Administrator shall by regulation establish a procedure for accomplishing the periodic review of registrations.

(iii) INITIAL REGISTRATION REVIEW.-The Administrator shall complete the registration review of each pesticide or pesticide case, which may be composed of 1 or more active ingredients and the products associated with the active ingredients, not later than the later of-

(I) October 1, 2022; or

(II) the date that is 15 years after the date on

which the first pesticide containing a new active ingredient is registered.

(iv) SUBSEQUENT REGISTRATION REVIEW.-Not later than 15 years after the date on which the initial registration review is completed under clause (iii) and each 15 years thereafter, the Administrator shall complete a subsequent registration review for each pesticide or pesticide case.

(v) CANCEllation.-No registration shall be canceled as a result of the registration review process unless the Administrator follows the procedures and substantive requirements of section 6 .

(B) DoCKETING.-

(i) IN GENERAL.-Subject to clause (ii), after meeting with 1 or more individuals that are not government employees to discuss matters relating to a registration review, the Administrator shall place in the docket minutes of the meeting, a list of attendees, and any documents exchanged at the meeting, not later than the earlier of-

(I) the date that is 45 days after the meeting; or

(II) the date of issuance of the registration review decision.

(ii) PRotected INFORMATION.-The Administrator shall identify, but not include in the docket, any confidential business information the disclosure of which is prohibited by section 10 .

(C) Limitation.-Nothing in this subsection shall prohibit the Administrator from undertaking any other review of a pesticide pursuant to this Act.

(2)(A) DATA.- The Administrator shall use the authority in subsection $(\mathrm{c})(2)(\mathrm{B})$ to require the submission of data when such data are necessary for a registration review.

(B) DATA SUBMISSION, COMPENSATION, AND EXEMPTION.For purposes of this subsection, the provisions of subsections (c)(1), (c)(2)(B), and (c)(2)(D) shall be utilized for and be applicable to any data required for registration review.

(h) REgistration ReQUiREMENTS FOR ANTIMicRobial PESTICIDES.-

(1) Evaluation of PROCESS.-To the maximum extent practicable consistent with the degrees of risk presented by an antimicrobial pesticide and the type of review appropriate to evaluate the risks, the Administrator shall identify and evaluate reforms to the antimicrobial registration process that would reduce review periods existing as of the date of enactment of this subsection [Aug. 3, 1996] for antimicrobial pesticide prod- 
uct registration applications and applications for amended registration of antimicrobial pesticide products, including-

(A) new antimicrobial active ingredients;

(B) new antimicrobial end-use products;

(C) substantially similar or identical antimicrobial pesticides; and

(D) amendments to antimicrobial pesticide registrations.

(2) REVIEW TIME PERIOD REDUCTION GOAL.-Each reform identified under paragraph (1) shall be designed to achieve the goal of reducing the review period following submission of a complete application, consistent with the degree of risk, to a period of not more than-

(A) 540 days for a new antimicrobial active ingredient pesticide registration;

(B) 270 days for a new antimicrobial use of a registered active ingredient;

(C) 120 days for any other new antimicrobial product;

(D) 90 days for a substantially similar or identical antimicrobial product;

(E) 90 days for an amendment to an antimicrobial registration that does not require scientific review of data; and

(F) 120 days for an amendment to an antimicrobial registration that requires scientific review of data and that is not otherwise described in this paragraph.

(3) IMPLEMENTATION.-

(A) Proposed RULEMAKing.-

(i) ISSUANCE.-Not later than 270 days after the date of enactment of this subsection [Aug. 3, 1996], the Administrator shall publish in the Federal Register proposed regulations to accelerate and improve the review of antimicrobial pesticide products designed to implement, to the extent practicable, the goals set forth in paragraph (2).

(ii) REQUIREMENTS.-Proposed regulations issued under clause (i) shall-

(I) define the various classes of antimicrobial use patterns, including household, industrial, and institutional disinfectants and sanitizing pesticides, preservatives, water treatment, and pulp and paper mill additives, and other such products intended to disinfect, sanitize, reduce, or mitigate growth or development of microbiological organisms, or protect inanimate objects, industrial processes or systems, surfaces, water, or other chemical substances from contamination, fouling, or deterioration caused by bacteria, viruses, fungi, protozoa, algae, or slime;

(II) differentiate the types of review undertaken for antimicrobial pesticides;

(III) conform the degree and type of review to the risks and benefits presented by antimicrobial pesticides and the function of review under this Act, considering the use patterns of the product, toxicity, expected exposure, and product type; 
(IV) ensure that the registration process is sufficient to maintain antimicrobial pesticide efficacy and that antimicrobial pesticide products continue to meet product performance standards and effectiveness levels for each type of label claim made; and

(V) implement effective and reliable deadlines for process management.

(iii) COMMENTS.-In developing the proposed regulations, the Administrator shall solicit the views from registrants and other affected parties to maximize the effectiveness of the rule development process.

(B) FinAL REGULATIONS.-

(i) ISSUANCE.-The Administrator shall issue final regulations not later than 240 days after the close of the comment period for the proposed regulations.

(ii) FAILURE TO MEET GOAL.-If a goal described in paragraph (2) is not met by the final regulations, the Administrator shall identify the goal, explain why the goal was not attained, describe the element of the regulations included instead, and identify future steps to attain the goal.

(iii) REQUIREMENTS.-In issuing final regulations, the Administrator shall-

(I) consider the establishment of a certification process for regulatory actions involving risks that can be responsibly managed, consistent with the degree of risk, in the most cost-efficient manner;

(II) consider the establishment of a certification process by approved laboratories as an adjunct to the review process;

(III) use all appropriate and cost-effective review mechanisms, including-

(aa) expanded use of notification and nonnotification procedures;

(bb) revised procedures for application review; and

(cc) allocation of appropriate resources to ensure streamlined management of antimicrobial pesticide registrations; and

(IV) clarify criteria for determination of the completeness of an application.

(C) EXPEDITED REVIEW.- This subsection does not affect the requirements or extend the deadlines or review periods contained in subsection (c)(3).

(D) ALTERNATIVE REVIEW PERIODS.-If the final regulations to carry out this paragraph are not effective 630 days after the date of enactment of this subsection [Aug. 3, 1996], until the final regulations become effective, the review period, beginning on the date of receipt by the Agency of a complete application, shall be-

(i) 2 years for a new antimicrobial active ingredient pesticide registration;

(ii) 1 year for a new antimicrobial use of a registered active ingredient; 

uct;

(iii) 180 days for any other new antimicrobial prod-

(iv) 90 days for a substantially similar or identical antimicrobial product;

(v) 90 days for an amendment to an antimicrobial registration that does not require scientific review of data; and

(vi) 120 days for an amendment to an antimicrobial registration that requires scientific review of data and that is not otherwise described in this subparagraph.

(E) WOOD PRESERVATIVES.-An application for the registration, or for an amendment to the registration, of a wood preservative product for which a claim of pesticidal activity listed in section $2(\mathrm{~mm})$ is made (regardless of any other pesticidal claim that is made with respect to the product) shall be reviewed by the Administrator within the same period as that established under this paragraph for an antimicrobial pesticide product application, consistent with the degree of risk posed by the use of the wood preservative product, if the application requires the applicant to satisfy the same data requirements as are required to support an application for a wood preservative product that is an antimicrobial pesticide.

(F) NOTIFICATION.-

(i) IN GENERAL.-Subject to clause (iii), the Administrator shall notify an applicant whether an application has been granted or denied not later than the final day of the appropriate review period under this paragraph, unless the applicant and the Administrator agree to a later date.

(ii) FINAL DECISION.-If the Administrator fails to notify an applicant within the period of time required under clause (i), the failure shall be considered an agency action unlawfully withheld or unreasonably delayed for purposes of judicial review under chapter 7 of title 5, United States Code.

(iii) EXEMPTION.-This subparagraph does not apply to an application for an antimicrobial pesticide that is filed under subsection (c)(3)(B) prior to 90 days after the date of enactment of this subsection [Aug. 3, 1996].

(iv) Limitation.-Notwithstanding clause (ii), the failure of the Administrator to notify an applicant for an amendment to a registration for an antimicrobial pesticide shall not be judicially reviewable in a Federal or State court if the amendment requires scientific review of data within-

(I) the time period specified in subparagraph

(D)(vi), in the absence of a final regulation under subparagraph (B); or

(II) the time period specified in paragraph $(2)(F)$, if adopted in a final regulation under subparagraph (B). 
(A) Submission.-Beginning on the date of enactment of this subsection [Aug. 3, 1996] and ending on the date that the goals under paragraph (2) are achieved, the Administrator shall, not later than March 1 of each year, prepare and submit an annual report to the Committee on Agriculture of the House of Representatives and the Committee on Agriculture, Nutrition, and Forestry of the Senate.

(B) REQUIREMENTS.-A report submitted under subparagraph (A) shall include a description of-

(i) measures taken to reduce the backlog of pending registration applications;

(ii) progress toward achieving reforms under this subsection; and

(iii) recommendations to improve the activities of the Agency pertaining to antimicrobial registrations.

\section{SEC. 4. [7 U.S.C. 136a-1] REREGISTRATION OF REGISTERED PES-} TICIDES.

(a) GENERAL RULE.-The Administrator shall reregister, in accordance with this section, each registered pesticide containing any active ingredient contained in any pesticide first registered before November 1, 1984, except for any pesticide as to which the Administrator has determined, after November 1, 1984, and before the effective date of this section [December 24, 1988], that-

(1) there are no outstanding data requirements; and

(2) the requirements of section 3(c)(5) have been satisfied.

(b) REREGISTRATION PHASES.-Reregistrations of pesticides under this section shall be carried out in the following phases:

(1) The first phase shall include the listing under subsection (c) of the active ingredients of the pesticides that will be reregistered.

(2) The second phase shall include the submission to the Administrator under subsection (d) of notices by registrants respecting their intention to seek reregistration, identification by registrants of missing and inadequate data for such pesticides, and commitments by registrants to replace such missing or inadequate data within the applicable time period.

(3) The third phase shall include submission to the Administrator by registrants of the information required under subsection (e).

(4) The fourth phase shall include an independent, initial review by the Administrator under subsection (f) of submissions under phases two and three, identification of outstanding data requirements, and the issuance, as necessary, of requests for additional data.

(5) The fifth phase shall include the review by the Administrator under subsection (g) of data submitted for reregistration and appropriate regulatory action by the Administrator.

(c) Phase One.-

(1) PRIORITY FOR REREgistration.-For purposes of the reregistration of the pesticides described in subsection (a), the Administrator shall list the active ingredients of pesticides and shall give priority to, among others, active ingredients (other than active ingredients for which registration standards have been issued before the effective date of this section [December $24,1988])$ that- 
(A) are in use on or in food or feed and may result in postharvest residues;

(B) may result in residues of potential toxicological concern in potable ground water, edible fish, or shellfish;

(C) have been determined by the Administrator before the effective date of this section [December 24, 1988] to have significant outstanding data requirements; or

(D) are used on crops, including in greenhouses and nurseries, where worker exposure is most likely to occur.

(2) REREGISTRATION LISTS.-For purposes of reregistration under this section, the Administrator shall by order-

(A) not later than 70 days after the effective date of this section [December 24, 1988], list pesticide active ingredients for which registration standards have been issued before such effective date;

(B) not later than 4 months after such effective date, list the first 150 pesticide active ingredients, as determined under paragraph (1);

(C) not later than 7 months after such effective date, list the second 150 pesticide active ingredients, as determined under paragraph (1); and

(D) not later than 10 months after such effective date, list the remainder of the pesticide active ingredients, as determined under paragraph (1).

Each list shall be published in the Federal Register.

(3) JUDICIAL REVIEW.-The content of a list issued by the Administrator under paragraph (2) shall not be subject to judicial review.

(4) NOTICE TO REGISTRANTS.-On the publication of a list of pesticide active ingredients under paragraph (2), the Administrator shall send by certified mail to the registrants of the pesticides containing such active ingredients a notice of the time by which the registrants are to notify the Administrator under subsection (d) whether the registrants intend to seek or not to seek reregistration of such pesticides.

(d) Phase Two.-

(1) IN GENERAL.-The registrant of a pesticide that contains an active ingredient listed under subparagraph (B), (C), or (D) of subsection (c)(2) shall submit to the Administrator, within the time period prescribed by paragraph (4), the notice described in paragraph (2) and any information, commitment, or offer described in paragraph (3).

(2) NotiCE OF INTENT TO SEEK OR NOT TO SEEK REREGISTRATION.-

(A) The registrant of a pesticide containing an active ingredient listed under subparagraph (B), (C), or (D) of subsection (c)(2) shall notify the Administrator by certified mail whether the registrant intends to seek or does not intend to seek reregistration of the pesticide.

(B) If a registrant submits a notice under subparagraph (A) of an intention not to seek reregistration of a pesticide, the Administrator shall publish a notice in the Federal Register stating that such a notice has been submitted.

(3) Missing OR INADEQUATE DATA.-Each registrant of a 
paragraph (B), (C), or (D) of subsection (c)(2) and for which the registrant submitted a notice under paragraph (2) of an intention to seek reregistration of such pesticide shall submit to the Administrator-

(A) in accordance with regulations issued by the Administrator under section 3 , an identification of-

(i) all data that are required by regulation to support the registration of the pesticide with respect to such active ingredient;

(ii) data that were submitted by the registrant previously in support of the registration of the pesticide that are inadequate to meet such regulations; and

(iii) data identified under clause (i) that have not been submitted to the Administrator; and (B) either-

(i) a commitment to replace the data identified under subparagraph (A)(ii) and submit the data identified under subparagraph (A)(iii) within the applicable time period prescribed by paragraph $(4)(\mathrm{B})$; or

(ii) an offer to share in the cost to be incurred by a person who has made a commitment under clause (i) to replace or submit the data and an offer to submit to arbitration as described by section $3(\mathrm{c})(2)(\mathrm{B})$ with regard to such cost sharing.

For purposes of a submission by a registrant under subparagraph $(\mathrm{A})(\mathrm{ii})$, data are inadequate if the data are derived from a study with respect to which the registrant is unable to make the certification prescribed by subsection $(e)(1)(G)$ that the registrant possesses or has access to the raw data used in or generated by such study. For purposes of a submission by a registrant under such subparagraph, data shall be considered to be inadequate if the data are derived from a study submitted before January 1, 1970, unless it is demonstrated to the satisfaction of the Administrator that such data should be considered to support the registration of the pesticide that is to be reregistered.

(4) TIME PERIODS.made-

(A) A submission under paragraph (2) or (3) shall be

(i) in the case of a pesticide containing an active ingredient listed under subsection $(c)(2)(B)$, not later than 3 months after the date of publication of the listing of such active ingredient;

(ii) in the case of a pesticide containing an active ingredient listed under subsection $(c)(2)(C)$, not later than 3 months after the date of publication of the listing of such active ingredient; and

(iii) in the case of a pesticide containing an active ingredient listed under subsection $(\mathrm{c})(2)(\mathrm{D})$, not later than 3 months after the date of publication of the listing of such active ingredient.

On application, the Administrator may extend a time period prescribed by this subparagraph if the Administrator determines that factors beyond the control of the registrant prevent the registrant from complying with such period. 
(B) A registrant shall submit data in accordance with a commitment entered into under paragraph $(3)(B)$ within a reasonable period of time, as determined by the Administrator, but not more than 48 months after the date the registrant submitted the commitment. The Administrator, on application of a registrant, may extend the period prescribed by the preceding sentence by no more than 2 years if extraordinary circumstances beyond the control of the registrant prevent the registrant from submitting data within such prescribed period. Upon application of a registrant, the Administrator shall, in the case of a minor use, extend the deadline for the production of residue chemistry data under this subparagraph for data required solely to support that minor use until the final deadline for submission of data under this section for the other uses of the pesticide established as of the date of enactment of the Food Quality Protection Act of 1996 [Aug. 3, 1996] if-

(i) the data to support other uses of the pesticide on a food are being provided;

(ii) the registrant, in submitting a request for such an extension provides a schedule, including interim dates to measure progress, to assure that the data production will be completed before the expiration of the extension period;

(iii) the Administrator has determined that such extension will not significantly delay the Administrator's schedule for issuing a reregistration eligibility determination required under this section; and

(iv) the Administrator has determined that based on existing data, such extension would not significantly increase the risk of any unreasonable adverse effect on the environment. ${ }^{4-1}$ If the Administrator grants an extension under this subparagraph, the Administrator shall monitor the development of the data and shall ensure that the registrant is meeting the schedule for the production of the data. If the Administrator determines that the registrant is not meeting or has not met the schedule for the production of such data, the Administrator may proceed in accordance with clause (iv) of section 3(c)(2)(B) or other provisions of this section, as appropriate, regarding the continued registration of the affected products with the minor use and shall inform the public of such action. Notwithstanding the provisions of this subparagraph, the Administrator may take action to modify or revoke the extension under this subparagraph if the Administrator determines that the extension for the minor use may cause an unreasonable adverse effect on the environment. In such circumstance, the Administrator shall provide written notice to the registrant revoking the extension of time for submission of data. Such data shall instead be due in accordance with the date then

4-1 Indentation of the following sentences of this subparagraph is so in original (as added by sec. 201(c)(2) of P.L. 104-170). Probably should be indented the same as flush matter 
established by the Administrator for submission of the data.

(5) CANCELlation AND REMOVAL.-

(A) If the registrant of a pesticide does not submit a notice under paragraph (2) or (3) within the time prescribed by paragraph (4)(A), the Administrator shall issue a notice of intent to cancel the registration of such registrant for such pesticide and shall publish the notice in the Federal Register and allow 60 days for the submission of comments on the notice. On expiration of such 60 days, the Administrator, by order and without a hearing, may cancel the registration or take such other action, including extension of applicable time periods, as may be necessary to enable reregistration of such pesticide by another person.

\section{(B)(i) If-}

(I) no registrant of a pesticide containing an active ingredient listed under subsection (c)(2) notifies the Administrator under paragraph (2) that the registrant intends to seek reregistration of any pesticide containing that active ingredient;

(II) no such registrant complies with paragraph (3)(A); or

(III) no such registrant makes a commitment under paragraph $(3)(\mathrm{B})$ to replace or submit all data described in clauses (ii) and (iii) of paragraph (3)(A);

the Administrator shall publish in the Federal Register a notice of intent to remove the active ingredient from the list established under subsection (c)(2) and a notice of intent to cancel the registrations of all pesticides containing such active ingredient and shall provide 60 days for comment on such notice.

(ii) After the 60-day period has expired, the Administrator, by order, may cancel any such registration without hearing, except that the Administrator shall not cancel a registration under this subparagraph if-

(I) during the comment period a person acquires the rights of the registrant in that registration;

(II) during the comment period that person furnishes a notice of intent to reregister the pesticide in accordance with paragraph (2); and

(III) not later than 120 days after the publication of the notice under this subparagraph, that person has complied with paragraph (3) and the fee prescribed by subsection (i)(1) has been paid.

(6) SUSPENSIONS AND PENALTIES.-The Administrator shall issue a notice of intent to suspend the registration of a pesticide in accordance with the procedures prescribed by section $3(\mathrm{c})(2)(\mathrm{B})(\mathrm{iv})$ if the Administrator determines that (A) progress is insufficient to ensure the submission of the data required for such pesticide under a commitment made under paragraph (3)(B) within the time period prescribed by paragraph (4)(B) or (B) the registrant has not submitted such data to the Administrator within such time period. If the registrant does not commit to support a specific minor use of the pesticide, but is supporting and providing data in a timely and adequate fashion to 
support uses of the pesticide on a food, or if all uses of the pesticide are nonfood uses and the registrant does not commit to support a specific minor use of the pesticide but is supporting and providing data in a timely and adequate fashion to support other nonfood uses of the pesticide, the Administrator, at the written request of the registrant, shall not take any action pursuant to this paragraph in regard to such unsupported minor use until the final deadline established as of the date of enactment of the Food Quality Protection Act of 1996 [Aug. 3, 1996], for the submission of data under this section for the supported uses identified pursuant to this paragraph unless the Administrator determines that the absence of the data is significant enough to cause human health or environmental concerns. On such a determination the Administrator may refuse the request for extension by the registrant. Upon receipt of the request from the registrant, the Administrator shall publish in the Federal Register a notice of the receipt of the request and the effective date upon which the uses not being supported will be voluntarily deleted from the registration pursuant to section 6(f)(1). If the Administrator grants an extension under this paragraph, the Administrator shall monitor the development of the data for the uses being supported and shall ensure that the registrant is meeting the schedule for the production of such data. If the Administrator determines that the registrant is not meeting or has not met the schedule for the production of such data, the Administrator may proceed in accordance with section $3(\mathrm{c})(2)(\mathrm{B})(\mathrm{iv})$ regarding the continued registration of the affected products with the minor and other uses and shall inform the public of such action in accordance with section 6(f)(2). Notwithstanding this subparagraph, the Administrator may deny, modify, or revoke the temporary extension under this paragraph if the Administrator determines that the continuation of the minor use may cause an unreasonable adverse effect on the environment. In the event of modification or revocation, the Administrator shall provide, in writing, to the registrant a notice revoking the temporary extension and establish a new effective date by which the minor use shall be deleted from the registration.

(e) Phase Three.-

(1) INFORMATION ABOUT STUDIES.-Each registrant of a pesticide that contains an active ingredient listed under subparagraph (B), (C), or (D) of subsection (c)(2) who has submitted a notice under subsection (d)(2) of an intent to seek the reregistration of such pesticide shall submit, in accordance with the guidelines issued under paragraph (4), to the Administrator-

(A) a summary of each study concerning the active ingredient previously submitted by the registrant in support of the registration of a pesticide containing such active ingredient and considered by the registrant to be adequate to meet the requirements of section 3 and the regulations issued under such section;

(B) a summary of each study concerning the active ingredient previously submitted by the registrant in support of the registration of a pesticide containing such active ingredient that may not comply with the requirements of section 3 and the regulations issued under such section but 
which the registrant asserts should be deemed to comply with such requirements and regulations;

(C) a reformat of the data from each study summarized under subparagraph (A) or (B) by the registrant concerning chronic dosing, oncogenicity, reproductive effects, mutagenicity, neurotoxicity, teratogenicity, or residue chemistry of the active ingredient that were submitted to the Administrator before January 1, 1982;

(D) where data described in subparagraph (C) are not required for the active ingredient by regulations issued under section 3, a reformat of acute and subchronic dosing data submitted by the registrant to the Administrator before January 1, 1982, that the registrant considers to be adequate to meet the requirements of section 3 and the regulations issued under such section;

(E) an identification of data that are required to be submitted to the Administrator under section 6(a)(2) indicating an adverse effect of the pesticide;

(F) an identification of any other information available that in the view of the registrant supports the registration;

$(G)$ a certification that the registrant or the Administrator possesses or has access to the raw data used in or generated by the studies that the registrant summarized under subparagraph $(\mathrm{A})$ or $(\mathrm{B})$;

(H) either-

(i) a commitment to submit data to fill each outstanding data requirement identified by the registrant; or

(ii) an offer to share in the cost of developing such data to be incurred by a person who has made a commitment under clause (i) to submit such data, and an offer to submit to arbitration as described by section $3(\mathrm{c})(2)(\mathrm{B})$ with regard to such cost sharing; and

(I) evidence of compliance with section 3(c)(1)(D)(ii) and regulations issued thereunder with regard to previously submitted data as if the registrant were now seeking the original registration of the pesticide.

A registrant who submits a certification under subparagraph (G) that is false shall be considered to have violated this Act and shall be subject to the penalties prescribed by section 14 . (2) TIME PERIODS.-

(A) The information required by paragraph (1) shall be submitted to the Administrator-

(i) in the case of a pesticide containing an active ingredient listed under subsection $(\mathrm{c})(2)(\mathrm{B})$, not later than 12 months after the date of publication of the listing of such active ingredient;

(ii) in the case of a pesticide containing an active ingredient listed under subsection $(c)(2)(C)$, not later than 12 months after the date of publication of the listing of such active ingredient; and

(iii) in the case of a pesticide containing an active ingredient listed under subsection (c)(2)(D), not later than 12 months after the date of publication of the listing of such active ingredient. 
(B) A registrant shall submit data in accordance with a commitment entered into under paragraph $(1)(\mathrm{H})$ within a reasonable period of time, as determined by the Administrator, but not more than 48 months after the date the registrant submitted the commitment under such paragraph. The Administrator, on application of a registrant, may extend the period prescribed by the preceding sentence by no more than 2 years if extraordinary circumstances beyond the control of the registrant prevent the registrant from submitting data within such prescribed period. Upon application of a registrant, the Administrator shall, in the case of a minor use, extend the deadline for the production of residue chemistry data under this subparagraph for data required solely to support that minor use until the final deadline for submission of data under this section for the other uses of the pesticide established as of the date of enactment of the Food Quality Protection Act of 1996 [Aug. 3,1996 ] if-

(i) the data to support other uses of the pesticide on a food are being provided;

(ii) the registrant, in submitting a request for such an extension provides a schedule, including interim dates to measure progress, to assure that the data production will be completed before the expiration of the extension period;

(iii) the Administrator has determined that such extension will not significantly delay the Administrator's schedule for issuing a reregistration eligibility determination required under this section; and

(iv) the Administrator has determined that based on existing data, such extension would not significantly increase the risk of any unreasonable adverse effect on the environment. ${ }^{4-2}$ If the Administrator grants an extension under this subparagraph, the Administrator shall monitor the development of the data and shall ensure that the registrant is meeting the schedule for the production of the data. If the Administrator determines that the registrant is not meeting or has not met the schedule for the production of such data, the Administrator may proceed in accordance with clause (iv) of section 3(c)(2)(B) or other provisions of this section, as appropriate, regarding the continued registration of the affected products with the minor use and shall inform the public of such action. Notwithstanding the provisions of this subparagraph, the Administrator may take action to modify or revoke the extension under this subparagraph if the Administrator determines that the extension for the minor use may cause an unreasonable adverse effect on the environment. In such circumstance, the Administrator shall provide written notice to the registrant revoking the extension of time for submission of data. Such data shall instead be due in accordance with the date then

4-2 Indentation of the following sentences of this subparagraph is so in original (as added by sec. 201(c)(2) of P.L. 104-170). Probably should be indented the same as flush matter of this subparagraph. 
established by the Administrator for submission of the data.

(3) Cancellation.-

(A) If the registrant of a pesticide fails to submit the information required by paragraph (1) within the time prescribed by paragraph (2), the Administrator, by order and without hearing, shall cancel the registration of such pesticide. If the registrant does not commit to support a specific minor use of the pesticide, but is supporting and providing data in a timely and adequate fashion to support uses of the pesticide on a food, or if all uses of the pesticide are nonfood uses and the registrant does not commit to support a specific minor use of the pesticide but is supporting and providing data in a timely and adequate fashion to support other nonfood uses of the pesticide, the Administrator, at the written request of the registrant, shall not take any action pursuant to this subparagraph in regard to such unsupported minor use until the final deadline established as of the date of enactment of the Food Quality Protection Act of 1996 [Aug. 3, 1996], for the submission of data under this section for the supported uses identified pursuant to this subparagraph unless the Administrator determines that the absence of the data is significant enough to cause human health or environmental concerns. On the basis of such determination, the Administrator may refuse the request for extension by the registrant. Upon receipt of the request from the registrant, the Administrator shall publish in the Federal Register a notice of the receipt of the request and the effective date upon which the uses not being supported will be voluntarily deleted from the registration pursuant to section $6(\mathrm{f})(1)$. If the Administrator grants an extension under this subparagraph, the Administrator shall monitor the development of the data for the uses being supported and shall ensure that the registrant is meeting the schedule for the production of such data. If the Administrator determines that the registrant is not meeting or has not met the schedule for the production of such data, the Administrator may proceed in accordance with section $3(\mathrm{c})(2)(\mathrm{B})(\mathrm{iv})$ regarding the continued registration of the affected products with the minor and other uses and shall inform the public of such action in accordance with section 6(f)(2). Notwithstanding this subparagraph, the Administrator may deny, modify, or revoke the temporary extension under this subparagraph if the Administrator determines that the continuation of the minor use may cause an unreasonable adverse effect on the environment. In the event of modification or revocation, the Administrator shall provide, in writing, to the registrant a notice revoking the temporary extension and establish a new effective date by which the minor use shall be deleted from the registration.

(B)(i) If the registrant of a pesticide submits the information required by paragraph (1) within the time prescribed by paragraph (2) and such information does not conform to the guidelines for submissions established by the Administrator, the Administrator shall determine 
whether the registrant made a good faith attempt to conform its submission to such guidelines.

(ii) If the Administrator determines that the registrant made a good faith attempt to conform its submission to such guidelines, the Administrator shall provide the registrant a reasonable period of time to make any necessary changes or corrections.

(iii)(I) If the Administrator determines that the registrant did not make a good faith attempt to conform its submission to such guidelines, the Administrator may issue a notice of intent to cancel the registration. Such a notice shall be sent to the registrant by certified mail.

(II) The registration shall be canceled without a hearing or further notice at the end of 30 days after receipt by the registrant of the notice unless during that time a request for a hearing is made by the registrant.

(III) If a hearing is requested, a hearing shall be conducted under section 6(d), except that the only matter for resolution at the hearing shall be whether the registrant made a good faith attempt to conform its submission to such guidelines. The hearing shall be held and a determination made within 75 days after receipt of a request for hearing.

(4) GUIDELINES.-

(A) Not later than 1 year after the effective date of this section [December 24, 1988], the Administrator, by order, shall issue guidelines to be followed by registrants in-

(i) summarizing studies;

(ii) reformatting studies;

(iii) identifying adverse information; and

(iv) identifying studies that have been submitted previously that may not meet the requirements of section 3 or regulations issued under such section, under paragraph (1).

(B) Guidelines issued under subparagraph (A) shall not be subject to judicial review.

(5) MONITORING.-The Administrator shall monitor the progress of registrants in acquiring and submitting the data required under paragraph (1).

(f) Phase FouR.-

(1) INDEPENDENT REVIEW AND IDENTIFICATION OF OUTSTANDING DATA REQUIREMENTS.-

(A) The Administrator shall review the submissions of all registrants of pesticides containing a particular active ingredient under subsections $(\mathrm{d})(3)$ and $(\mathrm{e})(1)$ to determine if such submissions identified all the data that are missing or inadequate for such active ingredient. To assist the review of the Administrator under this subparagraph, the Administrator may require a registrant seeking reregistration to submit complete copies of studies summarized under subsection (e)(1).

(B) The Administrator shall independently identify and publish in the Federal Register the outstanding data requirements for each active ingredient that is listed under subparagraph (B), (C), or (D) of subsection (c)(2) and that is contained in a pesticide to be reregistered under this sec- 
tion. The Administrator, at the same time, shall issue a notice under section 3(c)(2)(B) for the submission of the additional data that are required to meet such requirements.

(2) TIME PERIODS.-

(A) The Administrator shall take the action required by paragraph (1) -

(i) in the case of a pesticide containing an active ingredient listed under subsection $(\mathrm{c})(2)(\mathrm{B})$, not later than 18 months after the date of the listing of such active ingredient;

(ii) in the case of a pesticide containing an active ingredient listed under subsection $(\mathrm{c})(2)(\mathrm{C})$, not later than 24 months after the date of the listing of such active ingredient; and

(iii) in the case of a pesticide containing an active ingredient listed under subsection (c)(2)(D), not later than 33 months after the date of the listing of such active ingredient.

(B) If the Administrator issues a notice to a registrant under paragraph (1)(B) for the submission of additional data, the registrant shall submit such data within a reasonable period of time, as determined by the Administrator, but not to exceed 48 months after the issuance of such notice. The Administrator, on application of a registrant, may extend the period prescribed by the preceding sentence by no more than 2 years if extraordinary circumstances beyond the control of the registrant prevent the registrant from submitting data within such prescribed period. Upon application of a registrant, the Administrator shall, in the case of a minor use, extend the deadline for the production of residue chemistry data under this subparagraph for data required solely to support that minor use until the final deadline for submission of data under this section for the other uses of the pesticide established as of the date of enactment of the Food Quality Protection Act of 1996 [Aug. 3, 1996] if-

(i) the data to support other uses of the pesticide on a food are being provided;

(ii) the registrant, in submitting a request for such an extension provides a schedule, including interim dates to measure progress, to assure that the data production will be completed before the expiration of the extension period;

(iii) the Administrator has determined that such extension will not significantly delay the Administrator's schedule for issuing a reregistration eligibility determination required under this section; and

(iv) the Administrator has determined that based on existing data, such extension would not significantly increase the risk of any unreasonable adverse effect on the environment. ${ }^{4-3}$ If the Administrator grants an extension under this subparagraph, the Administrator shall monitor the development of the data

4-3 Indentation of the following sentences of this subparagraph is so in original (as added by sec. 201(c)(2) of P.L. 104-170). Probably should be indented the same as flush matter of this subparagraph. 
and shall ensure that the registrant is meeting the schedule for the production of the data. If the Administrator determines that the registrant is not meeting or has not met the schedule for the production of such data, the Administrator may proceed in accordance with clause (iv) of section 3(c)(2)(B) or other provisions of this section, as appropriate, regarding the continued registration of the affected products with the minor use and shall inform the public of such action. Notwithstanding the provisions of this subparagraph, the Administrator may take action to modify or revoke the extension under this subparagraph if the Administrator determines that the extension for the minor use may cause an unreasonable adverse effect on the environment. In such circumstance, the Administrator shall provide written notice to the registrant revoking the extension of time for submission of data. Such data shall instead be due in accordance with the date then established by the Administrator for submission of the data.

(3) SusPENSIONS AND PENALTIES.-The Administrator shall issue a notice of intent to suspend the registration of a pesticide in accordance with the procedures prescribed by section $3(\mathrm{c})(2)(\mathrm{B})(\mathrm{iv})$ if the Administrator determines that (A) tests necessary to fill an outstanding data requirement for such pesticide have not been initiated within 1 year after the issuance of a notice under paragraph $(1)(B)$, or (B) progress is insufficient to ensure submission of the data referred to in clause (A) within the time period prescribed by paragraph $(2)(\mathrm{B})$ or the required data have not been submitted to the Administrator within such time period. If the registrant does not commit to support a specific minor use of the pesticide, but is supporting and providing data in a timely and adequate fashion to support uses of the pesticide on a food, or if all uses of the pesticide are nonfood uses and the registrant does not commit to support a specific minor use of the pesticide but is supporting and providing data in a timely and adequate fashion to support other nonfood uses of the pesticide, the Administrator, at the written request of the registrant, shall not take any action pursuant to this paragraph in regard to such unsupported minor use until the final deadline established as of the date of enactment of the Food Quality Protection Act of 1996 [Aug. 3, 1996], for the submission of data under this section for the supported uses identified pursuant to this paragraph unless the Administrator determines that the absence of the data is significant enough to cause human health or environmental concerns. On such a determination the Administrator may refuse the request for extension by the registrant. Upon receipt of the request from the registrant, the Administrator shall publish in the Federal Register a notice of the receipt of the request and the effective date upon which the uses not being supported will be voluntarily deleted from the registration pursuant to section 6(f)(1). If the Administrator grants an extension under this paragraph, the Administrator shall monitor the development of the data for the uses being supported and shall ensure that the registrant is meeting the schedule for the production of such data. If the Ad- 
ministrator determines that the registrant is not meeting or has not met the schedule for the production of such data, the Administrator may proceed in accordance with section $3(\mathrm{c})(2)(\mathrm{B})(\mathrm{iv})$ regarding the continued registration of the affected products with the minor and other uses and shall inform the public of such action in accordance with section $6(f)(2)$. Notwithstanding this subparagraph, the Administrator may deny, modify, or revoke the temporary extension under this paragraph if the Administrator determines that the continuation of the minor use may cause an unreasonable adverse effect on the environment. In the event of modification or revocation, the Administrator shall provide, in writing, to the registrant a notice revoking the temporary extension and establish a new effective date by which the minor use shall be deleted from the registration.

(g) Phase Five.-

(1) DATA REVIEW.- - The Administrator shall conduct a thorough examination of all data submitted under this section concerning an active ingredient listed under subsection (c)(2) and of all other available data found by the Administrator to be relevant.

(2) REREGISTRATION AND OTHER ACTIONS.-

(A) IN GENERAL.-The Administrator shall make a determination as to eligibility for reregistration-

(i) for all active ingredients subject to reregistration under this section for which tolerances or exemptions from tolerances are required under the Federal Food, Drug, and Cosmetic Act (21 U.S.C. 301 et seq.), not later than the last date for tolerance reassessment established under section $408(q)(1)(C)$ of that Act $(21$ U.S.C. $346 a(q)(1)(C))$; and

(ii) for all other active ingredients subject to reregistration under this section, not later than October 3, 2008.

(B) Product-SPECIFIC DATA.-

(i) IN GENERAL.-Before reregistering a pesticide, the Administrator shall obtain any needed product-specific data regarding the pesticide by use of section $3(\mathrm{c})(2)(\mathrm{B})$ and shall review such data within 90 days after its submission.

(ii) TIMING.-

(I) IN GENERAL.-Subject to subclause (II), the Administrator shall require that data under this subparagraph be submitted to the Administrator not later than 8 months after a determination of eligibility under subparagraph (A) has been made for each active ingredient of the pesticide, unless the Administrator determines that a longer period is required for the generation of the data.

(II) EXTRAORDINARY CIRCUMSTANCES.-In the case of extraordinary circumstances, the Administrator may provide such a longer period, of not more than 2 additional years, for submission of data to the Administrator under this subparagraph. 
(C) After conducting the review required by paragraph (1) for each active ingredient of a pesticide and the review required by subparagraph (B) of this paragraph, the Administrator shall determine whether to reregister a pesticide by determining whether such pesticide meets the requirements of section 3(c)(5). If the Administrator determines that a pesticide is eligible to be reregistered, the Administrator shall reregister such pesticide within 6 months after the submission of the data concerning such pesticide under subparagraph (B).

(D) DETERMINATION TO NOT REREGISTER.-

(i) IN GENERAL.- If after conducting a review under paragraph (1) or subparagraph (B) of this paragraph the Administrator determines that a pesticide should not be reregistered, the Administrator shall take appropriate regulatory action.

(ii) TIMING FOR REGULATORY ACTION.-Regulatory action under clause (i) shall be completed as expeditiously as possible.

(E) As soon as the Administrator has sufficient information with respect to the dietary risk of a particular active ingredient, but in any event no later than the time the Administrator makes a determination under subparagraph (C) or (D) with respect to pesticides containing a particular active ingredient, the Administrator shall-

(i) reassess each associated tolerance and exemption from the requirement for a tolerance issued under section 408 of the Federal Food, Drug, and Cosmetic Act (21 U.S.C. 346a);

(ii) determine whether such tolerance or exemption meets the requirements of that Act;

(iii) determine whether additional tolerances or exemptions should be issued;

(iv) publish in the Federal Register a notice setting forth the determinations made under this subparagraph; and

(v) commence promptly such proceedings under this Act and section 408 of the Federal Food, Drug, and Cosmetic Act as are warranted by such determinations.

(h) Compensation of Data SubmitTer.-If data that are submitted by a registrant under subsection (d), (e), (f), or (g) are used to support the application of another person under section 3 , the registrant who submitted such data shall be entitled to compensation for the use of such data as prescribed by section 3(c)(1)(D). In determining the amount of such compensation, the fees paid by the registrant under this section shall be taken into account.

(i) FEES.-

(1) INITIAL FEE FOR FOOD OR FEED USE PESTICIDE ACTIVE INGREDIENTS. - The registrants of pesticides that contain an active ingredient that is listed under subparagraph (B), (C), or (D) of subsection (c)(2) and that is an active ingredient of any pesticide registered for a major food or feed use shall collectively pay a fee of $\$ 50,000$ on submission of information under paragraphs (2) and (3) of subsection (d) for such ingredient. 
(2) FINAL FEE FOR FOOD OR FEED USE PESTICIDE ACTIVE INGREDIENTS.- -

(A) The registrants of pesticides that contain an active ingredient that is listed under subparagraph (B), (C), or (D) of subsection (c)(2) and that is an active ingredient of any pesticide registered for a major food or feed use shall collectively pay a fee of $\$ 100,000-$

(i) on submission of information for such ingredient under subsection (e)(1) if data are reformatted under subsection $(\mathrm{e})(1)(\mathrm{C})$; or

(ii) on submission of data for such ingredient under subsection $(\mathrm{e})(2)(\mathrm{B})$ if data are not reformatted under subsection $(\mathrm{e})(1)(\mathrm{C})$.

(B) The registrants of pesticides that contain an active ingredient that is listed under subsection $(c)(2)(\mathrm{A})$ and that is an active ingredient of any pesticide registered for a major food or feed use shall collectively pay a fee of $\$ 150,000$ at such time as the Administrator shall prescribe. (3) FEES FOR OTHER PESTICIDE ACTIVE INGREDIENTS.-

(A) The registrants of pesticides that contain an active ingredient that is listed under subparagraph (B), (C), or (D) of subsection (c)(2) and that is not an active ingredient of any pesticide registered for a major food or feed use shall collectively pay fees in amounts determined by the Administrator. Such fees may not be less than one-half of, nor greater than, the fees required by paragraphs (1) and (2). A registrant shall pay such fees at the times corresponding to the times fees prescribed by paragraphs (1) and (2) are to be paid.

(B) The registrants of pesticides that contain an active ingredient that is listed under subsection $(c)(2)(\mathrm{A})$ and that is not an active ingredient of any pesticide that is registered for a major food or feed use shall collectively pay a fee of not more than $\$ 100,000$ and not less than $\$ 50,000$ at such time as the Administrator shall prescribe.

(4) REDUCTION OR WAIVER OF FEES FOR MINOR USE AND OTHER PESTICIDES.-

(A) An active ingredient that is contained only in pesticides that are registered solely for agricultural or nonagricultural minor uses, or a pesticide the value or volume of use of which is small, shall be exempt from the fees prescribed by paragraph (3).

(B) The Administrator shall exempt any public health pesticide from the payment of the fee prescribed under paragraph (3) if, in consultation with the Secretary of Health and Human Services, the Administrator determines, based on information supplied by the registrant, that the economic return to the registrant from sales of the pesticide does not support the registration or reregistration of the pesticide.

(C) An antimicrobial active ingredient, the production level of which does not exceed $1,000,000$ pounds per year, shall be exempt from the fees prescribed by paragraph (3). For purposes of this subparagraph, the term "antimicrobial active ingredient" means any active ingredient that is con- 
tained only in pesticides that are not registered for any food or feed use and that are-

(i) sanitizers intended to reduce the number of living bacteria or viable virus particles on inanimate surface or in water or air;

(ii) bacteriostats intended to inhibit the growth of bacteria in the presence of moisture;

(iii) disinfectants intended to destroy or irreversibly inactivate bacteria, fungi, or viruses on surfaces or inanimate objects;

(iv) sterilizers intended to destroy viruses and all living bacteria, fungi, and their spores on inanimate surfaces; or

(v) fungicides or fungistats.

(D)(i) Notwithstanding any other provision of this subsection, in the case of a small business registrant of a pesticide, the registrant shall pay a fee for the reregistration of each active ingredient of the pesticide that does not exceed an amount determined in accordance with this subparagraph.

(ii) If during the 3-year period prior to reregistration the average annual gross revenue of the registrant from pesticides containing such active ingredient is-

(I) less than $\$ 5,000,000$, the registrant shall pay 0.5 percent of such revenue;

(II) $\$ 5,000,000$ or more but less than $\$ 10,000,000$, the registrant shall pay 1 percent of such revenue; or (III) $\$ 10,000,000$ or more, the registrant shall pay 1.5 percent of such revenue, but not more than $\$ 150,000$.

(iii) For the purpose of this subparagraph, a small business registrant is a corporation, partnership, or unincorporated business that-

(I) has 150 or fewer employees; and

(II) during the 3 -year period prior to reregistration, had an average annual gross revenue from chemicals that did not exceed $\$ 40,000,000$.

(5) MAINTENANCE FEE.-

(A) IN GENERAL.-Subject to other provisions of this paragraph, each registrant of a pesticide shall pay an annual fee by January 15 of each year for each registration, except that no fee shall be charged for more than 200 registrations held by any registrant.

(B) In the case of a pesticide that is registered for a minor agricultural use, the Administrator may reduce or waive the payment of the fee imposed under this paragraph if the Administrator determines that the fee would significantly reduce the availability of the pesticide for the use.

(C) Total Amount of FEes.-The amount of each fee prescribed under subparagraph (A) shall be adjusted by the Administrator to a level that will result in the collection under this paragraph of, to the extent practicable, an ag- 
gregate amount of $\$ 22,000,000$ for each of fiscal years 2008 through $2012^{4-4}$

(D) 4-5 MAXIMUM AMOUNT OF FEES FOR REGISTRANTS.The maximum annual fee payable under this paragraph by-

(i) 4-6 a registrant holding not more than 50 pesticide registrations shall be $\$ 71,000$ for each of fiscal years 2008 through 2012; and

(ii) ${ }^{4-7}$ a registrant holding over 50 registrations shall be $\$ 123,000$ for each of fiscal years 2008 through 2012.

(E) 4-8MAXIMUM AMOUNT OF FEES FOR SMALL BUSINESSES.-

(i) IN GENERAL.-For a small business, the maximum annual fee payable under this paragraph by-

(I) a registrant holding not more than 50 pesticide registrations shall be $\$ 50,000$ for each of fiscal years 2008 through 2012; and

(II) a registrant holding over 50 pesticide registrations shall be $\$ 86,000$ for each of fiscal years 2008 through 2012.

(ii) DEFINITION OF SMALL BUSINESS.-

(I) IN GENERAL.-In clause (i), the term "small business" means a corporation, partnership, or unincorporated business that-

(aa) has 500 or fewer employees; and

(bb) during the 3-year period prior to the most recent maintenance fee billing cycle, had an average annual global gross revenue from pesticides that did not exceed $\$ 60,000,000$.

(II) AfFiliates.-

(aa) IN GENERAL.-In the case of a business entity with 1 or more affiliates, the gross revenue limit under subclause $(\mathrm{I})(\mathrm{bb})$ shall apply to the gross revenue for the entity and all of the affiliates of the entity, including parents and subsidiaries, if applicable.

(bb) AFFILIATED PERSONS.-For the purpose of item (aa), persons are affiliates of each other if, directly or indirectly, either person controls or has the power to control the other person, or a third person controls or has the power to control both persons.

(cc) INDICIA OF CONTROL.-For the purpose of item (aa), indicia of control include

${ }^{4-4}$ Lack of period is so in original (as amended by sec. 4(a) of P.L. 110-94). Probably should add a period at the end.

4-5 Title II of the Emergency Wartime Supplemental Appropriations Act, 2003, P.L. 10811, 117 Stat. 603, provided that "Within 30 days of enactment of this Act, the Administrator of the Environmental Protection Agency shall adjust each 'maximum annual fee payable' pursuant to 7 U.S.C. 136a-1(i)(5)(D) and (E) in a manner such that maintenance fee collections made to reach the level authorized in division $\mathrm{K}$ of Public Law 108-7 shall be established in the same proportion as those maintenance fee collections authorized in Public Law 107-73.”.

4-6 Subclause margins are so in original (as added by sec. 501(c)(1)(B)(ii) of P.L. 108199). Probably should be further indented.

4-7 Subclause margins are so in original (as added by sec. 501(c)(1)(B)(iii) of P.L. 108199). Probably should be further indented. 
interlocking management or ownership, identity of interests among family members, shared facilities and equipment, and common use of employees.

(F) The Administrator shall exempt any public health pesticide from the payment of the fee prescribed under paragraph (3) if, in consultation with the Secretary of Health and Humans ${ }^{4-9}$ Services, the Administrator determines, based on information supplied by the registrant, that the economic return to the registrant from sales of the pesticide does not support the registration or reregistration of the pesticide.

(G) If any fee prescribed by this paragraph with respect to the registration of a pesticide is not paid by a registrant by the time prescribed, the Administrator, by order and without hearing, may cancel the registration.

(H) The authority provided under this paragraph shall terminate on September 30, 2012.

(6) OTHER FEES.-Except as provided in section 33, during the period beginning on the date of enactment of this section [October 25, 1988] and ending on September 30, 2014, the Administrator may not levy any other fees for the registration of a pesticide under this Act except as provided in paragraphs (1) through (5).

(7) APPortionment.-

(A) If two or more registrants are required to pay any fee prescribed by paragraph (1), (2), or (3) with respect to a particular active ingredient, the fees for such active ingredient shall be apportioned among such registrants on the basis of the market share in United States sales of the active ingredient for the 3 calendar years preceding the date of payment of such fee, except that-

(i) small business registrants that produce the active ingredient shall pay fees in accordance with paragraph $(4)(\mathrm{C})$; and

(ii) registrants who have no market share but who choose to reregister a pesticide containing such active ingredient shall pay the lesser of-

(I) 15 percent of the reregistration fee; or

(II) a proportionate amount of such fee based on the lowest percentage market share held by any registrant active in the marketplace.

In no event shall registrants who have no market share but who choose to reregister a pesticide containing such active ingredient collectively pay more than 25 percent of the total active ingredient reregistration fee.

(B) The Administrator, by order, may require any registrant to submit such reports as the Administrator determines to be necessary to allow the Administrator to determine and apportion fees under this subsection, to determine the registrant's eligibility for a reduction or waiver of a fee, or to determine the volume usage for public health pesticides. 
(C) If any such report is not submitted by a registrant after receiving notice of such report requirement, or if any fee prescribed by this subsection (other than paragraph (5)) for an active ingredient is not paid by a registrant to the Administrator by the time prescribed under this subsection, the Administrator, by order and without hearing, may cancel each registration held by such registrant of a pesticide containing the active ingredient with respect to which the fee is imposed. The Administrator shall reapportion the fee among the remaining registrants and notify the registrants that the registrants are required to pay to the Administrator any unpaid balance of the fee within 30 days after receipt of such notice.

(j) Exemption of CERTAin REgistrants.-The requirements of subsections (d), (e), (f), and (i) (other than subsection (i)(5)) regarding data concerning an active ingredient and fees for review of such data shall not apply to any person who is the registrant of a pesticide to the extent that, under section 3(c)(2)(D), the person would not be required to submit or cite such data to obtain an initial registration of such pesticide.

(k) Reregistration and Expedited Processing Fund.-

(1) EstablishmenT.-There shall be established in the Treasury of the United States a reregistration and expedited processing fund which shall be known as the Reregistration and Expedited Processing Fund. ${ }^{4-10}$

(2) 4-11 SOURCE AND USE.-

(A) All moneys derived from fees collected by the Administrator under subsection (i) shall be deposited in the fund and shall be available to the Administrator, without fiscal year limitation, specifically to offset the costs of reregistration and expedited processing of the applications specified in paragraph (3) and to offset the costs of registration review under section $3(\mathrm{~g})$. Such moneys derived from fees may not be expended in any fiscal year to the extent such moneys derived from fees would exceed money appropriated for use by the Administrator and expended in such year for such costs of reregistration and expedited processing of such applications. The Administrator shall, prior to expending any such moneys derived from fees-

(i) effective October 1, 1997, adopt specific and cost accounting rules and procedures as approved by the General Accounting Office [General Accountability Office] and the Inspector General of the Environmental Protection Agency to ensure that moneys derived from fees are allocated solely to the costs of reregistration and expedited processing of the applications specified in paragraph (3) and to offset the costs of registration review under section $3(\mathrm{~g})$ in the same portion as appropriated funds;

4-10 Sec. 501(b) of P.L. 104-170 amended sec. 4(k)(1) (7 U.S.C. 136a-1(k)(1)) by inserting "which shall be known as the Reregistration and Expedited Processing Fund", without specifying the Act that was being amended. The amendment was executed to this Act to effectuate the probable intent of Congress.

4-11 Sec. 501(c) of P.L. 104-170 amended sec. 4(k)(2) (7 U.S.C. 136a-1(k)(2)) to read as provided above, without specifying the Act that was being amended. The amendment was 
(ii) prohibit the use of such moneys derived from fees to pay for any costs other than those necessary to achieve reregistration and expedited processing of the applications specified in paragraph (3) and to offset the costs of registration review under section $3(\mathrm{~g})$; and

(iii) ensure that personnel and facility costs associated with the functions to be carried out under this paragraph do not exceed agency averages for comparable personnel and facility costs.

(B) The Administrator shall also-

(i) complete the review of unreviewed reregistration studies required to support the reregistration eligibility decisions scheduled for completion in accordance with subsection (1)(2); and

(ii) contract for such outside assistance as may be necessary for review of required studies, using a generally accepted competitive process for the selection of vendors of such assistance.

(3) REVIEW OF INERT INGREDIENTS; EXPEDITED PROCESSING OF SIMILAR APPLICATIONS.-

(A) The Administrator shall use for each of the fiscal years 2004 through 2006, approximately $\$ 3,300,000$, and for each of fiscal years 2008 through 2012, between $1 / 8$ and $1 / 7$, of the maintenance fees collected in such fiscal year ${ }^{4-12}$ to obtain sufficient personnel and resourcesand

(i) to review and evaluate new inert ingredients;

(ii) to ensure the expedited processing and review of any application that-4-13

(I) proposes the initial or amended registration of an end-use pesticide that, if registered as proposed, would be identical or substantially similar in composition and labeling to a currently-registered pesticide identified in the application, or that would differ in composition and labeling from any such currently-registered pesticide only in ways that would not significantly increase the risk of unreasonable adverse effects on the environment;

(II) proposes an amendment to the registration of a registered pesticide that does not require scientific review of data; or

(III) proposes the initial or amended registration of an end use pesticide that, if registered as proposed, would be used for a public health pesticide.

4-12 P.L. 107-73 (115 Stat. 686) amended sec. 4(k)(3)(A) by striking "2001" and inserting "2002"; and by striking " $1 / 7$ " and inserting " $1 / 10$ ". In an earlier enactment, sec. 501(d)(1) of P.L. 104-170 amended sec. 4(k)(3) (7 U.S.C. 136a-1(k)(3)) by striking "for each of the fiscal years 1992, 1993, and 1994, 1/7th of the maintenance fees collected, up to 2 million each year" and inserting "for each of the fiscal years 1997 through 2001, not more than $1 / 7$ of the maintenance fees collected in such fiscal year", without specifying the Act that was being amended and without including a $\$$ before " 2 million". The earlier amendment was executed to this Act, and to strike " $\$ 2$ million", to effectuate the probable intent of Congress.

${ }^{4-13}$ So in original (as added by sec. 501(e)(2)(C) of division G of P.L. 108-199). Probably should be no indent before "that". 
(B) Any amounts made available under subparagraph (A) shall be used to obtain sufficient personnel and resources to carry out the activities described in such subparagraph that are in addition to the personnel and resources available to carry out such activities on the date of enactment of this section [October 25, 1988].

(C) ${ }^{4-14}$ So long as the Administrator has not met the time frames specified in clause (ii) of section 3(c)(3)(B) with respect to any application subject to section $3(\mathrm{c})(3)(\mathrm{B})$ that was received prior to the date of enactment of the Food Quality Protection Act of 1996 [Aug. 3, 1996], the Administrator shall use the full amount of the fees specified in subparagraph (A) for the purposes specified therein. Once all applications subject to section 3(c)(3)(B) that were received prior to such date of enactment have been acted upon, no limitation shall be imposed by the preceding sentence of this subparagraph so long as the Administrator meets the time frames specified in clause (ii) of section 3(c)(3)(B) on 90 percent of affected applications in a fiscal year. Should the Administrator not meet such time frames in a fiscal year, the limitations imposed by the first sentence of this subparagraph shall apply until all overdue applications subject to section $3(\mathrm{c})(3)(\mathrm{B})$ have been acted upon.

(4) UNUSED FUNDS.-Money in the fund not currently needed to carry out this section shall be-

(A) maintained on hand or on deposit;

(B) invested in obligations of the United States or guaranteed thereby; or

(C) invested in obligations, participations, or other instruments that are lawful investments for fiduciary, trust, or public funds.

(5) 4-15 ACCOUNTING AND PERFORMANCE.-The Administrator shall take all steps necessary to ensure that expenditures from fees authorized by subsection (i)(5)(C)(ii) are used only to carry out the goals established under subsection (l). The Reregistration and Expedited Processing Fund shall be designated as an Environmental Protection Agency component for purposes of section 3515(c) of title 31, United States Code. The annual audit required under section 3521 of such title of the financial statements of activities under this Act under section 3515(b) of such title shall include an audit of the fees collected under subsection (i)(5)(C) and disbursed, of the amount appropriated to match such fees, and of the Administrator's attainment of performance measures and goals established under subsection (1). Such an audit shall also include a review of the reasonableness of the overhead allocation and adequacy of disclosures of direct and indirect costs associated with carrying out the reregistration and expedited processing of the applications specified in paragraph (3), and the basis for and accuracy of all costs paid with moneys derived from such fees. The Inspector General shall conduct the annual audit and report the

4-14 Sec. 501(d)(2) of P.L. 104-170 added subpara. (C) to sec. 4(k)(3) (7 U.S.C. 136a$1(\mathrm{k})(3)$ ), without specifying the Act that was being amended. The amendment was executed to this Act to effectuate the probable intent of Congress.

4-15 Sec. 501(e) of P.L. 104-170 amended sec. 4(k)(5) (7 U.S.C. 136a-1(k)(5)) to read as provided above, without specifying the Act that was being amended. The amendment was 
findings and recommendations of such audit to the Administrator and to the Committees on Agriculture of the House of Representatives and the Senate. The cost of such audit shall be paid for out of the fees collected under subsection (i)(5)(C).

(1) 4-16 Performance Measures and Goal.-The Administrator shall establish and publish annually in the Federal Register performance measures and goals. Such measures and goals shall include-

(1) the number of products reregistered, canceled, or amended, the status of reregistration, the number and type of data requests under section 3(c)(2)(B) issued to support product reregistration by active ingredient, the progress in reducing the number of unreviewed, required reregistration studies, the aggregate status of tolerances reassessed, and the number of applications for registration submitted under subsection $(\mathrm{k})(3)$ that were approved or disapproved;

(2) the future schedule for reregistrations, including the projection for such schedules that will be issued under subsection $(\mathrm{g})(2)(\mathrm{A})$ and $(\mathrm{B})$ in the current fiscal year and the succeeding fiscal year; and

(3) the projected year of completion of the reregistrations under this section.

(m) JUDICIAL REVIEW.-Any failure of the Administrator to take any action required by this section shall be subject to judicial review under the procedures prescribed by section 16(b).

(n) Authorization of Funds to Develop Public Health DATA.-

(1) Definition.-For the purposes of this section, "Secretary" means the Secretary of Health and Human Services, acting through the Public Health Service.

(2) Consultation.- - In the case of a pesticide registered for use in public health programs for vector control or for other uses the Administrator determines to be human health protection uses, the Administrator shall, upon timely request by the registrant or any other interested person, or on the Administrator's own initiative may, consult with the Secretary prior to taking final action to suspend registration under section $3(\mathrm{c})(2)(\mathrm{B})(\mathrm{iv})$, or cancel a registration under section $4,6(\mathrm{e})$, or 6(f). In consultation with the Secretary, the Administrator shall prescribe the form and content of requests under this section.

(3) BENEFITS TO SUPPORT FAMILY.-The Administrator, after consulting with the Secretary, shall make a determination whether the potential benefits of continued use of the pesticide for public health or health protection purposes are of such significance as to warrant a commitment by the Secretary to conduct or to arrange for the conduct of the studies required by the Administrator to support continued registration under section 3 or reregistration under section 4 .

(4) ADDiTIONAL TIME.-If the Administrator determines that such a commitment is warranted and in the public interest, the Administrator shall notify the Secretary and shall, to the extent necessary, amend a notice issued under section

4-16 Sec. 501(f) of P.L. 104-170 amended sec. 4 (7 U.S.C. 136a-1) by redesignating subsecs. (l) and $(\mathrm{m})$ as subsecs. $(\mathrm{m})$ and $(\mathrm{n})$, respectively, and inserting a new subsec. (l), without specifying the Act that was being amended. The amendments were executed to this Act to effectuate the probable intent of Congress. 
$3(\mathrm{c})(2)(\mathrm{B})$ to specify additional reasonable time periods for submission of the data.

(5) ARRANGEMENTS.-The Secretary shall make such arrangements for the conduct of required studies as the Secretary finds necessary and appropriate to permit submission of data in accordance with the time periods prescribed by the Administrator. Such arrangements may include Public Health Service intramural research activities, grants, contracts, or cooperative agreements with academic, public health, or other organizations qualified by experience and training to conduct such studies.

(6) SUPPORT.-The Secretary may provide for support of the required studies using funds authorized to be appropriated under this section, the Public Health Service Act, or other appropriate authorities. After a determination is made under subsection (d), the Secretary shall notify the Committees on Appropriations of the House of Representatives and the Senate of the sums required to conduct the necessary studies.

(7) AUTHORIZATION OF APPROPRIATIONS.-There is authorized to be appropriated to carry out the purposes of this section $\$ 12,000,000$ for fiscal year 1997 , and such sums as may be necessary for succeeding fiscal years.

SEC. 5. [7 U.S.C. 136c] EXPERIMENTAL USE PERMITS.

(a) ISSUANCE.-Any person may apply to the Administrator for an experimental use permit for a pesticide. The Administrator shall review the application. After completion of the review, but not later than one hundred and twenty days after receipt of the application and all required supporting data, the Administrator shall either issue the permit or notify the applicant of the Administrator's determination not to issue the permit and the reasons therefor. The applicant may correct the application or request a waiver of the conditions for such permit within thirty days of receipt by the applicant of such notification. The Administrator may issue an experimental use permit only if the Administrator determines that the applicant needs such permit in order to accumulate information necessary to register a pesticide under section 3 of this Act. An application for an experimental use permit may be filed at any time.

(b) TEMPORARY TOLERANCE LEVEL.-If the Administrator determines that the use of a pesticide may reasonably be expected to result in any residue on or in food or feed, the Administrator may establish a temporary tolerance level for the residue of the pesticide before issuing the experimental use permit.

(c) UsE UNDER PERMIT.-Use of a pesticide under an experimental use permit shall be under the supervision of the Administrator, and shall be subject to such terms and conditions and be for such period of time as the Administrator may prescribe in the permit.

(d) STUdiES.-When any experimental use permit is issued for a pesticide containing any chemical or combination of chemicals which has not been included in any previously registered pesticide, the Administrator may specify that studies be conducted to detect whether the use of the pesticide under the permit may cause unreasonable adverse effects on the environment. All results of such studies shall be reported to the Administrator before such pesticide may be registered under section 3 . 
(e) REVOCATION.-The Administrator may revoke any experimental use permit, at any time, if the Administrator finds that its terms or conditions are being violated, or that its terms and conditions are inadequate to avoid unreasonable adverse effects on the environment.

(f) State Issuance of Permits.-Notwithstanding the foregoing provisions of this section, the Administrator shall, under such terms and conditions as the Administrator may by regulations prescribe, authorize any State to issue an experimental use permit for a pesticide. All provisions of section 11 relating to State plans shall apply with equal force to a State plan for the issuance of experimental use permits under this section.

(g) ExEMPtion FOR Agricultural Research Agencies.-Notwithstanding the foregoing provisions of this section, the Administrator may issue an experimental use permit for a pesticide to any public or private agricultural research agency or educational institution which applies for such permit. Each permit shall not exceed more than a one-year period or such other specific time as the Administrator may prescribe. Such permit shall be issued under such terms and conditions restricting the use of the pesticide as the Administrator may require. Such pesticide may be used only by such research agency or educational institution for purposes of experimentation.

SEC. 6. [7 U.S.C. 136d] ADMINISTRATIVE REVIEW; SUSPENSION.

(a) Existing STOCKS AND INFORMATION.-6-1

(1) EXISTING STOCKS.-The Administrator may permit the continued sale and use of existing stocks of a pesticide whose registration is suspended or canceled under this section, or section 3 or 4 , to such extent, under such conditions, and for such uses as the Administrator determines that such sale or use is not inconsistent with the purposes of this Act.

(2) INFORMATION.- - If at any time after the registration of a pesticide the registrant has additional factual information regarding unreasonable adverse effects on the environment of the pesticide, the registrant shall submit such information to the Administrator.

(b) Cancellation and Change in Classification.- - If it appears to the Administrator that a pesticide or its labeling or other material required to be submitted does not comply with the provisions of this Act or, when used in accordance with widespread and commonly recognized practice, generally causes unreasonable adverse effects on the environment, the Administrator may issue a notice of the Administrator's intent either-

(1) to cancel its registration or to change its classification together with the reasons (including the factual basis) for the Administrator's action, or

(2) to hold a hearing to determine whether or not its registration should be canceled or its classification changed.

Such notice shall be sent to the registrant and made public. In determining whether to issue any such notice, the Administrator shall include among those factors to be taken into account the impact of the action proposed in such notice on production and prices of agricultural commodities, retail food prices, and otherwise on the agri-

6-1 Sec. 106(a)(1) of P.L. 104-170 amended subsec. (a) by striking the heading and inserting “(a) EXISTING STOCKS AND INFORMATION.--". The second subsec. designation for 
cultural economy. At least 60 days prior to sending such notice to the registrant or making public such notice, whichever occurs first, the Administrator shall provide the Secretary of Agriculture with a copy of such notice and an analysis of such impact on the agricultural economy. If the Secretary comments in writing to the Administrator regarding the notice and analysis within 30 days after receiving them, the Administrator shall publish in the Federal Register (with the notice) the comments of the Secretary and the response of the Administrator with regard to the Secretary's comments. If the Secretary does not comment in writing to the Administrator regarding the notice and analysis within 30 days after receiving them, the Administrator may notify the registrant and make public the notice at any time after such 30-day period notwithstanding the foregoing 60-day time requirement. The time requirements imposed by the preceding 3 sentences may be waived or modified to the extent agreed upon by the Administrator and the Secretary. Notwithstanding any other provision of this subsection (b) and section 25(d), in the event that the Administrator determines that suspension of a pesticide registration is necessary to prevent an imminent hazard to human health, then upon such a finding the Administrator may waive the requirement of notice to and consultation with the Secretary of Agriculture pursuant to subsection (b) and of submission to the Scientific Advisory Panel pursuant to section 25(d) and proceed in accordance with subsection (c). When a public health use is affected, the Secretary of Health and Human Services should provide available benefits and use information, or an analysis thereof, in accordance with the procedures followed and subject to the same conditions as the Secretary of Agriculture in the case of agricultural pesticides. The proposed action shall become final and effective at the end of 30 days from receipt by the registrant, or publication, of a notice issued under paragraph (1), whichever occurs later, unless within that time either (i) the registrant makes the necessary corrections, if possible, or (ii) a request for a hearing is made by a person adversely affected by the notice. In the event a hearing is held pursuant to such a request or to the Administrator's determination under paragraph (2), a decision pertaining to registration or classification issued after completion of such hearing shall be final. In taking any final action under this subsection, the Administrator shall consider restricting a pesticide's use or uses as an alternative to cancellation and shall fully explain the reasons for these restrictions, and shall include among those factors to be taken into account the impact of such final action on production and prices of agricultural commodities, retail food prices, and otherwise on the agricultural economy, and the Administrator shall publish in the Federal Register an analysis of such impact.

(c) SUSPENSION.-

(1) ORDER.--If the Administrator determines that action is necessary to prevent an imminent hazard during the time required for cancellation or change in classification proceedings, the Administrator may, by order, suspend the registration of the pesticide immediately. Except as provided in paragraph (3), no order of suspension may be issued under this subsection unless the Administrator has issued, or at the same time issues, a notice of intention to cancel the registration or change the classification of the pesticide under subsection (b). Except as 
provided in paragraph (3), the Administrator shall notify the registrant prior to issuing any suspension order. Such notice shall include findings pertaining to the question of "imminent hazard". The registrant shall then have an opportunity, in accordance with the provisions of paragraph (2), for an expedited hearing before the Administrator on the question of whether an imminent hazard exists.

(2) EXPEDITE HEARING.-If no request for a hearing is submitted to the Administrator within five days of the registrant's receipt of the notification provided for by paragraph (1), the suspension order may be issued and shall take effect and shall not be reviewable by a court. If a hearing is requested, it shall commence within five days of the receipt of the request for such hearing unless the registrant and the Administrator agree that it shall commence at a later time. The hearing shall be held in accordance with the provisions of subchapter II of title 5 of the United States Code, except that the presiding officer need not be a certified hearing examiner. The presiding officer shall have ten days from the conclusion of the presentation of evidence to submit recommended findings and conclusions to the Administrator, who shall then have seven days to render a final order on the issue of suspension.

(3) EMERGENCY ORDER.-Whenever the Administrator determines that an emergency exists that does not permit the Administrator to hold a hearing before suspending, the Administrator may issue a suspension order in advance of notification to the registrant. The Administrator may issue an emergency order under this paragraph before issuing a notice of intention to cancel the registration or change the classification of the pesticide under subsection (b) and the Administrator shall proceed to issue the notice under subsection (b) within 90 days of issuing an emergency order. If the Administrator does not issue a notice under subsection (b) within 90 days of issuing an emergency order, the emergency order shall expire. In the case of an emergency order, paragraph (2) shall apply except that (A) the order of suspension shall be in effect pending the expeditious completion of the remedies provided by that paragraph and the issuance of a final order on suspension, and (B) no party other than the registrant and the Administrator shall participate except that any person adversely affected may file briefs within the time allotted by the Administrator's rules. Any person so filing briefs shall be considered a party to such proceeding for the purposes of section $16(\mathrm{~b})$.

(4) JUDICIAL REVIEW.-A final order on the question of suspension following a hearing shall be reviewable in accordance with Section 16 of this Act, notwithstanding the fact that any related cancellation proceedings have not been completed. Any order of suspension entered prior to a hearing before the Administrator shall be subject to immediate review in an action by the registrant or other interested person with the concurrence of the registrant in an appropriate district court, solely to determine whether the order of suspension was arbitrary, capricious or an abuse of discretion, or whether the order was issued in accordance with the procedures established by law. The effect of any order of the court will be only to stay the effectiveness of the suspension order, pending the Administra- 
tor's final decision with respect to cancellation or change in classification. This action may be maintained simultaneously with any administrative review proceeding under this section. The commencement of proceedings under this paragraph shall not operate as a stay of order, unless ordered by the court.

(d) Public Hearings and Scientific Review.--In the event a hearing is requested pursuant to subsection (b) or determined upon by the Administrator pursuant to subsection (b), such hearing shall be held after due notice for the purpose of receiving evidence relevant and material to the issues raised by the objections filed by the applicant or other interested parties, or to the issues stated by the Administrator, if the hearing is called by the Administrator rather than by the filing of objections. Upon a showing of relevance and reasonable scope of evidence sought by any party to a public hearing, the Hearing Examiner shall issue a subpena to compel testimony or production of documents from any person. The Hearing Examiner shall be guided by the principles of the Federal Rules of Civil Procedure in making any order for the protection of the witness or the content of documents produced and shall order the payment of reasonable fees and expenses as a condition to requiring testimony of the witness. On contest, the subpena may be enforced by an appropriate United States district court in accordance with the principles stated herein. Upon the request of any party to a public hearing and when in the Hearing Examiner's judgment it is necessary or desirable, the Hearing Examiner shall at any time before the hearing record is closed refer to a Committee of the National Academy of Sciences the relevant questions of scientific fact involved in the public hearing. No member of any committee of the National Academy of Sciences established to carry out the functions of this section shall have a financial or other conflict of interest with respect to any matter considered by such committee. The Committee of the National Academy of Sciences shall report in writing to the Hearing Examiner within 60 days after such referral on these questions of scientific fact. The report shall be made public and shall be considered as part of the hearing record. The Administrator shall enter into appropriate arrangements with the National Academy of Sciences to assure an objective and competent scientific review of the questions presented to Committees of the Academy and to provide such other scientific advisory services as may be required by the Administrator for carrying out the purposes of this Act. As soon as practicable after completion of the hearing (including the report of the Academy) but not later than 90 days thereafter, the Administrator shall evaluate the data and reports before the Administrator and issue an order either revoking the Administrator's notice of intention issued pursuant to this section, or shall issue an order either canceling the registration, changing the classification, denying the registration, or requiring modification of the labeling or packaging of the article. Such order shall be based only on substantial evidence of record of such hearing and shall set forth detailed findings of fact upon which the order is based.

(e) Conditional Registration.-

(1) The Administrator shall issue a notice of intent to cancel a registration issued under section 3(c)(7) of this Act if (A) the Administrator, at any time during the period provided for satisfaction of any condition imposed, determines that the registrant has failed to initiate and pursue appropriate action to- 
ward fulfilling any condition imposed, or (B) at the end of the period provided for satisfaction of any condition imposed, that condition has not been met. The Administrator may permit the continued sale and use of existing stocks of a pesticide whose conditional registration has been canceled under this subsection to such extent, under such conditions, and for such uses as the Administrator may specify if the Administrator determines that such sale or use is not inconsistent with the purposes of this Act and will not have unreasonable adverse effects on the environment.

(2) A cancellation proposed under this subsection shall become final and effective at the end of thirty days from receipt by the registrant of the notice of intent to cancel unless during that time a request for hearing is made by a person adversely affected by the notice. If a hearing is requested, a hearing shall be conducted under subsection (d) of this section. The only matters for resolution at that hearing shall be whether the registrant has initiated and pursued appropriate action to comply with the condition or conditions within the time provided or whether the condition or conditions have been satisfied within the time provided, and whether the Administrator's determination with respect to the disposition of existing stocks is consistent with this Act. A decision after completion of such hearing shall be final. Notwithstanding any other provision of this section, a hearing shall be held and a determination made within seventy-five days after receipt of a request for such hearing.

(f) General Provisions.-

(1) VOLUNTARY CANCELLATION.-

(A) A registrant may, at any time, request that a pesticide registration of the registrant be canceled or amended to terminate one or more pesticide uses.

(B) Before acting on a request under subparagraph (A), the Administrator shall publish in the Federal Register a notice of the receipt of the request and provide for a 30-day period in which the public may comment.

(C) In the case of a pesticide that is registered for a minor agricultural use, if the Administrator determines that the cancellation or termination of uses would adversely affect the availability of the pesticide for use, the Administrator-

(i) shall publish in the Federal Register a notice of the receipt of the request and make reasonable efforts to inform persons who so use the pesticide of the request; and

(ii) may not approve or reject the request until the termination of the 180-day period beginning on the date of publication of the notice in the Federal Register, except that the Administrator may waive the 180-day period upon the request of the registrant or if the Administrator determines that the continued use of the pesticide would pose an unreasonable adverse effect on the environment.

(D) Subject to paragraph (3)(B), after complying with this paragraph, the Administrator may approve or deny the request. 
(2) Publication of Notice.-A notice of denial of registration, intent to cancel, suspension, or intent to suspend issued under this Act or a notice issued under subsection (c)(4) or $(d)(5)(A)$ of section 4 shall be published in the Federal Register and shall be sent by certified mail, return receipt requested, to the registrant's or applicant's address of record on file with the Administrator. If the mailed notice is returned to the Administrator as undeliverable at that address, if delivery is refused, or if the Administrator otherwise is unable to accomplish delivery of the notice to the registrant or applicant after making reasonable efforts to do so, the notice shall be deemed to have been received by the registrant or applicant on the date the notice was published in the Federal Register.

(3) TRANSFER OF REGISTRATION OF PESTICIDES REGISTERED FOR MINOR AGRICULTURAL USES.-In the case of a pesticide that is registered for a minor agricultural use:

(A) During the 180-day period referred to in paragraph (1)(C)(ii), the registrant of the pesticide may notify the Administrator of an agreement between the registrant and a person or persons (including persons who so use the pesticide) to transfer the registration of the pesticide, in lieu of canceling or amending the registration to terminate the use.

(B) An application for transfer of registration, in conformance with any regulations the Administrator may adopt with respect to the transfer of the pesticide registrations, must be submitted to the Administrator within 30 days of the date of notification provided pursuant to subparagraph (A). If such an application is submitted, the Administrator shall approve the transfer and shall not approve the request for voluntary cancellation or amendment to terminate use unless the Administrator determines that the continued use of the pesticide would cause an unreasonable adverse effect on the environment.

(C) If the Administrator approves the transfer and the registrant transfers the registration of the pesticide, the Administrator shall not cancel or amend the registration to delete the use or rescind the transfer of the registration, during the 180-day period beginning on the date of the approval of the transfer unless the Administrator determines that the continued use of the pesticide would cause an unreasonable adverse effect on the environment.

(D) The new registrant of the pesticide shall assume the outstanding data and other requirements for the pesticide that are pending at the time of the transfer.

(4) UTILIZATION OF DATA FOR VOLUNTARILY CANCELED PESTICIDE.-When an application is filed with the Administrator for the registration of a pesticide for a minor use and another registrant subsequently voluntarily cancels its registration for an identical or substantially similar pesticide for an identical or substantially similar use, the Administrator shall process, review, and evaluate the pending application as if the voluntary cancellation had not yet taken place except that the Administrator shall not take such action if the Administrator determines that such minor use may cause an unreasonable adverse effect on the environment. In order to rely on this subsection, 
the applicant must certify that it agrees to satisfy any outstanding data requirements necessary to support the reregistration of the pesticide in accordance with the data submission schedule established by the Administrator.

(g) Notice for Stored Pesticides With Canceled or SusPENDED REGISTRATIONS.-

(1) IN GENERAL.-Any producer or exporter of pesticides, registrant of a pesticide, applicant for registration of a pesticide, applicant for or holder of an experimental use permit, commercial applicator, or any person who distributes or sells any pesticide, who possesses any pesticide which has had its registration canceled or suspended under this section shall notify the Administrator and appropriate State and local officials of-

(A) such possession,

(B) the quantity of such pesticide such person possesses, and

(C) the place at which such pesticide is stored.

(2) COPIES. - The Administrator shall transmit a copy of each notice submitted under this subsection to the regional office of the Environmental Protection Agency which has jurisdiction over the place of pesticide storage identified in the notice. (h) JUDICIAL REVIEW.-Final orders of the Administrator under this section shall be subject to judicial review pursuant to section 16.

\section{SEC. 7. [7 U.S.C. 136e] REGISTRATION OF ESTABLISHMENTS.}

(a) REQUIREMENT.-No person shall produce any pesticide subject to this Act or active ingredient used in producing a pesticide subject to this Act in any State unless the establishment in which it is produced is registered with the Administrator. The application for registration of any establishment shall include the name and address of the establishment and of the producer who operates such establishment.

(b) REGISTRATION.-Whenever the Administrator receives an application under subsection (a), the Administrator shall register the establishment and assign it an establishment number.

(c) INFORMATION REQUIRED.-

(1) Any producer operating an establishment registered under this section shall inform the Administrator within 30 days after it is registered of the types and amounts of pesticides and, if applicable, active ingredients used in producing pesticides-

(A) which the producer is currently producing;

(B) which the producer has produced during the past year; and

(C) which the producer has sold or distributed during the past year.

The information required by this paragraph shall be kept current and submitted to the Administrator annually as required under such regulations as the Administrator may prescribe.

(2) Any such producer shall, upon the request of the Administrator for the purpose of issuing a stop sale order pursuant to section 13, inform the Administrator of the name and address of any recipient of any pesticide produced in any registered establishment which the producer operates. 
(d) Confidential Records and Information.-Any information submitted to the Administrator pursuant to subsection (c) other than the names of the pesticides or active ingredients used in producing pesticides produced, sold, or distributed at an establishment shall be considered confidential and shall be subject to the provisions of section 10 .

\section{SEC. 8. [7 U.S.C. 136f] BOOKS AND RECORDS.}

(a) REQUIREMENTS.-The Administrator may prescribe regulations requiring producers, registrants, and applicants for registration to maintain such records with respect to their operations and the pesticides and devices produced as the Administrator determines are necessary for the effective enforcement of this Act and to make the records available for inspection and copying in the same manner as provided in subsection (b). No records required under this subsection shall extend to financial data, sales data other than shipment data, pricing data, personnel data, and research data (other than data relating to registered pesticides or to a pesticide for which an application for registration has been filed).

(b) INSPECTION.-For the purposes of enforcing the provisions of this Act, any producer, distributor, carrier, dealer, or any other person who sells or offers for sale, delivers or offers for delivery any pesticide or device subject to this Act, shall, upon request of any officer or employee of the Environmental Protection Agency or of any State or political subdivision, duly designated by the Administrator, furnish or permit such person at all reasonable times to have access to, and to copy: (1) all records showing the delivery, movement, or holding of such pesticide or device, including the quantity, the date of shipment and receipt, and the name of the consignor and consignee; or (2) in the event of the inability of any person to produce records containing such information, all other records and information relating to such delivery, movement, or holding of the pesticide or device. Any inspection with respect to any records and information referred to in this subsection shall not extend to financial data, sales data other than shipment data, pricing data, personnel data, and research data (other than data relating to registered pesticides or to a pesticide for which an application for registration has been filed). Before undertaking an inspection under this subsection, the officer or employee must present to the owner, operator, or agent in charge of the establishment or other place where pesticides or devices are held for distribution or sale, appropriate credentials and a written statement as to the reason for the inspection, including a statement as to whether a violation of the law is suspected. If no violation is suspected, an alternate and sufficient reason shall be given in writing. Each such inspection shall be commenced and completed with reasonable promptness.

SEC. 9. [7 U.S.C. 136g] INSPECTION OF ESTABLISHMENTS, ETC.

(a) IN GENERAL.- (1) For purposes of enforcing the provisions of this Act, officers or employees of the Environmental Protection Agency or of any State duly designated by the Administrator are authorized to enter at reasonable times (A) any establishment or other place where pesticides or devices are held for distribution or sale for the purpose of inspecting and obtaining samples of any pesticides or devices, packaged, labeled, and released for shipment, and samples of any containers or labeling for such pesticides or devices, or (B) any place where there is being held any pesticide the reg- 
istration of which has been suspended or canceled for the purpose of determining compliance with section 19.

(2) Before undertaking such inspection, the officers or employees must present to the owner, operator, or agent in charge of the establishment or other place where pesticides or devices are held for distribution or sale, appropriate credentials and a written statement as to the reason for the inspection, including a statement as to whether a violation of the law is suspected. If no violation is suspected, an alternate and sufficient reason shall be given in writing. Each such inspection shall be commenced and completed with reasonable promptness. If the officer or employee obtains any samples, prior to leaving the premises, the officer or employee shall give to the owner, operator, or agent in charge a receipt describing the samples obtained and, if requested, a portion of each such sample equal in volume or weight to the portion retained. If an analysis is made of such samples, a copy of the results of such analysis shall be furnished promptly to the owner, operator, or agent in charge.

(b) WARRANTS.-For purposes of enforcing the provisions of this Act and upon a showing to an officer or court of competent jurisdiction that there is reason to believe that the provisions of this Act have been violated, officers or employees duly designated by the Administrator are empowered to obtain and to execute warrants authorizing-

(1) entry, inspection, and copying of records for purposes of this section or section 8;

(2) inspection and reproduction of all records showing the quantity, date of shipment, and the name of consignor and consignee of any pesticide or device found in the establishment which is adulterated, misbranded, not registered (in the case of a pesticide) or otherwise in violation of this Act and in the event of the inability of any person to produce records containing such information, all other records and information relating to such delivery, movement, or holding of the pesticide or device; and

(3) the seizure of any pesticide or device which is in violation of this Act.

(c) ENFORCEMENT.-

(1) Certification of FACts to ATtorney General.-The examination of pesticides or devices shall be made in the Environmental Protection Agency or elsewhere as the Administrator may designate for the purpose of determining from such examinations whether they comply with the requirements of this Act. If it shall appear from any such examination that they fail to comply with the requirements of this Act, the Administrator shall cause notice to be given to the person against whom criminal or civil proceedings are contemplated. Any person so notified shall be given an opportunity to present the person's views, either orally or in writing, with regard to such contemplated proceedings, and if in the opinion of the Administrator it appears that the provisions of this Act have been violated by such person, then the Administrator shall certify the facts to the Attorney General, with a copy of the results of the analysis or the examination of such pesticide for the institution of a criminal proceeding pursuant to section $14(\mathrm{~b})$ or a civil proceeding under section 14(a), when the Administrator deter- 
mines that such action will be sufficient to effectuate the purposes of this Act.

(2) Notice NOT REQUIRED.-The notice of contemplated proceedings and opportunity to present views set forth in this subsection are not prerequisites to the institution of any proceeding by the Attorney General.

(3) WARNING NOTICES.-Nothing in this Act shall be construed as requiring the Administrator to institute proceedings for prosecution of minor violations of this Act whenever the Administrator believes that the public interest will be adequately served by a suitable written notice of warning.

SEC. 10. [7 U.S.C. 136h] PROTECTION OF TRADE SECRETS AND OTHER INFORMATION.

(a) IN GENERAL.-In submitting data required by this Act, the applicant may (1) clearly mark any portions thereof which in the applicant's opinion are trade secrets or commercial or financial information and (2) submit such marked material separately from other material required to be submitted under this Act.

(b) DisclosuRE.-Notwithstanding any other provision of this Act and subject to the limitations in subsections (d) and (e) of this section, the Administrator shall not make public information which in the Administrator's judgment contains or relates to trade secrets or commercial or financial information obtained from a person and privileged or confidential, except that, when necessary to carry out the provisions of this Act, information relating to formulas of products acquired by authorization of this Act may be revealed to any Federal agency consulted and may be revealed at a public hearing or in findings of fact issued by the Administrator.

(c) DISPUTES.-If the Administrator proposes to release for inspection information which the applicant or registrant believes to be protected from disclosure under subsection (b), the Administrator shall notify the applicant or registrant, in writing, by certified mail. The Administrator shall not thereafter make available for inspection such data until thirty days after receipt of the notice by the applicant or registrant. During this period, the applicant or registrant may institute an action in an appropriate district court for a declaratory judgment as to whether such information is subject to protection under subsection (b).

(d) LiMiTATIONS.-

(1) All information concerning the objectives, methodology, results, or significance of any test or experiment performed on or with a registered or previously registered pesticide or its separate ingredients, impurities, or degradation products, and any information concerning the effects of such pesticide on any organism or the behavior of such pesticide in the environment, including, but not limited to, data on safety to fish and wildlife, humans and other mammals, plants, animals, and soil, and studies on persistence, translocation and fate in the environment, and metabolism, shall be available for disclosure to the public. The use of such data for any registration purpose shall be governed by section 3 of this Act. This paragraph does not authorize the disclosure of any information that-

(A) discloses manufacturing or quality control processes, 
(B) discloses the details of any methods for testing, detecting, or measuring the quantity of any deliberately added inert ingredient of a pesticide, or

(C) discloses the identity or percentage quantity of any deliberately added inert ingredient of a pesticide, unless the Administrator has first determined that disclosure is necessary to protect against an unreasonable risk of injury to health or the environment.

(2) Information concerning production, distribution, sale, or inventories of a pesticide that is otherwise entitled to confidential treatment under subsection (b) of this section may be publicly disclosed in connection with a public proceeding to determine whether a pesticide, or any ingredient of a pesticide, causes unreasonable adverse effects on health or the environment, if the Administrator determines that such disclosure is necessary in the public interest.

(3) If the Administrator proposes to disclose information described in clause (A), (B), or (C) of paragraph (1) or in paragraph (2) of this subsection, the Administrator shall notify by certified mail the submitter of such information of the intent to release such information. The Administrator may not release such information, without the submitter's consent, until thirty days after the submitter has been furnished such notice. Where the Administrator finds that disclosure of information described in clause (A), (B), or (C) of paragraph (1) of this subsection is necessary to avoid or lessen an imminent and substantial risk of injury to the public health, the Administrator may set such shorter period of notice (but not less than ten days) and such method of notice as the Administrator finds appropriate. During such period the data submitter may institute an action in an appropriate district court to enjoin or limit the proposed disclosure. The court may enjoin disclosure, or limit the disclosure or the parties to whom disclosure shall be made, to the extent that-

(A) in the case of information described in clause (A), (B), or (C) of paragraph (1) of this subsection, the proposed disclosure is not required to protect against an unreasonable risk of injury to health or the environment; or

(B) in the case of information described in paragraph (2) of this subsection, the public interest in availability of the information in the public proceeding does not outweigh the interests in preserving the confidentiality of the information.

(e) Disclosure to CONTRACTORS.-Information otherwise protected from disclosure to the public under subsection (b) of this section may be disclosed to contractors with the United States and employees of such contractors if, in the opinion of the Administrator, such disclosure is necessary for the satisfactory performance by the contractor of a contract with the United States for the performance of work in connection with this Act and under such conditions as the Administrator may specify. The Administrator shall require as a condition to the disclosure of information under this subsection that the person receiving it take such security precautions respecting the information as the Administrator shall by regulation prescribe. 
(f) Penalty for Disclosure by Federal Employees.-(1) Any office or employee of the United States or former officer or employee of the United States who, by virtue of such employment or official position, has obtained possession of, or has access to, material the disclosure of which is prohibited by subsection (b) of this section, and who, knowing that disclosure of such material is prohibited by such subsection, willfully discloses the material in any manner to any person not entitled to receive it, shall be fined not more than $\$ 10,000$ or imprisoned for not more than one year, or both. Section 1905 of title 18 of the United States Code shall not apply with respect to the publishing, divulging, disclosure, or making known of, or making available, information reported or otherwise obtained under this Act. Nothing in this Act shall preempt any civil remedy under State or Federal law for wrongful disclosure of trade secrets.

(2) For the purposes of this section, any contractor with the United States who is furnished information as authorized by subsection (e) of this section, or any employee of any such contractor, shall be considered to be an employee of the United States.

(g) Disclosure to Foreign and Multinational Pesticide PRODUCERS.-(1) The Administrator shall not knowingly disclose information submitted by an applicant or registrant under this Act to any employee or agent of any business or other entity engaged in the production, sale, or distribution of pesticides in countries other than the United States or in addition to the United States or to any other person who intends to deliver such data to such foreign or multinational business or entity unless the applicant or registrant has consented to such disclosure. The Administrator shall require an affirmation from any person who intends to inspect data that such person does not seek access to the data for purposes of delivering it or offering it for sale to any such business or entity or its agents or employees and will not purposefully deliver or negligently cause the data to be delivered to such business or entity or its agents or employees. Notwithstanding any other provision of this subsection, the Administrator may disclose information to any person in connection with a public proceeding under law or regulation, subject to restrictions on the availability of information contained elsewhere in this Act, which information is relevant to a determination by the Administrator with respect to whether a pesticide, or any ingredient of a pesticide, causes unreasonable adverse effects on health or the environment.

(2) The Administrator shall maintain records of the names of persons to whom data are disclosed under this subsection and the persons or organizations they represent and shall inform the applicant or registrant of the names and affiliations of such persons.

(3) Section 1001 of title 18 of the United States Code shall apply to any affirmation made under paragraph (1) of this subsection.

SEC. 11. [7 U.S.C. 136i] USE OF RESTRICTED USE PESTICIDES; APPLICATORS.

(a) Certification Procedure.-

(1) FEDERAL CERTIFICATION.-In any State for which a State plan for applicator certification has not been approved by the Administrator, the Administrator, in consultation with the Governor of such State, shall conduct a program for the certification of applicators of pesticides. Such program shall conform to the requirements imposed upon the States under the provi- 
sions of subsection (a)(2) of this section and shall not require private applicators to take any examination to establish competency in the use of pesticides. Prior to the implementation of the program, the Administrator shall publish in the Federal Register for review and comment a summary of the Federal plan for applicator certification and shall make generally available within the State copies of the plan. The Administrator shall hold public hearings at one or more locations within the State if so requested by the Governor of such State during the thirty days following publication of the Federal Register notice inviting comment on the Federal plan. The hearings shall be held within thirty days following receipt of the request from the Governor. In any State in which the Administrator conducts a certification program, the Administrator may require any person engaging in the commercial application, sale, offering for sale, holding for sale, or distribution of any pesticide one or more uses of which have been classified for restricted use to maintain such records and submit such reports concerning the commercial application, sale, or distribution of such pesticide as the Administrator may be regulation prescribe. Subject to paragraph (2), the Administrator shall prescribe standards for the certification of applicators of pesticides. Such standards shall provide that to be certified, an individual must be determined to be competent with respect to the use and handling of pesticides, or to the use and handling of the pesticide or class of pesticides covered by such individual's certification. The certification standard for a private applicator shall, under a State plan submitted for approval, be deemed fulfilled by the applicator completing a certification form. The Administrator shall further assure that such form contains adequate information and affirmations to carry out the intent of this Act, and may include in the form an affirmation that the private applicator has completed a training program approved by the Administrator so long as the program does not require the private applicator to take, pursuant to a requirement prescribed by the Administrator, any examination to establish competency in the use of the pesticide. The Administrator may require any pesticide dealer participating in a certification program to be licensed under a State licensing program approved by the Administrator.

(2) State Certification.-If any State, at any time, desires to certify applicators of pesticides, the Governor of such State shall submit a State plan for such purpose. The Administrator shall approve the plan submitted by any State, or any modification thereof, if such plan in the Administrator's judgment-

(A) designates a State agency as the agency responsible for administering the plan throughout the State;

(B) contains satisfactory assurances that such agency has or will have the legal authority and qualified personnel necessary to carry out the plan;

(C) gives satisfactory assurances that the State will devote adequate funds to the administration of the plan;

(D) provides that the State agency will make such reports to the Administrator in such form and containing 
such information as the Administrator may from time to time require; and

(E) contains satisfactory assurances that State standards for the certification of applicators of pesticides conform with those standards prescribed by the Administrator under paragraph (1).

Any State certification program under this section shall be maintained in accordance with the State plan approved under this section.

(b) STATE Plans.-If the Administrator rejects a plan submitted under subsection (a)(2), the Administrator shall afford the State submitting the plan due notice and opportunity for hearing before so doing. If the Administrator approves a plan submitted under subsection (a)(2), then such State shall certify applicators of pesticides with respect to such State. Whenever the Administrator determines that a State is not administering the certification program in accordance with the plan approved under this section, the Administrator shall so notify the State and provide for a hearing at the request of the State, and, if appropriate corrective action is not taken within a reasonable time, not to exceed ninety days, the Administrator shall withdraw approval of such plan.

(c) Instruction in Integrated Pest Management TechNIQUES.- Standards prescribed by the Administrator for the certification of applicators of pesticides under subsection (a), and the State plans submitted to the Administrator under subsection (a), shall include provisions for making instructional materials concerning integrated pest management techniques available to individuals at their request in accordance with the provisions of section 23(c) of this Act, but such plans may not require that any individual receive instruction concerning such techniques or be shown to be competent with respect to the use of such techniques. The Administrator and States implementing such plans shall provide that all interested individuals are notified of the availability of such instructional materials.

(d) IN GENERAL.-No regulations prescribed by the Administrator for carrying out the provisions of this Act shall require any private applicator to maintain any records or file any reports or other documents.

(e) SEPARATE STANDARDS.-When establishing or approving standards for licensing or certification, the Administrator shall establish separate standards for commercial and private applicators.

SEC. 12. [7 U.S.C. 136j] UNLAWFUL ACTS.

(a) IN GENERAL.-

(1) Except as provided by subsection (b), it shall be unlawful for any person in any State to distribute or sell to any person-

(A) any pesticide that is not registered under section 3 or whose registration has been canceled or suspended, except to the extent that distribution or sale otherwise has been authorized by the Administrator under this Act;

(B) any registered pesticide if any claims made for it as a part of its distribution or sale substantially differ from any claims made for it as a part of the statement required in connection with its registration under section 3;

(C) any registered pesticide the composition of which differs at the time of its distribution or sale from its com- 
position as described in the statement required in connection with its registration under section 3;

(D) any pesticide which has not been colored or discolored pursuant to the provisions of section 25(c)(5);

(E) any pesticide which is adulterated or misbranded; or

(F) any device which is misbranded.

(2) It shall be unlawful for any person-

(A) to detach, alter, deface, or destroy, in whole or in part, any labeling required under this Act;

(B) to refuse to-

(i) prepare, maintain, or submit any records required by or under section $5,7,8,11$, or 19 ;

(ii) submit any reports required by or under section $5,6,7,8,11$, or 19 ; or

(iii) allow any entry, inspection, copying of records, or sampling authorized by this Act;

(C) to give a guaranty or undertaking provided for in subsection (b) which is false in any particular, except that a person who receives and relies upon a guaranty authorized under subsection (b) may give a guaranty to the same effect, which guaranty shall contain, in addition to the person's own name and address, the name and address of the person residing in the United States from whom the person received the guaranty or undertaking;

(D) to use for the person's own advantage or to reveal, other than to the Administrator, or officials or employees of the Environmental Protection Agency or other Federal executive agencies, or to the courts, or to physicians, pharmacists, and other qualified persons, needing such information for the performance of their duties, in accordance with such directions as the Administrator may prescribe, any information acquired by authority of this Act which is confidential under this Act;

(E) who is a registrant, wholesaler, dealer, retailer, or other distributor to advertise a product registered under this Act for restricted use without giving the classification of the product assigned to it under section 3;

(F) to distribute or sell, or to make available for use, or to use, any registered pesticide classified for restricted use for some or all purposes other than in accordance with section $3(\mathrm{~d})$ and any regulations thereunder, except that it shall not be unlawful to sell, under regulations issued by the Administrator, a restricted use pesticide to a person who is not a certified applicator for application by a certified applicator;

$(\mathrm{G})$ to use any registered pesticide in a manner inconsistent with its labeling;

(H) to use any pesticide which is under an experimental use permit contrary to the provisions of such permit;

(I) to violate any order issued under section 13;

(J) to violate any suspension order issued under section $3(\mathrm{c})(2)(\mathrm{B}), 4$, or 6 ; 
(K) to violate any cancellation order issued under this Act or to fail to submit a notice in accordance with section $6(\mathrm{~g})$

(L) who is a producer to violate any of the provisions of section 7;

(M) to knowingly falsify all or part of any application for registration, application for experimental use permit, any information submitted to the Administrator pursuant to section 7, any records required to be maintained pursuant to this Act, any report filed under this Act, or any information marked as confidential and submitted to the Administrator under any provision of this Act;

(N) who is a registrant, wholesaler, dealer, retailer, or other distributor to fail to file reports required by this Act;

(O) to add any substance to, or take any substance from, any pesticide in a manner that may defeat the purpose of this Act;

(P) to use any pesticide in tests on human beings unless such human beings (i) are fully informed of the nature and purposes of the test and of any physical and mental health consequences which are reasonably foreseeable therefrom, and (ii) freely volunteer to participate in the test;

(Q) to falsify all or part of any information relating to the testing of any pesticide (or any ingredient, metabolite, or degradation product thereof), including the nature of any protocol, procedure, substance, organism, or equipment used, observation made, or conclusion or opinion formed, submitted to the Administrator, or that the person knows will be furnished to the Administrator or will become a part of any records required to be maintained by this Act;

(R) to submit to the Administrator data known to be false in support of a registration; or or 19.

(S) to violate any regulation issued under section 3(a)

(b) EXEMPTIONS.-The penalties provided for a violation of paragraph (1) of subsection (a) shall not apply to-

(1) any person who establishes a guaranty signed by, and containing the name and address of, the registrant or person residing in the United States from whom the person purchased or received in good faith the pesticide in the same unbroken package, to the effect that the pesticide was lawfully registered at the time of sale and delivery to the person, and that it complies with the other requirements of this Act, and in such case the guarantor shall be subject to the penalties which would otherwise attach to the person holding the guaranty under the provisions of this Act;

(2) any carrier while lawfully shipping, transporting, or delivering for shipment any pesticide or device, if such carrier upon request of any officer or employee duly designated by the Administrator shall permit such officer or employee to copy all of its records concerning such pesticide or device;

(3) any public official while engaged in the performance of the official duties of the public official; 
(4) any person using or possessing any pesticide as provided by an experimental use permit in effect with respect to such pesticide and such use or possession; or

(5) any person who ships a substance or mixture of substances being put through tests in which the purpose is only to determine its value for pesticide purposes or to determine its toxicity or other properties and from which the user does not expect to receive any benefit in pest control from its use.

\section{SEC. 13. [7 U.S.C. 136k] STOP SALE, USE, REMOVAL, AND SEIZURE.}

(a) STOP SAlE, ETC., ORDERS.-Whenever any pesticide or device is found by the Administrator in any State and there is reason to believe on the basis of inspection or tests that such pesticide or device is in violation of any of the provisions of this Act, or that such pesticide or device has been or is intended to be distributed or sold in violation of any such provisions, or when the registration of the pesticide has been canceled by a final order or has been suspended, the Administrator may issue a written or printed "stop sale, use, or removal" order to any person who owns, controls, or has custody of such pesticide or device, and after receipt of such order no person shall sell, use, or remove the pesticide or device described in the order except in accordance with the provisions of the order.

(b) SEIZURE.-Any pesticide or device that is being transported or, having been transported, remains unsold or in original unbroken packages, or that is sold or offered for sale in any State, or that is imported from a foreign country, shall be liable to be proceeded against in any district court in the district where it is found and seized for confiscation by a process in rem for condemnation if-

(1) in the case of a pesticide-

(A) it is adulterated or misbranded;

(B) it is not registered pursuant to the provisions of section 3;

(C) its labeling fails to bear the information required by this Act;

(D) it is not colored or discolored and such coloring or discoloring is required under this Act; or

(E) any of the claims made for it or any of the directions for its use differ in substance from the representations made in connection with its registration;

(2) in the case of a device, it is misbranded; or

(3) in the case of a pesticide or device, when used in accordance with the requirements imposed under this Act and as directed by the labeling, it nevertheless causes unreasonable adverse effects on the environment.

In the case of a plant regulator, defoliant, or desiccant, used in accordance with the label claims and recommendations, physical or physiological effects on plants or parts thereof shall not be deemed to be injury, when such effects are the purpose for which the plant regulator, defoliant, or desiccant was applied.

(c) Disposition AFTER CONDEMnATION.-If the pesticide or device is condemned it shall, after entry of the decree, be disposed of by destruction or sale as the court may direct and the proceeds, if sold, less the court costs, shall be paid into the Treasury of the United States, but the pesticide or device shall not be sold contrary to the provisions of this Act or the laws of the jurisdiction in which it is sold. On payment of the costs of the condemnation proceedings 
and the execution and delivery of a good and sufficient bond conditioned that the pesticide or device shall not be sold or otherwise disposed of contrary to the provisions of the Act or the laws of any jurisdiction in which sold, the court may direct that such pesticide or device be delivered to the owner thereof. The proceedings of such condemnation cases shall conform, as near as may be to the proceedings in admiralty, except that either party may demand trial by jury of any issue of fact joined in any case, and all such proceedings shall be at the suit of and in the name of the United States.

(d) Court Costs, ETC.-When a decree of condemnation is entered against the pesticide or device, court costs and fees, storage, and other proper expenses shall be awarded against the person, if any, intervening as claimant of the pesticide or device.

SEC. 14. [7 U.S.C. 1361] PENALTIES.

(a) Civil Penalties.-

(1) IN GENERAL.-Any registrant, commercial applicator, wholesaler, dealer, retailer, or other distributor who violates any provision of this Act may be assessed a civil penalty by the Administrator of not more than $\$ 5,000$ for each offense.

(2) PRIVATE APPLICATOR.-Any private applicator or other person not included in paragraph (1) who violates any provision of this Act subsequent to receiving a written warning from the Administrator or following a citation for a prior violation, may be assessed a civil penalty by the Administrator of not more than $\$ 1,000$ for each offense, except that any applicator not included under paragraph (1) of this subsection who holds or applies registered pesticides, or uses dilutions of registered pesticides, only to provide a service of controlling pests without delivering any unapplied pesticide to any person so served, and who violates any provision of this Act may be assessed a civil penalty by the Administrator of not more than $\$ 500$ for the first offense nor more than $\$ 1,000$ for each subsequent offense.

(3) HEARING.-No civil penalty shall be assessed unless the person charged shall have been given notice and opportunity for a hearing on such charge in the county, parish, or incorporated city of the residence of the person charged.

(4) DETERMINATION OF PENALTY.-In determining the amount of the penalty, the Administrator shall consider the appropriateness of such penalty to the size of the business of the person charged, the effect on the person's ability to continue in business, and the gravity of the violation. Whenever the Administrator finds that the violation occurred despite the exercise of due care or did not cause significant harm to health or the environment, the Administrator may issue a warning in lieu of assessing a penalty.

(5) REFERENCES TO ATTORNEY GENERAL.-In case of inability to collect such civil penalty or failure of any person to pay all, or such portion of such civil penalty as the Administrator may determine, the Administrator shall refer the matter to the Attorney General, who shall recover such amount by action in the appropriate United States district court.

(b) Criminal Penalties.-

(1) IN GENERAL.-

(A) Any registrant, applicant for a registration, or pro- 
shall be fined not more than $\$ 50,000$ or imprisoned for not more than 1 year, or both.

(B) Any commercial applicator of a restricted use pesticide, or any other person not described in subparagraph (A) who distributes or sells pesticides or devices, who knowingly violates any provision of this Act shall be fined not more than $\$ 25,000$ or imprisoned for not more than 1 year, or both.

(2) PRIVATE APPLiCATOR.-Any private applicator or other person not included in paragraph (1) who knowingly violates any provision of this Act shall be guilty of a misdemeanor and shall on conviction be fined not more than $\$ 1,000$, or imprisoned for not more than 30 days, or both.

(3) Disclosure OF INFORMATiOn.-Any person, who, with intent to defraud, uses or reveals information relative to formulas of products acquired under the authority of section 3 , shall be fined not more than $\$ 10,000$, or imprisoned for not more than three years, or both.

(4) ACTS OF OFFICERS, AGENTS, ETC.-When construing and enforcing the provisions of this Act, the act, omission, or failure of any officer, agent, or other person acting for or employed by any person shall in every case be also deemed to be the act, omission, or failure of such person as well as that of the person employed.

SEC. 15. [7 U.S.C. 136m] INDEMNITIES.

(a) GENERAL INDEMNIFICATION.tion, if-

(1) IN GENERAL.-Except as otherwise provided in this sec-

(A) the Administrator notifies a registrant under section 6(c)(1) that the Administrator intends to suspend a registration or that an emergency order of suspension of a registration under section 6(c)(3) has been issued;

(B) the registration in question is suspended under section 6(c), and thereafter is canceled under section 6(b), 6(d), or 6(f); and

(C) any person who owned any quantity of the pesticide immediately before the notice to the registrant under subparagraph (A) suffered losses by reason of suspension or cancellation of the registration;

the Administrator shall make an indemnity payment to the person.

(2) EXCEPTION.-Paragraph (1) shall not apply if the Administrator finds that the person-

(A) had knowledge of facts that, in themselves, would have shown that the pesticide did not meet the requirements of section 3(c)(5) for registration; and

(B) continued thereafter to produce the pesticide without giving timely notice of such facts to the Administrator.

(3) REPORT.-If the Administrator takes an action under paragraph (1) that requires the payment of indemnification, the Administrator shall report to the Committee on Agriculture of the House of Representatives, the Committee on Agriculture, Nutrition, and Forestry of the Senate, and the Committees on Appropriations of the House of Representatives and the Senate 
(A) the action taken that requires the payment of indemnification;

(B) the reasons for taking the action;

(C) the estimated cost of the payment; and

(D) a request for the appropriation of funds for the payment.

(4) APPROPRIATION.-The Administrator may not make a payment of indemnification under paragraph (1) unless a specific line item appropriation of funds has been made in advance for the payment.

(b) INDEMNificAtion of END Users, DeAlers, AND DisTribUTORS.-

(1) END USERS.-If-

(A) the Administrator notifies a registrant under section 6(c)(1) that the Administrator intends to suspend a registration or that an emergency order of suspension of a registration under section 6(c)(3) has been issued;

(B) the registration in question is suspended under section 6(c), and thereafter is canceled under section $6(\mathrm{~b}), 6(\mathrm{~d})$, or $6(\mathrm{f})$; and

(C) any person who, immediately before the notice to the registrant under subparagraph (A), owned any quantity of the pesticide for purposes of applying or using the pesticide as an end user, rather than for purposes of distributing or selling it or further processing it for distribution or sale, suffered a loss by reason of the suspension or cancellation of the pesticide;

the person shall be entitled to an indemnity payment under this subsection for such quantity of the pesticide.

(2) DEALERS AND DisTRIBUTORS.-

(A) Any registrant, wholesaler, dealer, or other distributor (hereinafter in this paragraph referred to as a "seller") of a registered pesticide who distributes or sells the pesticide directly to any person not described as an end user in paragraph $(1)(\mathrm{C})$ shall, with respect to any quantity of the pesticide that such person cannot use or resell as a result of the suspension or cancellation of the pesticide, reimburse such person for the cost of first acquiring the pesticide from the seller (other than the cost of transportation, if any), unless the seller provided to the person at the time of distribution or sale a notice, in writing, that the pesticide is not subject to reimbursement by the seller.

(B) If-

(i) the Administrator notifies a registrant under section 6(c)(1) that the Administrator intends to suspend a registration or that an emergency order of suspension of a registration under section 6(c)(3) has been issued;

(ii) the registration in question is suspended under section 6(c), and thereafter is canceled under section $6(\mathrm{~b}), 6(\mathrm{~d})$, or $6(\mathrm{f})$;

(iii) any person who, immediately before the notice to the registrant under clause (i) -

(I) had not been notified in writing by the seller, as provided under subparagraph (A), that any quantity of the pesticide owned by such person is 
not subject to reimbursement by the seller in the event of suspension or cancellation of the pesticide; and

(II) owned any quantity of the pesticide for purposes of-

(aa) distributing or selling it; or

(bb) further processing it for distribution or sale directly to an end user;

suffered a loss by reason of the suspension or cancellation of the pesticide; and

(iv) the Administrator determines on the basis of a claim of loss submitted to the Administrator by the person, that the seller-

(I) did not provide the notice specified in subparagraph (A) to such person; and

(II) is and will continue to be unable to provide reimbursement to such person, as provided under subparagraph (A), for the loss referred to in clause (iii), as a result of the insolvency or bankruptcy of the seller and the seller's resulting inability to provide such reimbursement;

the person shall be entitled to an indemnity payment under this subsection for such quantity of the pesticide.

(C) If an indemnity payment is made by the United States under this paragraph, the United States shall be subrogated to any right that would otherwise be held under this paragraph by a seller who is unable to make a reimbursement in accordance with this paragraph with regard to reimbursements that otherwise would have been made by the seller.

(3) SoURCE.-Any payment required to be made under paragraph (1) or (2) shall be made from the appropriation provided under section 1304 of title 31, United States Code.

(4) AdMINISTRATIVE SETTLEMENT.-An administrative settlement of a claim for such indemnity may be made in accordance with the third paragraph of section 2414 of title 28, United States Code, and shall be regarded as if it were made under that section for purposes of section 1304 of title 31, United States Code.

(c) AMOUNT OF PAYMENT.-

(1) IN GENERAL.- The amount of an indemnity payment under subsection (a) or (b) to any person shall be determined on the basis of the cost of the pesticide owned by the person (other than the cost of transportation, if any) immediately before the issuance of the notice to the registrant referred to in subsection $(a)(1)(A),(b)(1)(A)$, or $(b)(2)(B)(i)$, except that in no event shall an indemnity payment to any person exceed the fair market value of the pesticide owned by the person immediately before the issuance of the notice.

(2) SPECIAL RULE.-Notwithstanding any other provision of this Act, the Administrator may provide a reasonable time for use or other disposal of the pesticide. In determining the quantity of any pesticide for which indemnity shall be paid under this section, proper adjustment shall be made for any pesticide used or otherwise disposed of by the owner. 
SEC. 16. [7 U.S.C. 136n] ADMINISTRATIVE PROCEDURE; JUDICIAL REVIEW.

(a) DistRICT CoURT REVIEW.-Except as otherwise provided in this Act, the refusal of the Administrator to cancel or suspend a registration or to change a classification not following a hearing and other final actions of the Administrator not committed to the discretion of the Administrator by law are judicially reviewable by the district courts of the United States.

(b) REVIEW BY COURT OF APPEALS.-In the case of actual controversy as to the validity of any order issued by the Administrator following a public hearing, any person who will be adversely affected by such order and who had been a party to the proceedings may obtain judicial review by filing in the United States court of appeals for the circuit wherein such person resides or has a place of business, within 60 days after the entry of such order, a petition praying that the order be set aside in whole or in part. A copy of the petition shall be forthwith transmitted by the clerk of the court to the Administrator or any officer designated by the Administrator for that purpose, and thereupon the Administrator shall file in the court the record of the proceedings on which the Administrator based the Administrator's order, as provided in section 2112 of title 28, United States Code. Upon the filing of such petition the court shall have exclusive jurisdiction to affirm or set aside the order complained of in whole or in part. The court shall consider all evidence of record. The order of the Administrator shall be sustained if it is supported by substantial evidence when considered on the record as a whole. The judgment of the court affirming or setting aside, in whole or in part, any order under this section shall be final, subject to review by the Supreme Court of the United States upon certiorari or certification as provided in section 1254 of title 28 of the United States Code. The commencement of proceedings under this section shall not, unless specifically ordered by the court to the contrary, operate as a stay of an order.

(c) JURISDICTION OF DISTRICT COURTS.-The district courts of the United States are vested with jurisdiction specifically to enforce, and to prevent and restrain violations of, this Act.

(d) NoticE OF JUDGMENTS.-The Administrator shall, by publication in such manner as the Administrator may prescribe, give notice of all judgments entered in actions instituted under the authority of this Act.

\section{SEC. 17. [7 U.S.C. 136o] IMPORTS AND EXPORTS.}

(a) Pesticides AND DEvices INTENDED FOR ExPORT.-Notwithstanding any other provision this Act, no pesticide or device or active ingredient used in producing a pesticide intended solely for export to any foreign country shall be deemed in violation of this Act-

(1) when prepared or packed according to the specifications or directions of the foreign purchaser, except that producers of such pesticides and devices and active ingredients used in producing pesticides shall be subject to sections 2(p), 2(q) (1) (A), (C), (D), (E), (G), and (H), 2(q) (2) (A), (B), (C) (i) and (iii), and (D), 7, and 8 of this Act; and

(2) in the case of any pesticide other than a pesticide registered under section 3 or sold under section 6(a) (1) of this Act, if, prior to export, the foreign purchaser has signed a statement acknowledging that the purchaser understands that such pes- 
ticide is not registered for use in the United States and cannot

be sold in the United States under this Act.

A copy of that statement shall be transmitted to an appropriate official of the government of the importing country.

(b) Cancellation Notices Furnished to Foreign GovernMENTS.-Whenever a registration, or a cancellation or suspension of the registration of a pesticide becomes effective, or ceases to be effective, the Administrator shall transmit through the State Department notification thereof to the governments of other countries and to appropriate international agencies. Such notification shall, upon request, include all information related to the cancellation or suspension of the registration of the pesticide and information concerning other pesticides that are registered under section 3 of this Act and that could be used in lieu of such pesticide.

(c) IMPORTATION OF PESTICIDES AND DEviCES.-The Secretary of the Treasury shall notify the Administrator of the arrival of pesticides and devices and shall deliver to the Administrator, upon the Administrator's request, samples of pesticides or devices which are being imported into the United States, giving notice to the owner or consignee, who may appear before the Administrator and have the right to introduce testimony. If it appears from the examination of a sample that it is adulterated, or misbranded or otherwise violates the provisions set forth in this Act, or is otherwise injurious to health or the environment, the pesticide or device may be refused admission, and the Secretary of the Treasury shall refuse delivery to the consignee and shall cause the destruction of any pesticide or device refused delivery which shall not be exported by the consignee within 90 days from the date of notice of such refusal under such regulations as the Secretary of the Treasury may prescribe. The Secretary of the Treasury may deliver to the consignee such pesticide or device pending examination and decision in the matter on execution of bond for the amount of the full invoice value of such pesticide or device, together with the duty thereon, and on refusal to return such pesticide or device for any cause to the custody of the Secretary of the Treasury, when demanded, for the purpose of excluding them from the country, or for any other purpose, said consignee shall forfeit the full amount of said bond. All charges for storage, cartage, and labor on pesticides or devices which are refused admission or delivery shall be paid by the owner or consignee, and in default of such payment shall constitute a lien against any future importation made by such owner or consignee.

(d) COOPERATION IN INTERNATIONAL EFFORTS.-

(1) IN GENERAL.- The Administrator shall, in cooperation with the Department of State and any other appropriate Federal agency, participate and cooperate in any international efforts to develop improved pesticide research and regulations.

(2) Department of STATE EXPENSES.-Any expenses incurred by an employee of the Environmental Protection Agency who participates in any international technical, economic, or policy review board, committee, or other official body that is meeting in relation to an international treaty shall be paid by the Department of State.

(e) Regulations.-The Secretary of the Treasury, in consultation with the Administrator, shall prescribe regulations for the enforcement of subsection (c) of this section. 
SEC. 18. [7 U.S.C. 136p] EXEMPTION OF FEDERAL AND STATE AGENCIES.

The Administrator may, at the Administrator's discretion, exempt any Federal or State agency from any provision of this Act if the Administrator determines that emergency conditions exist which require such exemption. The Administrator, in determining whether or not such emergency conditions exist, shall consult with the Secretary of Agriculture and the Governor of any State concerned if they request such determination.

SEC. 19. [7 U.S.C. 136q] STORAGE, DISPOSAL, TRANSPORTATION, AND RECALL.

(a) Storage, Disposal, And Transportation.-

(1) DATA REQUIREMENTS AND REGISTRATION OF PESTICIDES.-The Administrator may require under section 3 or 6 that-

(A) the registrant or applicant for registration of a pesticide submit or cite data or information regarding methods for the safe storage and disposal of excess quantities of the pesticide to support the registration or continued registration of a pesticide;

(B) the labeling of a pesticide contain requirements and procedures for the transportation, storage, and disposal of the pesticide, any container of the pesticide, any rinsate containing the pesticide, or any other material used to contain or collect excess or spilled quantities of the pesticide; and

(C) the registrant of a pesticide provide evidence of sufficient financial and other resources to carry out a recall plan under subsection (b), and provide for the disposition of the pesticide, in the event of suspension and cancellation of the pesticide.

(2) PESTICIDES.- - The Administrator may by regulation, or as part of an order issued under section 6 or an amendment to such an order-

(A) issue requirements and procedures to be followed by any person who stores or transports a pesticide the registration of which has been suspended or canceled;

(B) issue requirements and procedures to be followed by any person who disposes of stocks of a pesticide the registration of which has been suspended; and

(C) issue requirements and procedures for the disposal of any pesticide the registration of which has been canceled.

(3) CONTAINERS, RINSATES, AND OTHER MATERIALS.-The Administrator may by regulation, or as part of an order issued under section 6 or an amendment to such an order-

(A) issue requirements and procedures to be followed by any person who stores or transports any container of a pesticide the registration of which has been suspended or canceled, any rinsate containing the pesticide, or any other material used to contain or collect excess or spilled quantities of the pesticide;

(B) issue requirements and procedures to be followed by any person who disposes of stocks of any container of a pesticide the registration of which has been suspended, any rinsate containing the pesticide, or any other material used 
to contain or collect excess or spilled quantities of the pesticide; and

(C) issue requirements and procedures for the disposal of any container of a pesticide the registration of which has been canceled, any rinsate containing the pesticide, or any other material used to contain or collect excess or spilled quantities of the pesticide.

(4) CONTAINER RECYCLING.-The Secretary may promulgate a regulation for the return and recycling of disposable pesticide containers used for the distribution or sale of registered pesticide products in interstate commerce. Any such regulation requiring recycling of disposable pesticide containers shall not apply to antimicrobial pesticides (as defined in section 2) or other pesticide products intended for non-agricultural uses.

(b) RECALLS.-

(1) IN GENERAL.-If the registration of a pesticide has been suspended and canceled under section 6, and if the Administrator finds that recall of the pesticide is necessary to protect health or the environment, the Administrator shall order a recall of the pesticide in accordance with this subsection.

(2) VOLUNTARY RECALL.-If, after determining under paragraph (1) that a recall is necessary, the Administrator finds that voluntary recall by the registrant and others in the chain of distribution may be as safe and effective as a mandatory recall, the Administrator shall request the registrant of the pesticide to submit, within 60 days of the request, a plan for the voluntary recall of the pesticide. If such a plan is requested and submitted, the Administrator shall approve the plan and order the registrant to conduct the recall in accordance with the plan unless the Administrator determines, after an informal hearing, that the plan is inadequate to protect health or the environment.

(3) MANDATORY RECALL.-If, after determining under paragraph (1) that a recall is necessary, the Administrator does not request the submission of a plan under paragraph (2) or finds such a plan to be inadequate, the Administrator shall issue a regulation that prescribes a plan for the recall of the pesticide. A regulation issued under this paragraph may apply to any person who is or was a registrant, distributor, or seller of the pesticide, or any successor in interest to such a person.

(4) RECALL PROCEDURE.-A regulation issued under this subsection may require any person that is subject to the regulation to-

(A) arrange to make available one or more storage facilities to receive and store the pesticide to which the recall program applies, and inform the Administrator of the location of each such facility;

(B) accept and store at such a facility those existing stocks of such pesticide that are tendered by any other person who obtained the pesticide directly or indirectly from the person that is subject to such regulation;

(C) on the request of a person making such a tender, provide for proper transportation of the pesticide to a storage facility; and

(D) take such reasonable steps as the regulation may prescribe to inform persons who may be holders of the pes- 
ticide of the terms of the recall regulation and how those persons may tender the pesticide and arrange for transportation of the pesticide to a storage facility.

(5) Contents OF RECALL PLAN.-A recall plan established under this subsection shall include-

(A) the level in the distribution chain to which the recall is to extend, and a schedule for recall; and

(B) the means to be used to verify the effectiveness of the recall.

(6) REQUIREMENTS OR PROCEDURES.-No requirement or procedure imposed in accordance with paragraph (2) of subsection (a) may require the recall of existing stocks of the pesticide except as provided by this subsection.

(c) Storage Costs.-

(1) SUBMISSION OF PLAN.-A registrant who wishes to become eligible for reimbursement of storage costs incurred as a result of a recall prescribed under subsection (b) for a pesticide whose registration has been suspended and canceled shall, as soon as practicable after the suspension of the registration of the pesticide, submit to the Administrator a plan for the storage and disposal of the pesticide that meets criteria established by the Administrator by regulation.

(2) REIMBURSEMENT.-Within a reasonable period of time after such storage costs are incurred and paid by the registrant, the Administrator shall reimburse the registrant, on request, for-

(A) none of the costs incurred by the registrant before the date of submission of the plan referred to in paragraph (1) to the Administrator;

(B) 100 percent of the costs incurred by the registrant after the date of submission of the plan to the Administrator or the date of cancellation of the registration of the pesticide, whichever is later, but before the approval of the plan by the Administrator;

(C) 50 percent of the costs incurred by the registrant during the 1-year period beginning on the date of the approval of the plan by the Administrator or the date of cancellation of the registration of the pesticide, whichever is later;

(D) none of the costs incurred by the registrant during the 3-year period beginning on the 366th day following approval of the plan by the Administrator or the date of cancellation of the registration of the pesticide, whichever is later; and

(E) 25 percent of the costs incurred by the registrant during the period beginning on the first day of the 5th year following the date of the approval of the plan by the Administrator or the date of cancellation of the registration of the pesticide, whichever is later, and ending on the date that a disposal permit for the pesticide is issued by a State or an alternative plan for disposal of the pesticide in accordance with applicable law has been developed.

(d) Administration of Storage, Disposal, Transportation, AND RECALL PROGRAMS.-

(1) VOLUNTARY AGREEMENTS.-Nothing in this section shall 
between a seller and a buyer of any pesticide or other substance regarding the ultimate allocation of the costs of storage, transportation, or disposal of a pesticide.

(2) RULE AND REGULATION REVIEW.-Section 25(a)(4) shall not apply to any regulation issued under subsection (a)(2) or (b).

(3) Limitations.-No registrant shall be responsible under this section for a pesticide the registration of which is held by another person. No distributor or seller shall be responsible under this section for a pesticide that the distributor or seller did not hold or sell.

(4) SeIzure AND Penalties.-If the Administrator finds that a person who is subject to a regulation or order under subsection (a)(2) or (b) has failed substantially to comply with that regulation or order, the Administrator may take action under section 13 or 14 or obtain injunctive relief under section 16(c) against such person or any successor in interest of any such person.

(e) Container Design.-

(1) Procedures.-

(A) Not later than 3 years after the effective date of this subsection [December 24, 1988], the Administrator shall, in consultation with the heads of other interested Federal agencies, promulgate regulations for the design of pesticide containers that will promote the safe storage and disposal of pesticides.

(B) The regulations shall ensure, to the fullest extent practicable, that the containers-

(i) accommodate procedures used for the removal of pesticides from the containers and the rinsing of the containers;

(ii) facilitate the safe use of the containers, including elimination of splash and leakage of pesticides from the containers; and

(iii) facilitate the safe disposal of the containers;

(iv) facilitate the safe refill and reuse of the containers.

(2) COMPLIANCE.-The Administrator shall require compliance with the regulations referred to in paragraph (1) not later than 5 years after the effective date of this subsection [December 24,1988$]$.

(f) Pesticide Residue Removal.-

(1) Procedures.-

(A) Not later than 3 years after the effective date of this subsection [December 24, 1988], the Administrator shall, in consultation with the heads of other interested Federal agencies, promulgate regulations prescribing procedures and standards for the removal of pesticides from containers prior to disposal.

(B) The regulations may-

(i) specify, for each major type of pesticide container, procedures and standards providing for, at a minimum, triple rinsing or the equivalent degree of pesticide removal; 
(ii) specify procedures that can be implemented promptly and easily in various circumstances and conditions;

(iii) provide for reuse, whenever practicable, or disposal of rinse water and residue; and

(iv) be coordinated with requirements for the rinsing of containers imposed under the Solid Waste Disposal Act (42 U.S.C. 6901 et seq.).

(C) The Administrator may, at the discretion of the Administrator, exempt products intended solely for household use from the requirements of this subsection.

(2) COMPLIANCE.-Effective beginning 5 years after the effective date of this subsection [December 24, 1988], a State may not exercise primary enforcement responsibility under section 26 , or certify an applicator under section 11, unless the Administrator determines that the State is carrying out an adequate program to ensure compliance with this subsection.

(3) SOLID WASTE DISPOSAL ACT.-Nothing in this subsection shall affect the authorities or requirements concerning pesticide containers under the Solid Waste Disposal Act (42 U.S.C. 6901).

(g) Pesticide Container Study.-

(1) STUDY.-

(A) The Administrator shall conduct a study of options to encourage or require-

(i) the return, refill, and reuse of pesticide containers;

(ii) the development and use of pesticide formulations that facilitate the removal of pesticide residues from containers; and

(iii) the use of bulk storage facilities to reduce the number of pesticide containers requiring disposal.

(B) In conducting the study, the Administrator shall-

(i) consult with the heads of other interested Federal agencies, State agencies, industry groups, and environmental organizations; and

(ii) assess the feasibility, costs, and environmental benefits of encouraging or requiring various measures or actions.

(2) REPORT.-Not later than 2 years after the effective date of this subsection [December 24, 1988], the Administrator shall submit to Congress a report describing the results of the study required under paragraph (1).

(h) Relationship to Solid Waste Disposal Act.-

(1) IN GENERAL.-Nothing in this section shall diminish the authorities or requirements of the Solid Waste Disposal Act (42 U.S.C. 6901 et seq.).

(2) ANTIMICROBIAL PRODUCTS.-A household, industrial, or institutional antimicrobial product that is not subject to regulation under the Solid Waste Disposal Act (42 U.S.C. 6901 et seq.) shall not be subject to the provisions of subsections (a), (e), and (f), unless the Administrator determines that such product must be subject to such provisions to prevent an unreasonable adverse effect on the environment. 
SEC. 20. [7 U.S.C. 136r] RESEARCH AND MONITORING.

(a) RESEARCH.-The Administrator shall undertake research, including research by grant or contract with other Federal agencies, universities, or others as may be necessary to carry out the purposes of this Act, and the Administrator shall conduct research into integrated pest management in coordination with the Secretary of Agriculture. The Administrator shall also take care to ensure that such research does not duplicate research being undertaken by any other Federal agency.

(b) NAtional Monitoring Plan.-The Administrator shall formulate and periodically revise, in cooperation with other Federal, State, or local agencies, a national plan for monitoring pesticides.

(c) MONITORING.-The Administrator shall undertake such monitoring activities, including, but not limited to monitoring in air, soil, water, man, plants, and animals, as may be necessary for the implementation of this Act and of the national pesticide monitoring plan. The Administrator shall establish procedures for the monitoring of man and animals and their environment for incidental pesticide exposure, including, but not limited to, the quantification of incidental human and environmental pesticide pollution and the secular trends thereof, and identification of the sources of contamination and their relationship to human and environmental effects. Such activities shall be carried out in cooperation with other Federal, State, and local agencies.

\section{SEC. 21. [7 U.S.C. 136s] SOLICITATION OF COMMENTS; NOTICE OF PUBLIC HEARINGS.}

(a) SECRETARY OF AGRICULTURE.-The Administrator, before publishing regulations under this Act, shall solicit the views of the Secretary of Agriculture in accordance with the procedure described in section $25(\mathrm{a})$.

(b) Secretary of Health and Human Services.-The Administrator, before publishing regulations under this Act for any public health pesticide, shall solicit the views of the Secretary of Health and Human Services in the same manner as the views of the Secretary of Agriculture are solicited under section 25(a)(2).

(c) VIEWS.-In addition to any other authority relating to public hearings and solicitation of views, in connection with the suspension or cancellation of a pesticide registration or any other actions authorized under this Act, the Administrator may, at the Administrator's discretion, solicit the views of all interested persons, either orally or in writing, and seek such advice from scientists, farmers, farm organizations, and other qualified persons as the Administrator deems proper.

(d) NOTICE.-In connection with all public hearings under this Act the Administrator shall publish timely notice of such hearings in the Federal Register.

\section{SEC. 22. [7 U.S.C. 136t] DELEGATION AND COOPERATION.}

(a) DELEGATION.-All authority vested in the Administrator by virtue of the provisions of this Act may with like force and effect be executed by such employees of the Environmental Protection Agency as the Administrator may designate for the purpose.

(b) CoOPERATION.-The Administrator shall cooperate with the Department of Agriculture, any other Federal agency, and any appropriate agency of any State or any political subdivision thereof, in carrying out the provisions of this Act, and in securing uniformity of regulations. 
SEC. 23. [7 U.S.C. 136u] STATE COOPERATION, AID, AND TRAINING. (a) CoOPERATIVE AGREEMENTS.-The Administrator may enter into cooperative agreements with States and Indian tribes-

(1) to delegate to any State or Indian tribe the authority to cooperate in the enforcement of this Act through the use of its personnel or facilities, to train personnel of the State or Indian tribe to cooperate in the enforcement of this Act, and to assist States and Indian tribes in implementing cooperative enforcement programs through grants-in-aid; and

(2) to assist States in developing and administering State programs, and Indian tribes that enter into cooperative agreements, to train and certify applicators consistent with the standards the Administrator prescribes.

Effective with the fiscal year beginning October 1, 1978, there are authorized to be appropriated annually such funds as may be necessary for the Administrator to provide through cooperative agreements an amount equal to 50 percent of the anticipated cost to each State or Indian tribe, as agreed to under such cooperative agreements, of conducting training and certification programs during such fiscal year. If funds sufficient to pay 50 percent of the costs for any year are not appropriated, the share of each State and Indian tribe shall be reduced in a like proportion in allocating available funds.

(b) ConTracts FOR TRAINING.-In addition, the Administrator may enter into contracts with Federal, State, or Indian tribal agencies for the purpose of encouraging the training of certified applicators.

(c) INFORMATION AND EDUCATION.-The Administrator shall, in cooperation with the Secretary of Agriculture, use the services of the cooperative State extension services to inform and educate pesticide users about accepted uses and other regulations made under this Act.

SEC. 24. [7 U.S.C. 136v] AUTHORITY OF STATES.

(a) IN GENERAL. - A State may regulate the sale or use of any federally registered pesticide or device in the State, but only if and to the extent the regulation does not permit any sale or use prohibited by this Act.

(b) UNIFORMITY.--Such State shall not impose or continue in effect any requirements for labeling or packaging in addition to or different from those required under this Act.

(c) ADDITIONAL USES.-

(1) A State may provide registration for additional uses of federally registered pesticides formulated for distribution and use within that State to meet special local needs in accord with the purposes of this Act and if registration for such use has not previously been denied, disapproved, or canceled by the Administrator. Such registration shall be deemed registration under section 3 for all purposes of this Act, but shall authorize distribution and use only within such State.

(2) A registration issued by a State under this subsection shall not be effective for more than ninety days if disapproved by the Administrator within that period. Prior to disapproval, the Administrator shall, except as provided in paragraph (3) of this subsection, advise the State of the Administrator's intention to disapprove and the reasons therefor, and provide the State time to respond. The Administrator shall not prohibit or 
disapprove a registration issued by a State under this subsection (A) on the basis of lack of essentiality of a pesticide or (B) except as provided in paragraph (3) of this subsection, if its composition and use patterns are similar to those of a federally registered pesticide.

(3) In no instance may a State issue a registration for a food or feed use unless there exists a tolerance or exemption under the Federal Food, Drug, and Cosmetic Act that permits the residues of the pesticide on the food or feed. If the Administrator determines that a registration issued by a State is inconsistent with the Federal Food, Drug, and Cosmetic Act, or the use of, a pesticide under a registration issued by a State constitutes an imminent hazard, the Administrator may immediately disapprove the registration.

(4) If the Administrator finds, in accordance with standards set forth in regulations issued under section 25 of this Act, that a State is not capable of exercising adequate controls to assure that State registration under this section will be in accord with the purposes of this Act or has failed to exercise adequate controls, the Administrator may suspend the authority of the State to register pesticides until such time as the Administrator is satisfied that the State can and will exercise adequate controls. Prior to any such suspension, the Administrator shall advise the State of the Administrator's intention to suspend and the reasons therefor and provide the State time to respond.

SEC. 25. [7 U.S.C. 136w] AUTHORITY OF ADMINISTRATOR.

(a) IN GENERAL.-

(1) REgULATIONs.-The Administrator is authorized in accordance with the procedure described in paragraph (2), to prescribe regulations to carry out the provisions of this Act. Such regulations shall take into account the difference in concept and usage between various classes of pesticides, including public health pesticides, and differences in environmental risk and the appropriate data for evaluating such risk between agricultural, nonagricultural, and public health pesticides.

(2) PRoCEDURE.-

(A) Proposed Regulations.-At least 60 days prior to signing any proposed regulation for publication in the Federal Register, the Administrator shall provide the Secretary of Agriculture with a copy of such regulation. If the Secretary comments in writing to the Administrator regarding any such regulation within 30 days after receiving it, the Administrator shall publish in the Federal Register (with the proposed regulation) the comments of the Secretary and the response of the Administrator with regard to the Secretary's comments. If the Secretary does not comment in writing to the Administrator regarding the regulation within 30 days after receiving it, the Administrator may sign such regulation for publication in the Federal Register any time after such 30-day period notwithstanding the foregoing 60-day time requirement.

(B) Final REgUlations.-At least 30 days prior to signing any regulation in final form for publication in the Federal Register, the Administrator shall provide the Secretary of Agriculture with a copy of such regulation. If the Secretary comments in writing to the Administrator re- 
garding any such final regulation within 15 days after receiving it, the Administrator shall publish in the Federal Register (with the final regulation) the comments of the Secretary, if requested by the Secretary, and the response of the Administrator concerning the Secretary's comments. If the Secretary does not comment in writing to the Administrator regarding the regulation within 15 days after receiving it, the Administrator may sign such regulation for publication in the Federal Register at any time after such 15-day period notwithstanding the foregoing 30-day time requirement. In taking any final action under this subsection, the Administrator shall include among those factors to be taken into account the effect of the regulation on production and prices of agricultural commodities, retail food prices, and otherwise on the agricultural economy, and the Administrator shall publish in the Federal Register an analysis of such effect.

(C) TIME REQUIREMENTS.-The time requirements imposed by subparagraphs (A) and (B) may be waived or modified to the extent agreed upon by the Administrator and the Secretary.

(D) Publication in the FEDERAL REGister.-The Administrator shall, simultaneously with any notification to the Secretary of Agriculture under this paragraph prior to the issuance of any proposed or final regulation, publish such notification in the Federal Register.

(3) Congressional COMMiTTEes.-At such time as the Administrator is required under paragraph (2) of this subsection to provide the Secretary of Agriculture with a copy of proposed regulations and a copy of the final form of regulations, the Administrator shall also furnish a copy of such regulations to the Committee on Agriculture of the House of Representatives and the Committee on Agriculture, Nutrition, and Forestry of the Senate.

(4) Congressional REviEW OF REGulations.-Simultaneously with the promulgation of any rule or regulation under this Act, the Administrator shall transmit a copy thereof to the Secretary of the Senate and the Clerk of the House of Representatives. The rule or regulation shall not become effective until the passage of 60 calendar days after the rule or regulation is so transmitted.

(b) ExEMPTION OF PESTICIDEs.-The Administrator may exempt from the requirements of this Act by regulation any pesticide which the Administrator determines either (1) to be adequately regulated by another Federal agency, or (2) to be of a character which is unnecessary to be subject to this Act in order to carry out the purposes of this Act.

(c) OTHER AUTHORITY.-The Administrator, after notice and opportunity for hearing, is authorized-

(1) to declare a pest any form of plant or animal life (other than man and other than bacteria, virus, and other micro-organisms on or in living man or other living animals) which is injurious to health or the environment;

(2) to determine any pesticide which contains any substance or substances in quantities highly toxic to man; 
(3) to establish standards (which shall be consistent with those established under the authority of the Poison Prevention Packaging Act (Public Law 91-601)) with respect to the package, container, or wrapping in which a pesticide or device is enclosed for use or consumption, in order to protect children and adults from serious injury or illness resulting from accidental ingestion or contact with pesticides or devices regulated by this Act as well as to accomplish the other purposes of this Act;

(4) to specify those classes of devices which shall be subject to any provision of paragraph $2(\mathrm{q})(1)$ or section 7 of this Act upon the Administrator's determination that application of such provision is necessary to effectuate the purposes of this Act;

(5) to prescribe regulations requiring any pesticide to be colored or discolored if the Administrator determines that such requirement is feasible and is necessary for the protection of health and the environment; and

(6) to determine and establish suitable names to be used in the ingredient statement.

(d) SCIENTIFIC ADVISORY PANEL.-

(1) IN GENERAL. - The Administrator shall submit to an advisory panel for comment as to the impact on health and the environment of the action proposed in notices of intent issued under section 6(b) and of the proposed and final form of regulations issued under section 25(a) within the same time periods as provided for the comments of the Secretary of Agriculture under such sections. The time requirements for notices of intent and proposed and final forms of regulation may not be modified or waived unless in addition to meeting the requirements of section $6(\mathrm{~b})$ or $25(\mathrm{a})$, as applicable, the advisory panel has failed to comment on the proposed action within the prescribed time period or has agreed to the modification or waiver. The Administrator shall also solicit from the advisory panel comments, evaluations, and recommendations for operating guidelines to improve the effectiveness and quality of scientific analyses made by personnel of the Environmental Protection Agency that lead to decisions by the Administrator in carrying out the provisions of this Act. The comments, evaluations, and recommendations of the advisory panel submitted under this subsection and the response of the Administrator shall be published in the Federal Register in the same manner as provided for publication of the comments of the Secretary of Agriculture under such sections. The chairman of the advisory panel, after consultation with the Administrator, may create temporary subpanels on specific projects to assist the full advisory panel in expediting and preparing its evaluations, comments, and recommendations. The subpanels may be composed of scientists other than members of the advisory panel, as deemed necessary for the purpose of evaluating scientific studies relied upon by the Administrator with respect to proposed action. Such additional scientists shall be selected by the advisory panel. The panel referred to in this subsection shall consist of 7 members appointed by the Administrator from a list of 12 nominees, 6 nominated by the National Institutes of Health and 6 by the National Science Foundation, utilizing a system of staggered terms of appointment. Members of the panel shall be selected 
on the basis of their professional qualifications to assess the effects of the impact of pesticides on health and the environment. To the extent feasible to insure multidisciplinary representation, the panel membership shall include representation from the disciplines of toxicology, pathology, environmental biology, and related sciences. If a vacancy occurs on the panel due to expiration of a term, resignation, or any other reason, each replacement shall be selected by the Administrator from a group of 4 nominees, 2 submitted by each of the nominating entities named in this subsection. The Administrator may extend the term of a panel member until the new member is appointed to fill the vacancy. If a vacancy occurs due to resignation, or reason other than expiration of a term, the Administrator shall appoint a member to serve during the unexpired term utilizing the nomination process set forth in this subsection. Should the list of nominees provided under this subsection be unsatisfactory, the Administrator may request an additional set of nominees from the nominating entities. The Administrator may require such information from the nominees to the advisory panel as the Administrator deems necessary, and the Administrator shall publish in the Federal Register the name, address, and professional affiliations of each nominee. Each member of the panel shall receive per diem compensation at a rate not in excess of that fixed for GS-18 of the General Schedule as may be determined by the Administrator, except that any such member who holds another office or position under the Federal Government the compensation for which exceeds such rate may elect to receive compensation at the rate provided for such other office or position in lieu of the compensation provided by this subsection. In order to assure the objectivity of the advisory panel, the Administrator shall promulgate regulations regarding conflicts of interest with respect to the members of the panel. The advisory panel established under this section shall be permanent. In performing the functions assigned by this Act, the panel shall consult and coordinate its activities with the Science Advisory Board established under the Environmental Research, Development, and Demonstration Authorization Act of 1978. Whenever the Administrator exercises authority under section 6(c) of this Act to immediately suspend the registration of any pesticide to prevent an imminent hazard, the Administrator shall promptly submit to the advisory panel for comment, as to the impact on health and the environment, the action taken to suspend the registration of such pesticide.

(2) SCIENCE REVIEW BOARD.-There is established a Science Review Board to consist of 60 scientists who shall be available to the Scientific Advisory Panel to assist in reviews conducted by the Panel. Members of the Board shall be selected in the same manner as members of temporary subpanels created under paragraph (1). Members of the Board shall be compensated in the same manner as members of the Panel.

(e) PEER REVIEW.- The Administrator shall, by written procedures, provide for peer review with respect to the design, protocols, and conduct of major scientific studies conducted under this Act by the Environmental Protection Agency or by any other Federal agency, any State or political subdivision thereof, or any institution or 
with the Environmental Protection Agency. In such procedures, the Administrator shall also provide for peer review, using the advisory panel established under subsection (d) of this section or appropriate experts appointed by the Administrator from a current list of nominees maintained by such panel, with respect to the results of any such scientific studies relied upon by the Administrator with respect to actions the Administrator may take relating to the change in classification, suspension, or cancellation of a pesticide. Whenever the Administrator determines that circumstances do not permit the peer review of the results of any such scientific study prior to the Administrator's exercising authority under section 6(c) of this Act to immediately suspend the registration of any pesticide to prevent an imminent hazard, the Administrator shall promptly thereafter provide for the conduct of peer review as provided in this sentence. The evaluations and relevant documentation constituting the peer review that relate to the proposed scientific studies and the results of the completed scientific studies shall be included in the submission for comment forwarded by the Administrator to the advisory panel as provided in subsection (d). As used in this subsection, the term "peer review" shall mean an independent evaluation by scientific experts, either within or outside the Environmental Protection Agency, in the appropriate disciplines.

\section{SEC. 26. [7 U.S.C. 136w-1] STATE PRIMARY ENFORCEMENT RESPON-} SIBILITY.

(a) In GENERAL.-For the purposes of this Act, a State shall have primary enforcement responsibility for pesticide use violations during any period for which the Administrator determines that such State-

(1) has adopted adequate pesticide use laws and regulations, except that the Administrator may not require a State to have pesticide use laws that are more stringent than this Act;

(2) has adopted and is implementing adequate procedures for the enforcement of such State laws and regulations; and

(3) will keep such records and make such reports showing compliance with paragraphs (1) and (2) of this subsection as the Administrator may require by regulation.

(b) SPECIAL RULES.-Notwithstanding the provisions of subsection (a) of this section, any State that enters into a cooperative agreement with the Administrator under section 23 of this Act for the enforcement of pesticide use restrictions shall have the primary enforcement responsibility for pesticide use violations. Any State that has a plan approved by the Administrator in accordance with the requirements of section 11 of this Act that the Administrator determines meets the criteria set out in subsection (a) of this section shall have the primary enforcement responsibility for pesticide use violations. The Administrator shall make such determinations with respect to State plans under section 11 of this Act in effect on the date of enactment of the Federal Pesticide Act of 1978 [September 30,1978] not later than six months after that date.

(c) ADMINISTRATOR.-The Administrator shall have primary enforcement responsibility for those States that do not have primary enforcement responsibility under this Act. Notwithstanding the provisions of section 2(e)(1) of this Act, during any period when the Administrator has such enforcement responsibility, section 8(b) of this Act shall apply to the books and records of commercial applicators and to any applicator who holds or applies pesticides, or uses dilu- 
tions of pesticides, only to provide a service of controlling pests without delivering any unapplied pesticide to any person so served, and section 9(a) of this Act shall apply to the establishment or other place where pesticides or devices are held for application by such persons with respect to pesticides or devices held for such application.

SEC. 27. [7 U.S.C. 136w-2] FAILURE BY THE STATE TO ASSURE ENFORCEMENT OF STATE PESTICIDE USE REGULATIONS.

(a) REFERRAL.-Upon receipt of any complaint or other information alleging or indicating a significant violation of the pesticide use provisions of this Act, the Administrator shall refer the matter to the appropriate State officials for their investigation of the matter consistent with the requirements of this Act. If, within thirty days, the State has not commenced appropriate enforcement action, the Administrator may act upon the complaint or information to the extent authorized under this Act.

(b) NoTICE.-Whenever the Administrator determines that a State having primary enforcement responsibility for pesticide use violations is not carrying out (or cannot carry out due to the lack of adequate legal authority) such responsibility, the Administrator shall notify the State. Such notice shall specify those aspects of the administration of the State program that are determined to be inadequate. The State shall have ninety days after receipt of the notice to correct any deficiencies. If after that time the Administrator determines that the State program remains inadequate, the Administrator may rescind, in whole or in part, the State's primary enforcement responsibility for pesticide use violations.

(c) Construction.--Neither section 26 of this Act nor this section shall limit the authority of the Administrator to enforce this Act, where the Administrator determines that emergency conditions exist that require immediate action on the part of the Administrator and the State authority is unwilling or unable adequately to respond to the emergency.

SEC. 28. [7 U.S.C. 136w-3] IDENTIFICATION OF PESTS; COOPERATION WITH DEPARTMENT OF AGRICULTURE'S PROGRAM.

(a) IN GENERAL.-The Administrator, in coordination with the Secretary of Agriculture, shall identify those pests that must be brought under control. The Administrator shall also coordinate and cooperate with the Secretary of Agriculture's research and implementation programs to develop and improve the safe use and effectiveness of chemical, biological, and alternative methods to combat and control pests that reduce the quality and economical production and distribution of agricultural products to domestic and foreign consumers.

(b) Pest Control Availability.-

(1) IN GENERAL.-The Administrator, in cooperation with the Secretary of Agriculture, shall identify-

(A) available methods of pest control by crop or animal;

(B) minor pest control problems, both in minor crops and minor or localized problems in major crops; and

(C) factors limiting the availability of specific pest control methods, such as resistance to control methods and regulatory actions limiting the availability of control methods.

(2) REPORT.-The Secretary of Agriculture shall, not later 
[November 28, 1990] and annually thereafter, prepare a report and send the report to the Administrator. The report shall-

(A) contain the information described in paragraph (1) and the information required by section 1651 of the Food, Agriculture, Conservation, and Trade Act of 1990;

(B) identify the crucial pest control needs where a shortage of control methods is indicated by the information described in paragraph (1); and

(C) describe in detail research and extension efforts designed to address the needs identified in subparagraph (B).

(c) Integrated Pest MANAGEMent.-The Administrator, in cooperation with the Secretary of Agriculture, shall develop approaches to the control of pests based on integrated pest management that respond to the needs of producers, with a special emphasis on minor pests.

(d) Public Health Pests.-The Administrator, in coordination with the Secretary of Agriculture and the Secretary of Health and Human Services, shall identify pests of significant public health importance and, in coordination with the Public Health Service, develop and implement programs to improve and facilitate the safe and necessary use of chemical, biological, and other methods to combat and control such pests of public health importance.

SEC. 29. [7 U.S.C. 136w-4] ANNUAL REPORT.

The Administrator shall submit an annual report to Congress before February 16 of each year and the first report shall be due February 15, 1979. The report shall include the total number of applications for conditional registration under sections 3(c)(7)(B) and $3(\mathrm{c})(7)(\mathrm{C})$ of this Act that were filed during the immediately preceding fiscal year, and, with respect to those applications approved, the Administrator shall report the Administrator's findings in each case, the conditions imposed and any modification of such conditions in each case, and the quantities produced of such pesticides.

SEC. 30. [7 U.S.C. 136w-5] MINIMUM REQUIREMENTS FOR TRAINING OF MAINTENANCE APPLICATORS AND SERVICE TECHNICIANS.

Each State may establish minimum requirements for training of maintenance applicators and service technicians. Such training may include instruction in the safe and effective handling and use of pesticides in accordance with the Environmental Protection Agency approved labeling, and instruction in integrated pest management techniques. The authority of the Administrator with respect to minimum requirements for training of maintenance applicators and service technicians shall be limited to ensuring that each State understands the provisions of this section.

SEC. 31. [7 U.S.C. 136w-6] ENVIRONMENTAL PROTECTION AGENCY MINOR USE PROGRAM.

(a) The Administrator shall assure coordination of minor use issues through the establishment of a minor use program within the Office of Pesticide Programs. Such office shall be responsible for coordinating the development of minor use programs and policies and consulting with growers regarding minor use issues and registrations and amendments which are submitted to the Environmental Protection Agency.

(b) The Office of Pesticide Programs shall prepare a public report concerning the progress made on the registration of minor uses, including implementation of the exclusive use as an incentive 
for registering new minor uses, within 3 years of the passage of the Food Quality Protection Act of 1996. [Aug. 3, 1996]

SEC. 32. [7 U.S.C. 136w-7] DEPARTMENT OF AGRICULTURE MINOR USE PROGRAM.

(a) IN GENERAL.-The Secretary of Agriculture (hereinafter in this section referred to as the "Secretary") shall assure the coordination of the responsibilities of the Department of Agriculture related to minor uses of pesticides, including-

(1) carrying out the Inter-Regional Project Number 4 (IR4) as described in section 2 of Public Law 89-106 (7 U.S.C. $450 \mathrm{i}(\mathrm{e}))$ and the national pesticide resistance monitoring program established under section 1651 of the Food, Agriculture, Conservation, and Trade Act of 1990 (7 U.S.C. 5882);

(2) supporting integrated pest management research;

(3) consulting with growers to develop data for minor uses; and

(4) providing assistance for minor use registrations, tolerances, and reregistrations with the Environmental Protection Agency.

(b)(1) Minor Use Pesticide Data.-

(A) GRANT AUTHORITY.-The Secretary, in consultation with the Administrator, shall establish a program to make grants for the development of data to support minor use pesticide registrations and reregistrations. The amount of any such grant shall not exceed $1 / 2$ of the cost of the project for which the grant is made.

(B) APPLICANTS.-Any person who wants to develop data to support minor use pesticide registrations and reregistrations may apply for a grant under subparagraph (A). Priority shall be given to an applicant for such a grant who does not directly receive funds from the sale of pesticides registered for minor uses.

(C) DATA OWNERSHIP.-Any data that is developed under a grant under subparagraph (A) shall be jointly owned by the Department of Agriculture and the person who received the grant. Such a person shall enter into an agreement with the Secretary under which such person shall share any fee paid to such person under section $3(\mathrm{c})(1)(\mathrm{F})$.

(2) Minor Use Pesticide Data Revolving Fund.-

(A) Establishment.-There is established in the Treasury of the United States a revolving fund to be known as the Minor Use Pesticide Data Revolving Fund. The Fund shall be available without fiscal year limitation to carry out the authorized purposes of this subsection.

(B) CONTENTS OF THE FUND.-There shall be deposited in the Fund-

(i) such amounts as may be appropriated to support the purposes of this subsection; and

(ii) fees collected by the Secretary for any data developed under a grant under paragraph (1)(A).

(C) AUTHORIZATIONS OF APPROPRIATIONS.-There are authorized to be appropriated for each fiscal year to carry out the purposes of this subsection $\$ 10,000,000$ to remain available until expended. 
SEC. 33. [7 U.S.C. 136w-8] PESTICIDE REGISTRATION SERVICE FEES.

(a) DEFINITION OF COSTS.-In this section, the term "costs", when used with respect to review and decisionmaking pertaining to an application for which registration service fees are paid under this section, means-

(1) costs to the extent that-

(A) officers and employees provide direct support for the review and decisionmaking for covered pesticide applications, associated tolerances, and corresponding risk and benefits information and analyses;

(B) persons and organizations under contract with the Administrator engage in the review of the applications, and corresponding risk and benefits information and assessments; and

(C) advisory committees and other accredited persons or organizations, on the request of the Administrator, engage in the peer review of risk or benefits information associated with covered pesticide applications;

(2) costs of management of information, and the acquisition, maintenance, and repair of computer and telecommunication resources (including software), used to support review of pesticide applications, associated tolerances, and corresponding risk and benefits information and analyses; and

(3) costs of collecting registration service fees under subsections (b) and (c) and reporting, auditing, and accounting under this section.

(b) FEes.-

(1) IN GENERAL.-Effective beginning on the effective date of the Pesticide Registration Improvement Act of 2003, the Administrator shall assess and collect covered pesticide registration service fees in accordance with this section.

(2) COVERED PESTICIDE REGISTRATION APPLICATIONS.-

(A) IN GENERAL.-An application for the registration of a pesticide covered by this Act that is received by the Administrator on or after the effective date of the Pesticide Registration Improvement Act of 2003 shall be subject to a registration service fee under this section.

(B) EXISTING APPLICATIONS.-

(i) IN GENERAL.- Subject to clause (ii), an application for the registration of a pesticide that was submitted to the Administrator before the effective date of the Pesticide Registration Improvement Act of 2003 and is pending on that effective date shall be subject to a service fee under this section if the application is for the registration of a new active ingredient that is not listed in the Registration Division 2003 Work Plan of the Office of Pesticide Programs of the Environmental Protection Agency.

(ii) TOLERANCE OR EXEMPTION FEES.-The amount of any fee otherwise payable for an application described in clause (i) under this section shall be reduced by the amount of any fees paid to support the related petition for a pesticide tolerance or exemption under the Federal Food, Drug, and Cosmetic Act (21 U.S.C. 301 et seq.). 
(C) Documentation.-An application subject to a registration service fee under this section shall be submitted with documentation certifying-

(i) payment of the registration service fee; or

(ii) payment of at least 25 percent of the registration service fee and a request for a waiver from or reduction of the remaining amount of the registration service fee.

(D) PAYMENT.-The registration service fee required under this subsection shall be due upon submission of the application.

(E) APPLICATIONS SUBJECT TO ADDITIONAL FEES.-An application may be subject to additional fees if-

(i) the applicant identified the incorrect registration service fee and decision review period;

(ii) after review of a waiver request, the Administrator denies the waiver request; or

(iii) after review of the application, the Administrator determines that a different registration service fee and decision review period apply to the application. (F) EFFECT OF FAILURE TO PAY FEES.-The Administrator shall reject any application submitted without the required registration service fee.

(G) NON-REFUNDABLE PORTION OF FEES.-

(i) IN GENERAL.-The Administrator shall retain 25 percent of the applicable registration service fee.

(ii) LIMITATION.-Any waiver, refund, credit or other reduction in the registration service fee shall not exceed 75 percent of the registration service fee.

(H) COLLECTION OF UNPAID FEES.-In any case in which the Administrator does not receive payment of a registration service fee (or applicable portion of the registration service fee) by the date that is 30 days after the fee is due, the fee shall be treated as a claim of the United States Government subject to subchapter II of chapter 37 of title 31, United States Code.

(3) SCHEDULE OF COVERED APPLICATIONS AND REGISTRATION SERVICE FEES.-

(A) IN GENERAL.-Not later than 30 days after the effective date of the Pesticide Registration Improvement Renewal Act, the Administrator shall publish in the Federal Register a schedule of covered pesticide registration applications and corresponding registration service fees.

(B) REPORT.-Subject to paragraph (6), the schedule shall be the same as the applicable schedule appearing in the Congressional Record on pages S10409 through S10411, dated July 31, 2007.

(4) PENDing PESTICIDE REGisTRATION APPLiCATIONS.-

(A) IN GENERAL.-An applicant that submitted a registration application to the Administrator before the effective date of the Pesticide Registration Improvement Act of 2003 , but that is not required to pay a registration service fee under paragraph (2)(B), may, on a voluntary basis, pay a registration service fee in accordance with paragraph (2)(B). 
(B) VoluntaRY FEe.-The Administrator may not compel payment of a registration service fee for an application described in subparagraph (A).

(C) Documentation.-An application for which a voluntary registration service fee is paid under this paragraph shall be submitted with documentation certifying-

(i) payment of the registration service fee; or

(ii) a request for a waiver from or reduction of the registration service fee.

(5) RESUBMISSION OF PESTICIDE REGISTRATION APPLICATIONS.-If a pesticide registration application is submitted by a person that paid the fee for the application under paragraph (2), is determined by the Administrator to be complete, and is not approved or is withdrawn (without a waiver or refund), the submission of the same pesticide registration application by the same person (or a licensee, assignee, or successor of the person) shall not be subject to a fee under paragraph (2).

(6) FEE ADJUSTMENT.-

(A) IN GENERAL.-Effective for a covered pesticide registration application received during the period beginning on October 1, 2008, and ending on September 30, 2010, the Administrator shall increase by 5 percent the registration service fee payable for the application under paragraph (3).

(B) ADDITIONAL ADJUSTMENT.-Effective for a covered pesticide registration application received on or after October 1, 2010, the Administrator shall increase by an additional 5 percent the registration service fee in effect as of September 30, 2010.

(C) Publication.- The Administrator shall publish in the Federal Register the revised registration service fee schedules.

(7) WAIVERS AND REDUCTIONS.-

(A) IN GENERAL.-An applicant for a covered pesticide registration may request the Administrator to waive or reduce the amount of a registration service fee payable under this section under the circumstances described in subparagraphs (D) through (G).

(B) Documentation.-

(i) IN GENERAL.-A request for a waiver from or reduction of the registration service fee shall be accompanied by appropriate documentation demonstrating the basis for the waiver or reduction.

(ii) CERTIFICATION.-The applicant shall provide to the Administrator a written certification, signed by a responsible officer, that the documentation submitted to support the waiver or reduction request is accurate.

(iii) INACCURATE DOCUMENTATION.-An application shall be subject to the applicable registration service fee payable under paragraph (3) if, at any time, the Administrator determines that-

(I) the documentation supporting the waiver or reduction request is not accurate; or

(II) based on the documentation or any other information, the waiver or reduction should not have been granted or should not be granted. 
(C) Determination to GRANT OR DENY REQUEST.-As soon as practicable, but not later than 60 days, after the date on which the Administrator receives a request for a waiver or reduction of a registration service fee under this paragraph, the Administrator shall-

(i) determine whether to grant or deny the request; and

(ii) notify the applicant of the determination.

(D) MinOR USES.-

(i) IN GENERAL.-The Administrator may exempt from, or waive a portion of, the registration service fee for an application for minor uses for a pesticide.

(ii) SUPPORTING DOCUMENTATION.-An applicant requesting a waiver or exemption under this subparagraph shall provide supporting documentation that demonstrates, to the satisfaction of the Administrator, that anticipated revenues from the uses that are the subject of the application would be insufficient to justify imposition of the full application fee.

(E) IR-4 EXEMPTION.-The Administrator shall exempt an application from the registration service fee if the Administrator determines that-

(i) the application is solely associated with a tolerance petition submitted in connection with the InterRegional Project Number 4 (IR-4) as described in section 2 of Public Law 89-106 (7 U.S.C. 450i(e)); and

(ii) the exemption is in the public interest.

(F) SMALL BUSINESSES.-

(i) IN GENERAL.-The Administrator shall waive 50 percent of the registration service fees payable by an entity for a covered pesticide registration application under this section if the entity is a small business (as defined in section $4(\mathrm{i})(5)(\mathrm{E})(\mathrm{ii})$ ) at the time of application.

(ii) WAIVER OF FEES.-The Administrator shall waive 75 percent of the registration service fees payable by an entity under this section if the entity-

(I) is a small business (as defined in section $4(\mathrm{i})(5)(\mathrm{E})(\mathrm{ii}))$ at the time of application; and

(II) has average annual global gross revenues described in section $4(\mathrm{i})(5)(\mathrm{E})(\mathrm{ii})(\mathrm{I})(\mathrm{bb})$ that does not exceed $\$ 10,000,000$, at the time of application.

(iii) FORMATION FOR WAIVER.-The Administrator shall not grant a waiver under this subparagraph if the Administrator determines that the entity submitting the application has been formed or manipulated primarily for the purpose of qualifying for the waiver.

(iv) DoCUMENTATION.-An entity requesting a waiver under this subparagraph shall provide to the Administrator-

(I) documentation demonstrating that the entity is a small business (as defined in section $4(\mathrm{i})(5)(\mathrm{E})(\mathrm{ii}))$ at the time of application; and 
(II) if the entity is requesting a waiver of 75 percent of the applicable. ${ }^{33-1}$ registration service fees payable under this section, documentation demonstrating that the entity has an average annual global gross revenues described in section $4(\mathrm{i})(5)(\mathrm{E})(\mathrm{ii})(\mathrm{I})(\mathrm{bb})$ that does not exceed $\$ 10,000,000$, at the time of application.

(G) FEDERAL AND STATE AGENCY EXEMPTIONS.-An agency of the Federal Government or a State government shall be exempt from covered registration service fees under this section.

(8) REFUNDS.-

(A) EARLY WITHDRAWALS.-If, during the first 60 days after the beginning of the applicable decision time review period under subsection (f)(3), a covered pesticide registration application is withdrawn by the applicant, the Administrator shall refund all but 25 percent of the total registration service fee payable under paragraph (3) for the application.

(B) WITHDRAWALS AFTER THE FIRST 60 DAYS OF DECISION REVIEW TIME PERIOD.-

(i) IN GENERAL.- If a covered pesticide registration application is withdrawn after the first 60 days of the applicable decision time review period, the Administrator shall determine what portion, if any, of the total registration service fee payable under paragraph (3) for the application may be refunded based on the proportion of the work completed at the time of withdrawal.

(ii) TIMING.-The Administrator shall-

(I) make the determination described in clause

(i) not later than 90 days after the date the application is withdrawn; and

(II) provide any refund as soon as practicable after the determination.

(C) DISCRETIONARY REFUNDS.-

(i) IN GENERAL. - In the case of a pesticide registration application that has been filed with the Administrator and has not been withdrawn by the applicant, but for which the Administrator has not yet made a final determination, the Administrator may refund a portion of a covered registration service fee if the Administrator determines that the refund is justified.

(ii) BASIS.- The Administrator may provide a refund for an application under this subparagraph-

(I) on the basis that, in reviewing the application, the Administrator has considered data submitted in support of another pesticide registration application; or

(II) on the basis that the Administrator completed portions of the review of the application before the effective date of this section.

(D) CREDITED FEES.-In determining whether to grant a refund under this paragraph, the Administrator shall

${ }^{33-1}$ So in original (as amended by sec. 5(c)(2) of Public Law 110-94). Probably should strike the period. 
take into account any portion of the registration service fees credited under paragraph (2) or (4).

(c) PEsticide Registration Fund.-

(1) EstaBlishmENT.-There is established in the Treasury of the United States a Pesticide Registration Fund to be used in carrying out this section (referred to in this section as the "Fund"), consisting of-

(A) such amounts as are deposited in the Fund under paragraph (2);

(B) any interest earned on investment of amounts in the Fund under paragraph (5); and

(C) any proceeds from the sale or redemption of investments held in the Fund.

(2) DePOSITS IN FUND.-Subject to paragraph (4), the Administrator shall deposit fees collected under this section in the Fund.

(3) EXPENDITURES FROM FUND.-

(A) IN GENERAL. - Subject to subparagraphs (B) and (C) and paragraph (4), the Administrator may make expenditures from the Fund-

(i) to cover the costs associated with the review and decisionmaking pertaining to all applications for which registration service fees have been paid under this section; and

(ii) to otherwise carry out this section.

(B) WORKER PROTECTION.-

(i) IN GENERAL.-For each of fiscal years 2008 through 2012, the Administrator shall use approximately $1 / 17$ of the amount in the Fund (but not less than $\$ 1,000,000)$ to enhance scientific and regulatory activities relating to worker protection.

(ii) PARTNERSHIP GRANTS.-Of the amounts in the Fund, the Administrator shall use for partnership grants-

(I) for each of fiscal years 2008 and 2009, $\$ 750,000$; and

(II) for each of fiscal years 2010 through 2012, $\$ 500,000$.

(iii) Pesticide SAFETy EDUCATION PROGRAM.-Of the amounts in the Fund, the Administrator shall use $\$ 500,000$ for each of fiscal years 2008 through 2012 to carry out the pesticide safety education program.

(4) Collections AND APPROPRIATIONS ACTS.- The fees authorized by this section and amounts deposited in the Fund(A) shall be collected and made available for obligation only to the extent provided in advance in appropriations Acts; and

(B) shall be available without fiscal year limitation.

(5) UNUSED FUNDS.-

(A) IN GENERAL.-Amounts in the Fund not currently needed to carry out this section shall be-

(i) ${ }^{33-2}$ maintained readily available or on deposit;

(ii) invested in obligations of the United States or guaranteed by the United States; or

${ }^{33-2}$ Indentation of clauses (i) through (iii) is so in original (as amended by sec. 5(e)(3)(A) 
(iii) invested in obligations, participations, or other instruments that are lawful investments for fiduciary, trust, or public funds.

(B) USE OF INVESTMENT INCOME.-After consultation with the Secretary of the Treasury, the Administrator may use income from investments described in clauses (ii) and (iii) of subparagraph (A) to carry out this section.

(d) Assessment of FeEs.-

(1) DEFINITION OF COVERED FUNCTIONS.-In this subsection, the term "covered functions" means functions of the Office of Pesticide Programs of the Environmental Protection Agency, as identified in key programs and projects of the final operating plan for the Environmental Protection Agency submitted as part of the budget process for fiscal year 2002, regardless of any subsequent transfer of 1 or more of the functions to another office or agency or the subsequent transfer of a new function to the Office of Pesticide Programs.

(2) MINIMUM AMOUNT OF APPROPRIATIONS.-Registration service fees may not be assessed for a fiscal year under this section unless the amount of appropriations for salaries, contracts, and expenses for the functions (as in existence in fiscal year 2002) of the Office of Pesticide Programs of the Environmental Protection Agency for the fiscal year (excluding the amount of any fees appropriated for the fiscal year) are equal to or greater than the amount of appropriations for covered functions for fiscal year 2002 (excluding the amount of any fees appropriated for the fiscal year).

(3) USE OF FEES.-Registration service fees authorized by this section shall be available, in the aggregate, only to defray increase in the costs associated with the review and decisionmaking for the review of pesticide registration applications and associated tolerances (including increases in the number of fulltime equivalent positions in the Environmental Protection Agency engaged in those activities) over the costs for fiscal year 2002, excluding costs paid from fees appropriated for the fiscal year.

(4) COMPLIANCE.-The requirements of paragraph (2) shall have been considered to have been met for any fiscal year if the amount of appropriations for salaries, contracts, and expenses for the functions (as in existence in fiscal year 2002) of the Office of Pesticide Programs of the Environmental Protection Agency for the fiscal year (excluding the amount of any fees appropriated for the fiscal year) is not more than 3 percent below the amount of appropriations for covered functions for fiscal year 2002 (excluding the amount of any fees appropriated for the fiscal year).

(5) SubSEquent AUTHORITY.-If the Administrator does not assess registration service fees under subsection (b) during any portion of a fiscal year as the result of paragraph (2) and is subsequently permitted to assess the fees under subsection (b) during the fiscal year, the Administrator shall assess and collect the fees, without any modification in rate, at any time during the fiscal year, notwithstanding any provisions of subsection (b) relating to the date fees are to be paid.

(e) Reforms to Reduce Decision Time Review Periods.-To

the maximum extent practicable consistent with the degrees of risk 
presented by pesticides and the type of review appropriate to evaluate risks, the Administrator shall identify and evaluate reforms to the pesticide registration process under this Act with the goal of reducing decision review periods in effect on the effective date of the Pesticide Registration Improvement Act of 2003 for pesticide registration actions for covered pesticide registration applications (including reduced risk applications).

(f) Decision Time Review Periods.-

(1) IN GENERAL.-Not later than 30 days after the effective date of the Pesticide Registration Improvement Renewal Act, the Administrator shall publish in the Federal Register a schedule of decision review periods for covered pesticide registration actions and corresponding registration service fees under this Act.

(2) REPORT.-The schedule shall be the same as the applicable schedule appearing in the Congressional Record on pages S10409 through S10411, dated July 31, 2007.

(3) APPLICATIONS SUBJECT TO DECISION TIME REVIEW PERIODS.-The decision time review periods specified in paragraph (1) shall apply to-

(A) covered pesticide registration applications subject to registration service fees under subsection $(b)(2)$;

(B) covered pesticide registration applications for which an applicant has voluntarily paid registration service fees under subsection (b)(4); and

(C) covered pesticide registration applications listed in the Registration Division 2003 Work Plan of the Office of Pesticide Programs of the Environmental Protection Agency.

(4) StART OF DECISION TIME REVIEW PERIOD.-

(A) IN GENERAL.-Except as provided in subparagraphs (C), (D), and (E), in the case of a pesticide registration application accompanied by the registration service fee required under this section, the decision time review period begins 21 days after the date on which the Administrator receives the covered pesticide registration application.

(B) COMPLETENESS OF APPLICATION.-

(i) IN GENERAL.-Not later than 21 days after receiving an application and the required registration service fee, the Administrator shall conduct an initial screening of the contents of the application in accordance with clause (iii).

(ii) REJECTION.-If the Administrator determines under clause (i) that the application does not pass the initial screening and cannot be corrected within the 21day period, the Administrator shall reject the application not later than 10 days after making the determination.

(iii) REQUIREMENTS OF SCREENING.-In conducting an initial screening of an application, the Administrator shall determine whether-

(I)(aa) the applicable registration service fee has been paid; or

(bb) at least 25 percent of the applicable registration service fee has been paid and the application contains a waiver or refund request for the 
outstanding amount and documentation establishing the basis for the waiver request; and

(II) the application contains all the necessary forms, data, and draft labeling, formatted in accordance with guidance published by the Administrator.

(C) APPLICATIONS WITH WAIVER OR REDUCTION REQUESTS.-

(i) IN GENERAL.- In the case of an application submitted with a request for a waiver or reduction of registration service fees under subsection (b)(7), the decision time review period shall be determined in accordance with this subparagraph.

(ii) REQUEST GRANTED WITH NO ADDITIONAL FEES REQUIRED.-If the Administrator grants the waiver or reduction request and no additional fee is required, the decision time review period begins on the earlier of-

(I) the date on which the Administrator grants the request; or

(II) the date that is 60 days after the date of receipt of the application.

(iii) REQUEST GRANTED WITH ADDITIONAL FEES REQUIRED.-If the Administrator grants the waiver or reduction request, in whole or in part, but an additional registration service fee is required, the decision time review period begins on the date on which the Administrator receives certification of payment of the applicable registration service fee.

(iv) REQUEST DENIED.-If the Administrator denies the waiver or reduction request, the decision time review period begins on the date on which the Administrator receives certification of payment of the applicable registration service fee.

(D) PENDING APPLICATIONS.-

(i) IN GENERAL.-The start of the decision time review period for applications described in clause (ii) shall be the date on which the Administrator receives certification of payment of the applicable registration service fee.

(ii) Applications.-Clause (i) applies to-

(I) covered pesticide registration applications for which voluntary fees have been paid under subsection (b)(4); and

(II) covered pesticide registration applications received on or after the effective date of the Pesticide Registration Improvement Act of 2003 but submitted without the applicable registration service fee required under this section due to the inability of the Administrator to assess fees under subsection $(d)(1)$.

(E) 2003 WORK PLAN.-In the case of a covered pesticide registration application listed in the Registration Division 2003 Work Plan of the Office of Pesticide Programs of the Environmental Protection Agency, the decision time review period begins on the date that is 30 days after the 
effective date of the Pesticide Registration Improvement Act of 2003.

(5) EXTENSION OF DECISION TIME REVIEW PERIOD.-The Administrator and the applicant may mutually agree in writing to extend a decision time review period under this subsection.

(g) JUDiCIAL REVIEW.-

(1) IN GENERAL.-Any applicant adversely affected by the failure of the Administrator to make a determination on the application of the applicant for registration of a new active ingredient or new use for which a registration service fee is paid under this section may obtain judicial review of the failure solely under this section.

(2) SCOPE.-

(A) IN GENERAL.-In an action brought under this subsection, the only issue on review is whether the Administrator failed to make a determination on the application specified in paragraph (1) by the end of the applicable decision time review period required under subsection (f) for the application.

(B) OTHER ACTIONS.-No other action authorized or required under this section shall be judicially reviewable by a Federal or State court.

(3) TIMING.-

(A) IN GENERAL.-A person may not obtain judicial review of the failure of the Administrator to make a determination on the application specified in paragraph (1) before the expiration of the 2-year period that begins on the date on which the decision time review period for the application ends.

(B) Meeting with administrator.-To be eligible to seek judicial review under this subsection, a person seeking the review shall first request in writing, at least 120 days before filing the complaint for judicial review, a decision review meeting with the Administrator.

(4) REMEDIES.-The Administrator may not be required or permitted to refund any portion of a registration service fee paid in response to a complaint that the Administrator has failed to make a determination on the covered pesticide registration application specified in paragraph (1) by the end of the applicable decision review period.

(h) ACCOUnTING.-The Administrator shall-

(1) provide an annual accounting of the registration service fees paid to the Administrator and disbursed from the Fund, by providing financial statements in accordance with-

(A) the Chief Financial Officers Act of 1990 (Public Law 101-576; 104 Stat. 2838) and amendments made by that Act; and

(B) the Government Management Reform Act of 1994

(Public Law 103-356; 108 Stat. 3410) and amendments made by that Act;

(2) provide an accounting describing expenditures from the Fund authorized under subsection (c); and

(3) provide an annual accounting describing collections and expenditures authorized under subsection (d). 
(1) Financial statements of Agencies.-For the purpose of section 3515(c) of title 31, United States Code, the Fund shall be considered a component of an executive agency.

(2) ComponEnTs.-The annual audit required under sections 3515(b) and 3521 of that title of the financial statements of activities under this section shall include an analysis of -

(A) the fees collected under subsection (b) and disbursed;

(B) compliance with subsection (f);

(C) the amount appropriated to meet the requirements of subsection $(\mathrm{d})(1)$; and

(D) the reasonableness of the allocation of the overhead allocation of costs associated with the review and decisionmaking pertaining to applications under this section. (3) INSPECTOR GENERAL.-The Inspector General of the Environmental Protection Agency shall-

(A) conduct the annual audit required under this subsection; and

(B) report the findings and recommendations of the audit to the Administrator and to the appropriate committees of Congress.

(j) Personnel Levels.-All full-time equivalent positions supported by fees authorized and collected under this section shall not be counted against the agency-wide personnel level goals of the Environmental Protection Agency.

(k) REPORTS.-

(1) IN GENERAL.-Not later than March 1, 2005, and each March 1 thereafter through March 1, 2014, the Administrator shall publish an annual report describing actions taken under this section.

(2) Contents.-The report shall include-

(A) a review of the progress made in carrying out each requirement of subsections (e) and (f), including-

(i) the number of applications reviewed, including the decision times for each application specified in subsection (f);

(ii) the number of label amendments that have been reviewed using electronic means;

(iii) the amount of money from the Reregistration and Expedited Processing Fund used to carry out inert ingredient review and review of similar applications under section $4(\mathrm{k})(3)$;

(iv) the number of applications completed for identical or substantially similar applications under section $3(\mathrm{c})(3)(\mathrm{B})$, including the number of such applications completed within 90 days pursuant to that section;

(v) the number of actions pending in each category of actions described in subsection (f)(3), as well as the number of inert ingredients;

(vi) to the extent determined appropriate by the Administrator and consistent with the authorities of the Administrator and limitations on delegation of functions by the Administrator, recommendations for-

(I) expanding the use of self-certification in all 
(II) providing for accreditation of outside reviewers and the use of outside reviewers to conduct the review of major portions of applications;

(III) reviewing the scope of use of the notification process to cover broader categories of registration actions;

(IV) providing for electronic submission and review of labels, including process improvements to further enhance the procedures used in electronic label review; and

(V) the allowance and use of summaries of acute toxicity studies; and

(vii) the use of performance-based contracts, other contracts, and procurement to ensure that-

(I) the goals of this Act for the timely review of applications for registration are met; and

(II) the registration program is administered in the most productive and cost effective manner practicable;

(B) a description of the staffing and resources relating to the costs associated with the review and decisionmaking pertaining to applications;

(C) a review of the progress in meeting the timeline requirements of section $4(\mathrm{~g})$;

(D) a review of the progress in carrying out section $3(\mathrm{~g})$, includingviewed;

(i) the number of pesticides or pesticide cases re-

(ii) a description of the staffing and resources relating to the costs associated with the review and decision making relating to reregistration and registration review for compliance with the deadlines specified in this Act;

(iii) to the extent determined appropriate by the Administrator and consistent with the authorities of the Administrator and limitations on delegation of functions by the Administrator, recommendations for-

(I) process improvements in the handling of registration review under section $3(\mathrm{~g})$;

(II) providing for accreditation of outside reviewers and the use of outside reviewers in the registration review process; and

(III) streamlining the registration review process, consistent with section $3(\mathrm{~g})$;

(E) a review of the progress in meeting the timeline requirements for the review of antimicrobial pesticide products under section $3(\mathrm{~h})$; and

(F) a review of the progress in carrying out the review of inert ingredients, including the number of applications pending, the number of new applications, the number of applications reviewed, staffing, and resources devoted to the review of inert ingredients and recommendations to improve the timeliness of review of inert ingredients.

(3) METHOD.-The Administrator shall publish a report required by this subsection by such method as the Administrator determines to be the most effective for efficiently disseminating 
the report, including publication of the report on the Internet site of the Environmental Protection Agency.

(1) SAVINGS ClaUSE.-Nothing in this section affects any other duties, obligations, or authorities established by any other section of this Act, including the right to judicial review of duties, obligations, or authorities established by any other section of this Act.

(m) TERMINATION OF EFFECTIVENESS.-

(1) IN GENERAL.-Except as provided in paragraph (2), the authority provided by this section terminates on September 30, 2012.

(2) PHASE OUT.-

(A) FISCAL YEAR 2013.-During fiscal year 2013, the requirement to pay and collect registration service fees applies, except that the level of registration service fees payable under this section shall be reduced 40 percent below the level in effect on September 30, 2012.

(B) FISCAL YEAR 2014.-During fiscal year 2014, the requirement to pay and collect registration service fees applies, except that the level of registration service fees payable under this section shall be reduced 70 percent below the level in effect on September 30, 2012.

(C) SEPTEMBER 30, 2014.--Effective September 30, 2014, the requirement to pay and collect registration service fees terminates.

(D) DECISION REVIEW PERIODS.-

(i) PENDING APPLICATIONS.-In the case of an application received under this section before September 30,2012 , the application shall be reviewed in accordance with subsection (f).

(ii) NEW APPLICATIONS.-In the case of an application received under this section on or after September 30,2012 , subsection (f) shall not apply to the application.

SEC. 34. [7 U.S.C. 136x] SEVERABILITY.

If any provision of this Act or the application thereof to any person or circumstance is held invalid, the invalidity shall not affect other provisions or applications of this Act which can be given effect without regard to the invalid provision or application, and to this end the provisions of this Act are severable.

SEC. 35. [7 U.S.C. 136y] AUTHORIZATION FOR APPROPRIATIONS.

There is authorized to be appropriated to carry out this Act (other than section 23(a)) -

(1) $\$ 83,000,000$ for fiscal year 1989 , of which not more than $\$ 13,735,500$ shall be available for research under this Act;

(2) $\$ 95,000,000$ for fiscal year 1990 , of which not more than $\$ 14,343,600$ shall be available for research under this Act; and

(3) $\$ 95,000,000$ for fiscal year 1991, of which not more than $\$ 14,978,200$ shall be available for research under this Act. 